SJ Quinney College of Law, University of Utah Utah Law Digital Commons

\title{
What Caused the 2016 Chicago Homicide Spike? An Empirical Examination of the 'ACLU Effect' and the Role of Stop and Frisks in Preventing Gun Violence
}

Paul Cassell

S.J. Quinney College of Law, University of Utah, paul.cassell@law.utah.edu

Richard Fowles

Department of Economics, University of Utah

Follow this and additional works at: https://dc.law.utah.edu/scholarship

Part of the Criminal Law Commons, Criminal Procedure Commons, Fourth Amendment Commons, and the Human Rights Law Commons

\section{Recommended Citation}

Cassell, Paul and Fowles, Richard, "What Caused the 2016 Chicago Homicide Spike? An Empirical Examination of the 'ACLU Effect' and the Role of Stop and Frisks in Preventing Gun Violence" (2018). Utah Law Faculty Scholarship. 95.

https://dc.law.utah.edu/scholarship/95 


\title{
DRAFT OF APRIL 2, 2018
}

\section{What Caused the 2016 Chicago Homicide Spike? AN EMPIRICAL EXAMINATION OF THE "ACLU EFFECT" AND the Role of Stop and Frisks in Preventing Gun VIOLENCE}

\author{
Paul G. Cassell \& Richard Fowles
}

\begin{abstract}
Homicides increased dramatically in Chicago in 2016. In 2015, 480 Chicago residents were killed. The next year, 754 were killed-274 more homicide victims, tragically producing an extraordinary 58\% increase in a single year. This article attempts to unravel what happened.

This article provides empirical evidence that the reduction in stop and frisks by the Chicago Police Department beginning around December 2015 was responsible for the homicide spike that started immediately thereafter. The sharp decline in the number of stop and frisks is a strong candidate for the causal factor, particularly since the timing of the homicide spike so perfectly coincides with the decline. Regression analysis of the homicide spike and related shooting crimes identifies the stop and frisk variable as the likely cause. The results are highly statistically significant and robust over a large number of alternative specifications. And a qualitative review for possible "omitted variables" in the regression equations fails to identify any other plausible candidates that fits the data as well as the decline in stop and frisks.

Our regression equations permit quantification of the costs of the decline in stop and frisks. Because of fewer stop and frisks in 2016, it appears that (conservatively calculating) approximately 236 additional victims were killed and 1115 additional shootings occurred in that year alone. And these tremendous costs are not evenly distributed, but rather are concentrated among Chicago's African-American and Hispanic communities.
\end{abstract}

The most likely explanation for the fall in stop and frisks that appears to have triggered the homicide spike is a consent decree entered into by the American Civil Liberties Union (ACLU) with the Chicago Police Department (CPD). Accordingly, modifications to that consent decree may be appropriate.

More broadly, these findings shed important light on the on-going national debate about stop and frisk policies. The fact that America's "Second City" suffered so badly from a decline in stop and frisks suggests that the arguably 
contrary experience in New York City may be an anomaly. The costs of crimeand particularly gun crimes-are too significant to avoid considering every possible measure for reducing the toll. The evidence gathered here suggests that stop and frisk policies may be truly lifesaving measures that have to be considered as part of any effective law enforcement response to gun violence.

\section{TABLE OF CONTENTS}

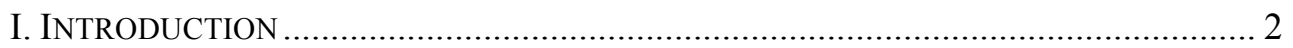

II. AN OVERVIEW OF THE 2016 CHICAgO Homicide SPIKE ................................. 4

III. THE Dimensions AND TIMING OF THE HoMicIDE SPIKE ................................... 7

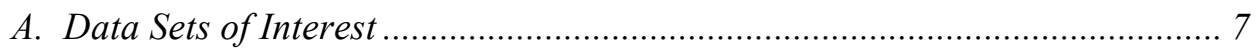

B. Seasonal Adjustment of Homicide and Shooting Data................................ 11

C. Identifying the Existence and Timing of a Break Point............................... 12

IV. Changes IN Stop AND Frisk as a CAUSE of THE Homicide SPIKE .............. 14

A. What the Causal Factor Needs to Explain .................................................. 14

1. The Homicide Spike was Limited to Chicago ........................................ 14

2. The Chicago Spike was Largely Limited to Gun-Related Crimes............. 17

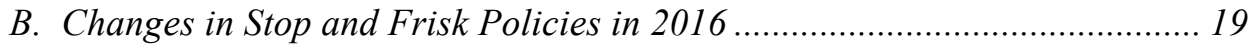

1. The Decline in Stop and Frisks in 2016 ............................................ 19

2. The Linkage Between Declines in Stop and Frisks and Gun Crimes........ 21

3. The Experience of Other Cities and Declining Stop and Frisks............... 26

C. Regression Analysis of Chicago's Decline in Stop and Frisks and the

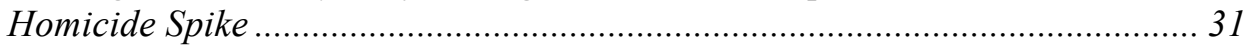

V. OTHER Possible CAUSES OF THE Homicide SPIKE........................................ 36

A. Other Plausible, But Ultimately Inadequate, Candidates for the Homicide

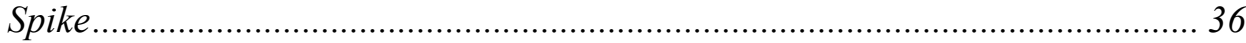

1. Release of the Laquan McDonald Shooting Video .................................. 37

2. The Federal Investigation of the Chicago Police Department .................. 43

3. Changes in Police Leadership .............................................................. 46

B. Other Highly Implausible Candidates for Explaining the Spike .................... 48

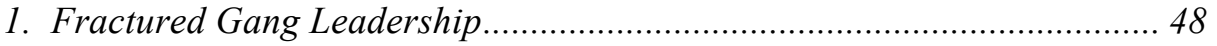

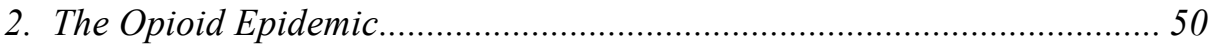

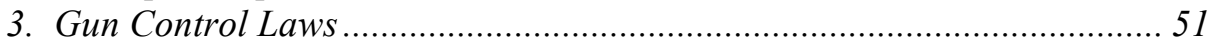

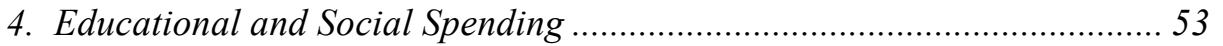

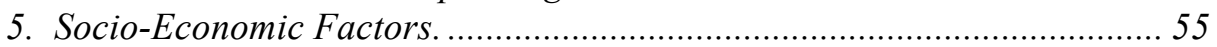

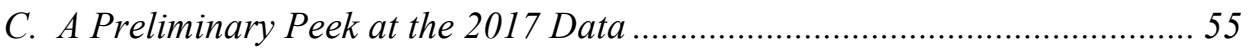

VI. MODEL SPECIFICATION OF THE REGRESSION EQUATIONS ..............................58

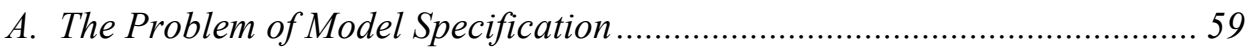

B. Bayesian Model Averaging of the Regression Equations ............................ 60

VII. QUANTIFICATION OF THE COSTS OF THE DECLINE IN STOP AND FRISKS....... 62

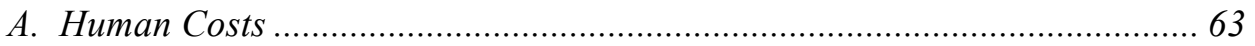

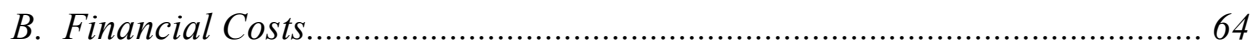


VIII. THE DROP IN STOP AND FRISKS AS AN “ACLU EFFECT” ..............................6 65

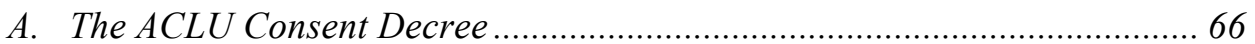

B. Contemporaneous Reports of an "ACLU Effect"........................................... 68

C. The ACLU Consent Decree Compared to Illinois Legislation....................... 74

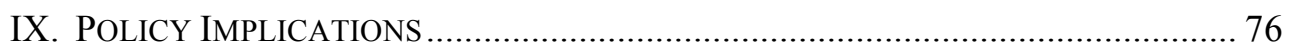

A. Reassessing the Benefits of Stop and Frisk .............................................. 76

B. Reassuring Minority Communities about the Value of Stop and Frisk......... 79

C. Removing or at Least Simplifying the Investigative Stop Report ................. 84

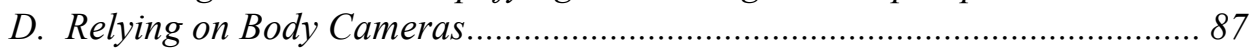

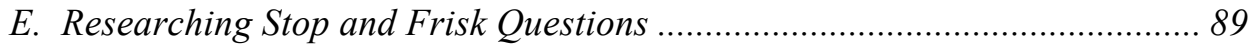

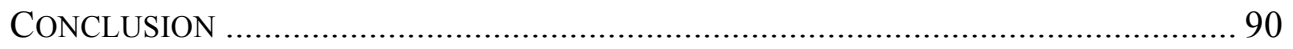

APPENDIX A: THE 2016 CHICAGO HoMICIDE VICTIMS ........................................... 92

APPENDIX B: THE CHICAGO INVESTIGATIVE STOP REPORT .................................. 96

APPENDiX C: The ChICAgo InVESTIGATIVE STOP ReCEIPT ................................. 99 


\title{
What Caused the 2016 Chicago Homicide SPIKe? AN EMPIRICAL EXAMINATION OF THE "ACLU EFFECT" AND THE ROLE of Stop And Frisks in Preventing Gun Violence
}

\author{
Paul G. Cassell \& Richard Fowles"
}

"So by January 2016, the city was on fire. ... Cops had to worry about the ACLU deal. And many of them became scared and demoralized. . . So cops stopped making stops. And kids started shooting more-because they could, and because the rule of law, law enforcement, had been delegitimized. And that created an atmosphere of chaos."

- Letter from Chicago U.S. Attorney Zachary Fardon, upon his resignation in March 2017. ${ }^{1}$

"We reject any suggestion of a so-called 'ACLU effect' to explain the recent spike in gun violence on Chicago's streets. There is no discernible link between the rate of invasive street stops and searches by police and the level of violence... . There simply is not any evidence of this so-called "effect."

-Public letter from the Illinois ACLU on February 1, 2016 regarding the Chicago homicide spike. ${ }^{2}$

"As they were babies, coming up, I had to tell them 'when you hear shots, you gotta get down.",

- Ronald N. Boyce Presidential Professor of Criminal Law and University Distinguished Professor of Law, S.J. Quinney College of Law at the University of Utah.

. Professor, Economics Department, University of Utah.

The authors thank Chuck Abernathy, Shima Baradaran Baughman, Patricia Cassell, Griffin Edwards, Jonah Gelbach, Erika George, Michael Maltz, Josh Marquis, Ed Mogul, Lawrence Rosenthal, Stephen Rushin, Wesley Skogan, Matt Tokson, and the participants in a colloquium at the S.J. Quinney College of Law for helpful comments, and also Maryann Dennis, Chaunceton Bird, Valeri Craigle, Felicity Murphy, and Susan Snyder for excellent research assistance. The authors remain solely responsible for any errors.

Although this Article was a collaborative effort, Cassell had initial responsibility for data collection and legal analysis, and Fowles had initial responsibility for statistical analysis. We appreciate financial support provided by the Albert and Elaine Borchard Fund for Faculty Excellence. We thank the Chicago Police Department, which helped us gather data for this article. We also thank the University of Chicago Crime Lab, which released an informative report on gun violence in Chicago, which we used as one source of data for our analysis.

${ }^{1}$ Open Letter from Former U.S. Attorney Zachary Fardon, CHI. TRIB., Mar. 16, 2017, http://www.chicagotribune.com/news/local/breaking/ct-open-letter-zachary-fardon20170313-htmlstory.html [hereinafter Fardon Resignation Letter].

2 Statement on So-Called "ACLU Effect" on Chicago Crime Spike, ACLU OF ILL. (Feb. 1, 2016), https://www.aclu-il.org/en/press-releases/statement-so-called-aclu-effectchicago-crime-spike. 
- Chicago resident Stepanie Armas, explaining what she taught her kids from a very young age. ${ }^{3}$

\section{INTRODUCTION}

Homicides increased dramatically in Chicago in 2016. In 2015, 480 Chicago residents were killed. The next year, 754 were killed-274 more homicide victims, tragically producing an extraordinary $58 \%$ increase in a single year. This article attempts to unravel what happened.

We are not the first to analyze this important question, as others have observed this startling year-to-year change in homicides. However, a surprising lack of empirical effort has been devoted to exploring the causal factor or factors. This issue is, to put it bluntly, of life or death importance. Against a frightening backdrop of an annual baseline of about 500 homicides in Chicago each year, something in 2016 led to the death of more than 250 additional victims. What was it?

Several different factors have been proposed as the cause of the homicide spike. Some have argued that a so-called "ACLU effect"- a decline in law enforcement effectiveness due to a consent decree that the American Civil Liberties Union (ACLU) signed with the Chicago Police Department (CPD) shortly before the start of 2016 - was responsible. Others have pointed to the release of a video showing the police fatally shooting 17 -year-old Laquan McDonald in the back as the pivot point. Still others have suggested a change in gang dynamics in the city. And a variety of other factors might well have been in play.

While the two of us have differing points of view on various subjects, we both share a commitment to empirically-based assessment of such questions - an empirical bent that has led us to team up in the past. ${ }^{4}$ In this paper, we bring empirical research tools to bear in an attempt to identify what changed in Chicago between 2015 and 2016. While such analysis may be unable to provide definitive answers, it can suggest which factors are more likely than others. Given that, quite literally, more than two hundred additional victims died in 2016 in some of Chicago's most impoverished neighborhoods - and more might similarly be killed in the future in Chicago and elsewhere-finding answers must be regarded as a high priority.

${ }_{3}^{3}$ Amanda Wills, Sergio Hernandez, \& Marlena Baldacci, 762 Murders. 12 Months. 1 American City, CNN, Jan. 2, 2017, http://www.cnn.com/2017/01/02/us/chicago-murderrate-2016-visual-guide/index.html

${ }^{4}$ See, e.g., Paul G. Cassell \& Richard Fowles, Handcuffing the Cops? A Thirty-Year Perspective on Miranda's Harmful Effects on Law Enforcement, 50 STAN. L. REV. 1055 (1998). 
Our analysis proceeds in several steps. Part II describes in general terms what is quite accurately called a "spike" in homicides in Chicago in 2016. A 58\% yearto-year change in America's "Second City" is staggering, suggesting something changed dramatically to initiate the increase.

Part III attempts to pinpoint the time when things changed in Chicago-what might be called the "inflection" or "break" point in the data series. We begin by seasonally adjusting Chicago homicide and shooting data, which show significant seasonal fluctuation from cold weather months to warm weather months. Once the data are seasonally adjusted, a change or "break" in the data series can be statistically detected around November 2015.

Part IV explores the possibility that, as some have alleged, a reduction in stop and frisks by the Chicago Police Department that commenced at the very end of 2015 was responsible for the homicide spike starting immediately thereafter. Goods reasons exist for believing that the decline in stop and frisks caused the spike. Regression analysis of the homicide spike strongly supports this conclusion, as the steep decline in stop and frisks is strongly linked, at extremely high levels of statistical significance, to the sharp increase in homicides (and other shooting crimes) in 2016. We also explain why the possibly contrary experience with reductions in stop and frisks in New York City may be exceptional and inapplicable to Chicago and other cities.

Part V qualitatively searches for other possible factors that might be responsible for the Chicago homicide spike. For various reasons, none of these other candidates fit the data as well as the decline in stop and frisks.

Part VI looks at issues surrounding specification of our regression equations. Bayesian Model Averaging ("BMA") provide strong statistical evidence that our findings are robust in the sense that they are not due to inclusion or exclusion of any particular variables.

Part VII provides quantification of the costs of the decline in stop and frisks, both in human and financial terms. We conclude that, because of fewer stop and frisks in 2016, a conservative estimate is that approximately 236 additional homicides and 1115 additional shootings occurred that year. A reasonable estimate of the social costs associated with these additional homicides and shootings is about $\$ 1,500,000,000$. And these costs are concentrated in Chicago's African-American and Hispanic communities.

Part VIII explains why the ACLU settlement agreement with the Chicago Police Department is the most likely cause of the decline in stop and frisks. 
Part IX offers some tentative suggestions for how policy-makers might reassess the importance and benefits of stop and frisk practices on the streets of Chicago and other cities across the country.

In a concluding section, we situate our findings within a larger body of developing empirical literature supporting the conclusion that restrictions on law enforcement investigations has real-world consequences by reducing police effectiveness. Sadly, Chicago's 2016 homicide spike may be a reflection of the tragic consequences that follow when that linkage is ignored.

\section{AN OverviEW OF THE 2016 CHICAGO HoMicide SPIKE}

2016 was a news-making year for Chicago. The city, however, was not receiving accolades but rather garnering unwanted attention for a nearly unprecedented spike in homicides - a "crushing wave of violence." More than 750 people were killed in Chicago in 2016, the highest number of homicides the city experienced in nearly 20 years. ${ }^{6}$ In fact, in the previous nine years, Chicago's yearly homicides were between 400 and $500 .^{7}$ A look at the previous decade will help reveal the staggering increase in Chicago's 2016 homicide number.

Beginning in 2001, when 667 people were murdered in Chicago, the annual totals generally declined overall through 2015 . Then, suddenly in 2016, the number of homicides increased by more than $50 \%$, "the largest single-year homicide increase of the last 25 years among the five most populous United States cities." ${ }^{\prime 8}$ Figure 1 depicts Chicago's annual homicides for the last ten years.

\footnotetext{
${ }^{5}$ The Chicago Lessons That Chicago Has to Relearn, CHI. TRIB., Sept. 25, 2016, at 22 2016 WLNR 29152627.

${ }^{6}$ Azadeh Ansari \& Rosa Flores, Chicago's 762 Homicides in 2016 is Highest in 19 Years, CNN (Jan. 2, 2017 22:20 GMT), http://edition.cnn.com/2017/01/01/us/chicago-murders2016/index.html.

${ }^{7}$ Ray Sanchez \& Jason Hanna, Chicago Police Tout 14\% Homicide Drop, and Concede There's More To Do, CNN, Dec. 1, 2017, http://www.cnn.com/2017/12/01/us/chicagohomicide-shooting-statistics/index.html.

${ }^{8}$ Wills, Hernandez, \& Baldacci, 762 Murders. 12 Months. 1 American City., supra note 3.
} 


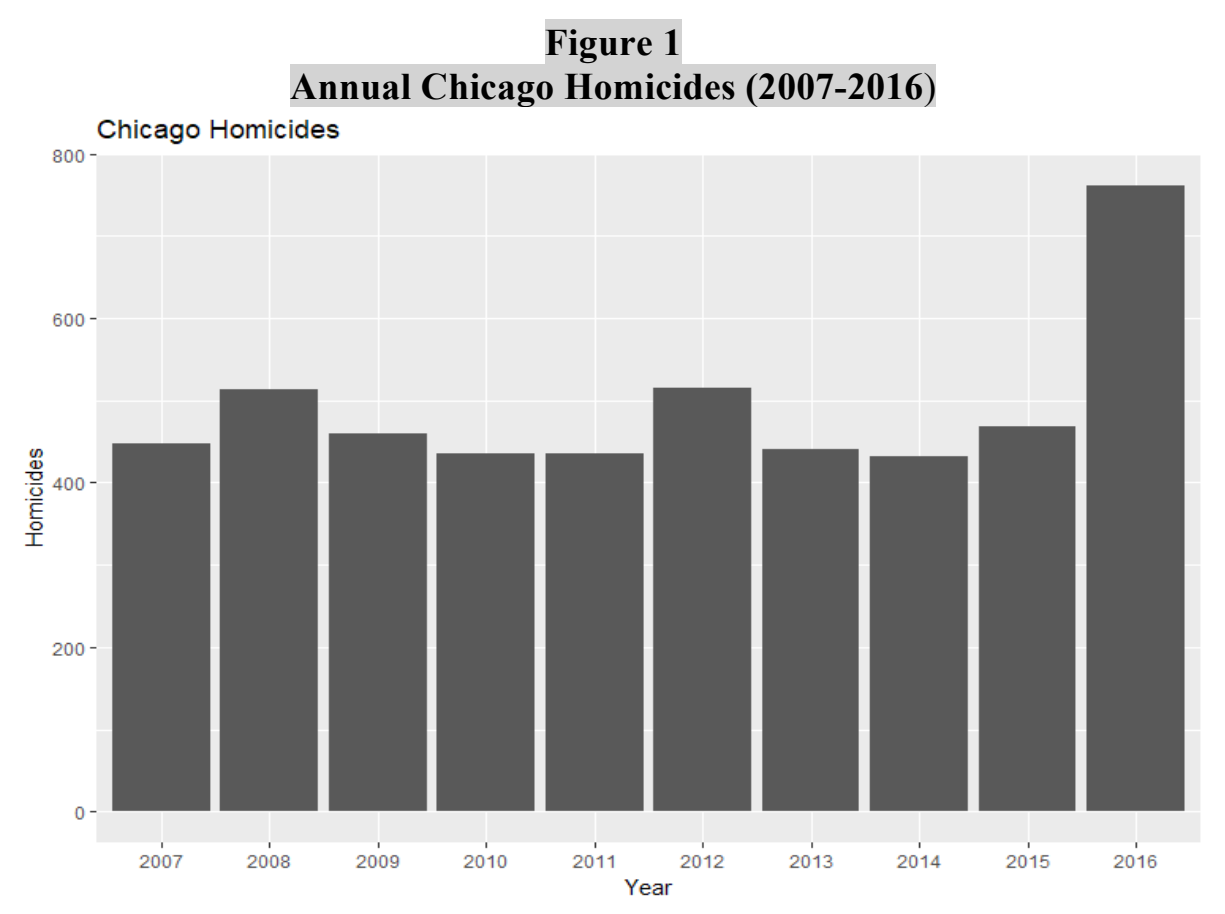

Such a stark surge did not go unnoticed. Before the year was half over, Chicago's increasing homicide rate was making national headlines. ${ }^{9}$ It was even a point of discussion for Donald Trump during the first presidential debate in September 2016, when then-candidate Trump described Chicago as a "war-torn country." In January 2017, the television program 60 Minutes aired "Crisis in Chicago," in which the correspondent recounted, "In the six days we were in Chicago, 55 people were shot, 16 were killed. We were struck by just how routine it all felt. The dead and wounded were removed with grim efficiency-right down to the hazmat crews that cleaned away the blood. Murder seemed almost normal.".11

The violence that tore through the city (particularly in neighborhoods on the south and west sides of town) took many victims and left behind broken families

\footnotetext{
${ }^{9}$ See, e.g., Ford Fessenden \& Haeyoun Park, Chicago's Murder Problem, N.Y. TIMES, May 27, 2016 (noting that by mid-May 2016, homicides increased by $62 \%$ and shootings were up by $60 \%$ ), https://www.nytimes.com/interactive/2016/05/18/us/chicago-murderproblem.html?_r=1.

${ }^{10}$ Aaron Blake, The First Trump-Clinton Presidential Debate Transcript, Annotated, WASH. Post, Sept. 26, 2016, https://www.washingtonpost.com/news/thefix/wp/2016/09/26/the-first-trump-clinton-presidential-debate-transcriptannotated/?utm_term=.f44340584aa1.

${ }^{11}$ Chicago's Crime Epidemic: How You Can Help, CHI. TRIB., Jan. 4, 2017, at 16, 2017 WLNR 234998.
} 
and communities. As one Chicagoan noted, "Once we leave the house, what do we do? It could be me or one of my daughters." 12 Another resident, when asked what it was like to live in his neighborhood said, "I've seen five young men lose their lives on this block. . . . You don't know what it's like to be numb."13 An 8-year-old girl was shot in the arm during a vigil for a 14-year-old. She was "the 30th child aged 13 or younger shot in Chicago" as of August 2016. ${ }^{14}$ On the last day of that bloody year, hundreds of Chicagoans marched down Michigan Avenue (Chicago's so-called "Magnificent Mile"), carrying more than 750 crosses - each numbered to represent where each death fell in the year's homicide count."

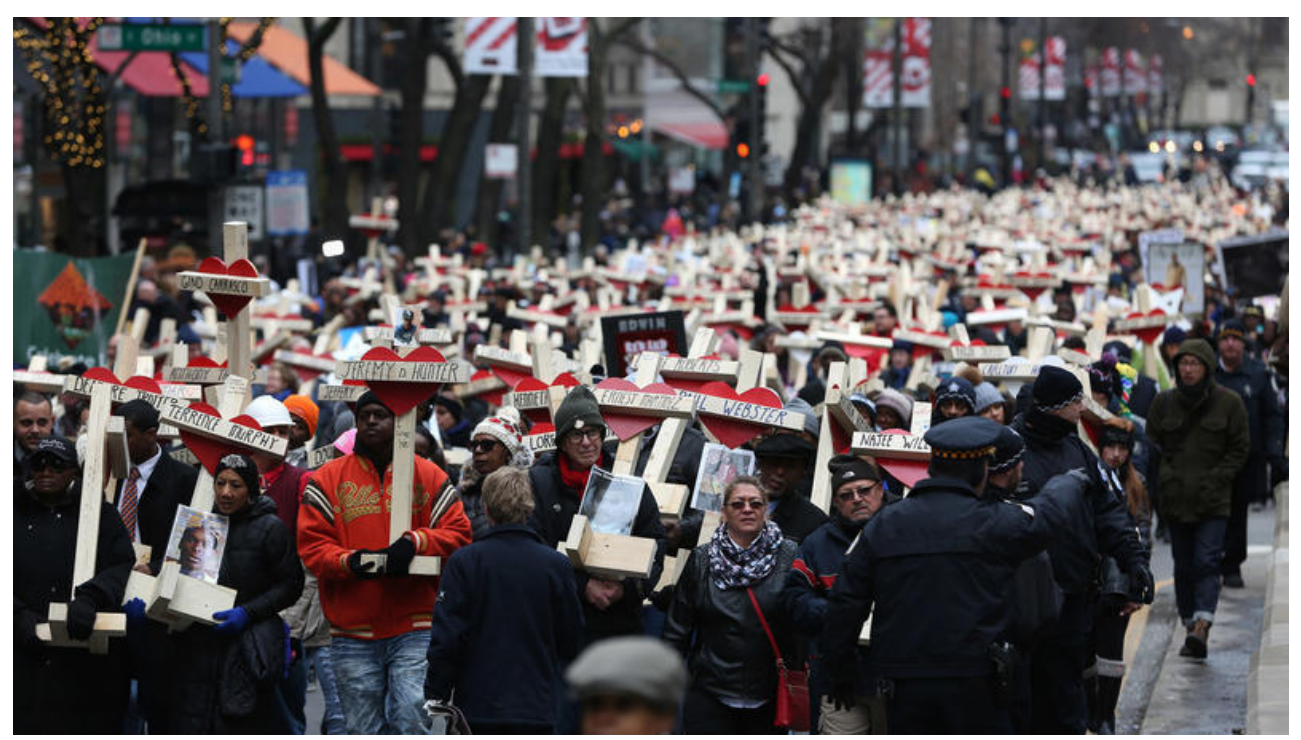

Marchers in Chicago carry crosses bearing the names of the victims of Chicago's gun violence, December 31, 2016. Source: Chicago Tribune (copyright permission pending).

\footnotetext{
${ }^{12}$ Jeremy Gorner, 700 Homicides-With a Month To Go Chicago Killings Increase $56 \%$ Over 2015, Reaching Levels Not Seen in Two Decades, CHI. TRIB., Dec. 3, 2016 at 1, 2016 WLNR 36891574.

${ }^{13}$ Annie Sweeney, ONE GUN'S JOURNEY 42 Bullets Fired, 2 People Killed, 5 Wounded: A Stolen Glock Turned Into a 'Gang Gun' Over a Violent Year, CHI. TRIB., Oct. 9, 2016, at 1, 2016 WLNR 30931543.

${ }^{14}$ Elvia Malagon, Alexandra Chachkevitch, \& Peter Nickeas, Amid Vigil's Grief, Girl is Shot "I was Hollering for my Mommy," 8-year-old Hit in Arm Says, CHI. TRIB., Aug. 23, 2016, at 1, 2016 WLNR 25684469.

${ }^{15}$ Marwa Eltagouri, Crosses Witness to Those Killed in 2016, CHI TRIB., Jan. 1, 2017, at 13, 2017 WLNR 35661.
} 
The victims of the shootings did not mirror Chicago's population. To the contrary, the vast majority of the victims were racial minorities. ${ }^{16}$ Of the 2016 victims, 78\% were African-American, 16\% were Hispanic, and 5\% were white."

\section{ThE Dimensions AND TIMING OF THE HOMICIDE SPIKE}

Having set out some of the background about Chicago's 2016 homicide spike, in this section we undertake a quantitative exploration of the data to see if we can learn anything more about the spike. We begin by explaining our data sources and why it is necessary to adjust them for seasonal fluctuations when making this inquiry. We then try to identify whether a structural change exists in each of the series and, if so, when that change occurred.

\section{A. Data Sets of Interest}

Our interest is in Chicago's homicide spike, so naturally our first data set is the number of homicides in Chicago. Data on the subject were graciously provided to us by the Chicago Police Department. That data came in monthly form, as shown from 2012 to 2016 in Figure 2.

\footnotetext{
${ }^{16}$ See Dahleen Glanton, With 500 Homicides in Chicago, Time for African-Americans to Get Tough on Crime, CHI. TRIB., Sept. 7, 2016, http://www .chicagotribune.com/news/columnists/ct-violence-african-americans-glanton20160907-column.html (discussing disproportionate number of African-American victims, as well as perpetrators, in Chicago in 2016).

${ }^{17}$ See Univ. OF CHI. CRime Lab, Gun Violence in ChicAgo, 2016 at 13 (2017) [hereinafter CHICAGO CRIME LAB]. Cf. Lawrence Rosenthal, Good and Bad Ways to Address Police Violence, 48 URBAn LAWYER 675, 701 (2016) (reporting homicide victimization rate for blacks in the U.S. is about six times higher than for whites). To avoid overlooking the human element in our research, we have tried to focus on the victims in our research. A listing of the names of all homicide victims in Chicago in 2016 is found in Appendix A.
} 
Figure 2

Chicago Homicides 2012 Through 2016 (Monthly Data)

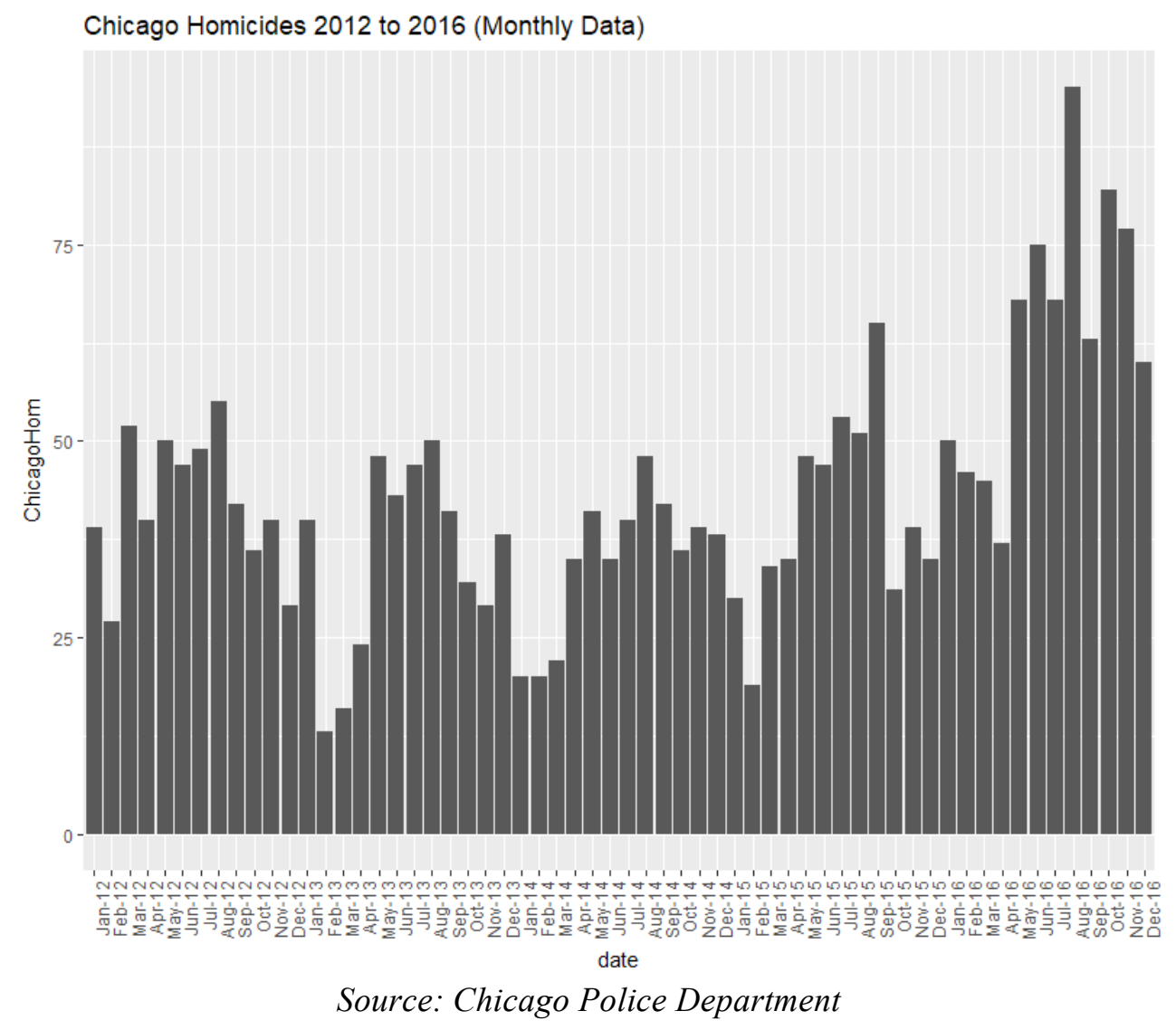

In addition to collecting homicide data, the Chicago Police Department also collects several other closely-related data sets. Most of Chicago's homicides are committed by firearms, ${ }^{18}$ so it is interesting and helpful to look at shooting data. The Chicago Police Department made available to us data for fatal shootings and non-fatal shootings. Naturally, these two categories can be summed to produce a third category of total shootings.

\footnotetext{
${ }^{18}$ See id. at 9 (concluding that $90 \%$ of Chicago homicides in 2016 involved a firearm). Nationally for 2016 , about $73 \%$ of murders involved firearms. FED. BUREAU OF INVESTIGATION, UNIFORM CRIME REPORTS, CRIME IN THE UNITED STATES 2016, tbl.4 (2017), https://ucr.fbi.gov/crime-in-the-u.s/2016/crime-in-the-u.s.-2016/topic-pages/murder [hereinafter 2016 UCR].
} 
Each of these three data sets shows a generally similar pattern to that exhibited by the homicide data set. For example, the figures for non-fatal shootings in Chicago during the same time period (2012 through 2016) reveal a sharp increase in 2016, as shown in Figure 3.

\section{Figure 3
Chicago Shootings 2012 Through 2016 (Monthly Data)}

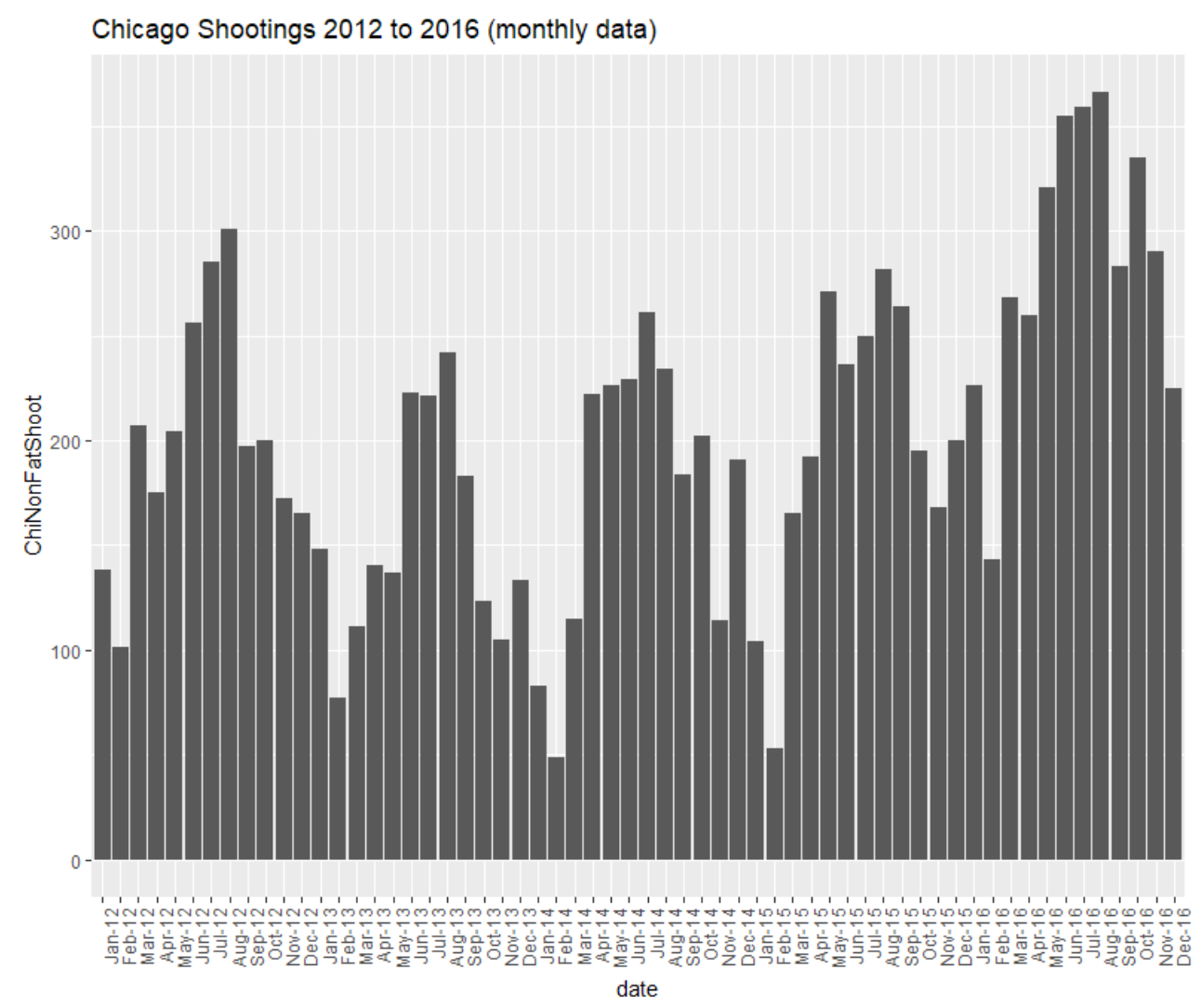

While our main interest is the homicide data, also exploring the shooting data makes considerable sense. A close connection exists between shootings and homicides, because (at least in some cases) a homicide can be described as a shooting for which medical care did not arrive sufficiently quickly. ${ }^{19}$ In this article, we analyze monthly data from 2012 through 2016 for these four Chicago

\footnotetext{
${ }^{19}$ See Anthony R Harris et al., Murder and Medicine: The Lethality of Criminal Assault 1960-1999, 6 HOMICIDE STUD. 128 (2002) (discussing connection between serious assaults and homicides).
} 
data series: (1) homicides; (2) fatal shootings; (3) non-fatal shootings; and (4) total shootings, which are simply the sum of the previous two categories.

Before diving into an analysis of these data, a brief word about their accuracy may be useful. Generally speaking, homicide data are well known for being among the most reliable of crime data, because homicides attract attention and police data on homicides are generally consistent with other sources of information (such as public health reports). ${ }^{20}$ However, there have been some recent suggestions that the Chicago Police Department has manipulated its crime data to make things appear rosier than they really were-including manipulation classifications of a handful of homicides. ${ }^{21}$ Our interest here is not in sorting out classifications for a few disputed homicides, but rather trends lines that move from month to month. Against that backdrop, reclassification of a few homicides here or there would not be likely to affect any of the issues we discuss in this article. Moreover, we have available to us a second data set - fatal shootings - which would be much more difficult to manipulate than the "homicide" data, which requires some degree of assessment as to the cause of death. We compared the trends in fatal shootings and homicides and could find no significant differences between them. Our data are clearly accurate enough for our purposes.

It may also be relevant to note that in 2014 the Office of Inspector General for the City of Chicago conducted an audit of some of CPD's crime statistics for assault. ${ }^{22} \mathrm{CPD}$ acknowledged some mistakes and submitted revised totals to the FBI for 2012. ${ }^{23}$ Our analysis does not involve assault data, but if it did, the audit and subsequent corrections might provide an additional suggestion of accuracy.

We analyzed monthly data on these times series from 2012 to 2016 . A starting point of 2012 was selected because that would provide several years of baseline data before the increase began. We selected 2016 as an ending point because, when we began our research collaboration (in spring 2017), that was the

${ }^{20}$ See JAMES Q. Wilson \& Richard J. HeRnNSTEIN, CRIME AND HuMAN NATURE 34 (1985).

${ }^{21}$ David Bernstein \& Noah Isackson, The Truth About Chicago's Crime Rates, CHI. MAG., Apr. 7, 2014, http://www.chicagomag.com/Chicago-Magazine/May-2014/Chicago-crimerates/; see also David Bernstein \& Noah Isackson, The Truth About Chicago's Crime Rates: Part 2, CHI. MAG., May 19, 2014, http://www.chicagomag.com/ChicagoMagazine/June-2014/Chicago-crime-statistics; David Bernstein \& Noah Isackson, New Tricks, CHI. MAG., May 11, 2015, http://www.chicagomag.com/Chicago-Magazine/June2015/Chicago-crime-stats/.

22 OfFice of InSPECTOR GENERAL FOR THE CITY OF CHICAGO, REPORT OF THE OFFICE OF Inspector General: Chicago Police Department Assault-Related CRime STATISTICS ClassificATION AND REPORTING AUdit (2014), http://chicagoinspectorgeneral.org/wp-content/uploads/2014/04/OIG-Crime-StatsAudit.pdf.

${ }^{23}$ Id. at $17-18$ 
last complete year for which data was available. While a full year of 2017 data has since become available, additional changes have occurred in Chicago policing that would complicate discussions, as discussed at greater length below, ${ }^{24}$ and we do not have access to a full year of 2017 data for other data sets of interest.

\section{B. Seasonal Adjustment of Homicide and Shooting Data}

As is readily apparent from Figures 2 and 3 above, homicides and shootings in Chicago fluctuate significantly throughout each year. A standard explanation for these variations is that crime data exhibit "seasonality," with more crimes committed in the warmer months than in the colder months. Good empirical support exists for the standard explanation, ${ }^{25}$ particularly given that some studies find that crime seasonality is stronger in cities with colder climate ${ }^{26}$ (a group which would include Chicago). The connection between crime and weather, however, is not always validated in empirical studies. ${ }^{27}$ For instance, a recent analysis of Chicago crime data by the Chicago Tribune concluded that while frequency for some crimes increased with temperature, homicides did not. ${ }^{28}$

${ }^{24}$ See infra notes $239-52$ and accompanying text.

${ }^{25}$ See, e.g., Craig A. Anderson, Heat and Violence, CURRENT DiReCTIONS IN PSYCHOL. SCI. 33 (2001) (concluding hot temperatures increase violence directly by increasing feelings of hostility); Gerhard J. Falk, The Influence of the Seasons on the Crime Rate, 43 J. CRIM. L. \& CRIMINOLOGY 199, 212 (1952) (violent crimes consistently reach the maximum frequency in the summer, but criminal homicides can be higher in December than in June and August); Brian Jacobs et al., The Dynamics of Criminal Behavior: Evidence from Weather Shocks, 42 J. HuM. RESOURCES 489 (2007) (finding that weather, and particularly temperature, is strongly correlated with violent crime); Shannon J. Linning et al., Crime Seasonality: Examining the Temporal Fluctuations of Property Crime in Cities with Varying Climates, 61 INT'L J. OFFENDER THERAPY \& COMP. CRIMINOLOGY 1866 (2017); see also Andrew W. Lehren \& Al Baker, In New York, Number of Killings Rises with Heat, N.Y. TIMES, June 18, 2009 (qualitatively concluding that more homicides occur in New York during the summer), http://www.nytimes.com/2009/06/19/nyregion/19murder.html.

${ }^{26}$ See, e.g., J.R. Hipp et al., Crimes of Opportunity or Crimes of Emotion? Testing Two Explanations of Seasonal Change in Crime, 82 SoC. FORCES 13333 (2004); Linning et al., supra note 25, at 1884-88; D. McDowall et al., Seasonal Cycles in Crime, and their Variability, 28 J. QUAN. CRIMINOLOGY 389 (2012).

${ }^{27}$ See, e.g., Ellen G. Cohn, Weather and Crime, 30 Brit. J. Criminology. 51 (1990) (finding that while assaults tend to increase with temperature, at least up to $85^{\circ}$, the relationship for homicides is uncertain).

${ }^{28}$ Mowafak Allaham \& Ryan Marx, Does a Hot Summer Mean More Crime? Here's What the Data Show, CHI. TRIB., Aug. 23, 2017, http://www.chicagotribune.com/news/data/ctcrime-heat-analysis-htmlstory.html; see also Dean DeChiaro, Does Chicago's Homicide Rate Rise and Fall with Cold Winter Weather?, MediLl ReP. CHI., Feb. 5, 2015, $\mathrm{http}: / /$ news.medill.northwestern.edu/chicago/does-chicagos-homicide-rate-rise-and-fallwith-cold-winter-weather-2/. 
With our data, simple visual observation of the twelve-month patterns for homicides and shootings strongly suggested the presence of seasonality. This hypothesis was confirmed more rigorously by detecting seasonality through traditional time series decomposition, using ARIMA (automatic autoregressive moving average time series analysis, as calculated by R). In light of the seasonality in our data, we performed a standard, classical time series decomposition to remove seasonal variations in both the homicide and shootings data.

\section{Identifying the Existence and Timing of a Break Point}

With seasonality thus removed from our data sets, we were in a position to begin examining them to try to identify if and when the data began to change. As discussed above, we have strong reasons for believing that something changed in Chicago around the start of 2016 - the existence of a Chicago homicide "spike" was widely observed at the time and discussed throughout Chicago and, indeed, nationally. ${ }^{29}$ Because we have monthly data series spanning 2012 to 2016, it is possible to run statistical tests to see if the series exhibit what are known as "structural breaks"-i.e., a change in the trend line of the data at some particular point in time. ${ }^{30}$ Reviewing data for a structural break is a pure time series question about a single data series. Moreover, standard statistical software is available to perform such examinations. Using the structural change function (strucchange ${ }^{31}$ ) in the standard software package known as $R$, we reviewed the four data series at hand. Table 1 shows the date on which a structural change is detected in each series, as well as confidence bands for the earliest data for the change and the latest date for the change (at the standard $95 \%$ confidence level).

${ }^{29}$ See, e.g., Mark Berman, Led by Chicago, Homicides Spiking Again in Some Big U.S. Cities, CHI. TRIB. Sept. 19, 2016, http://www.chicagotribune.com/news/local/breaking/cthomicides-spiking-big-city-chicago-20160919-story.html.

30 See, e.g., Paul G. Cassell \& Richard Fowles, Still Handcuffing the Cops? A Review of Fifty Years of Empirical Evidence of Miranda's Harmful Effects on Law Enforcement, 97 BOST. U.L. REV. 685, 757 (2017) (performing structure break analysis on crime clearance rates).

31 See Achim Zeileis et al., Strucchange: An R Package for Testing for Structural Change in Linear Regression Models, 7 J. STAT. SOFTWARE 1, 15 (2002). 
Table 1

Structural Changes in Data Series

\begin{tabular}{|l|l|l|l|}
\hline Data Series & Structural Change & Earliest Date & Latest Date \\
\hline Homicides & January 2016 & November 2015 & February 2016 \\
\hline Fatal Shootings & December 2015 & November 2015 & January 2016 \\
\hline Non-Fatal Shootings & October 2015 & September 2015 & November 2015 \\
\hline Total shootings & October 2015 & September 2015 & November 2015 \\
\hline
\end{tabular}

Because of our interest in identifying a cause (or causes) for the homicide spike, we highlight the fact that the strucchange program quantitatively identifies January 2016 as the break point for the homicide data. Interestingly, the University of Chicago Crime Lab qualitatively identified this same month as the break point in its important earlier research. ${ }^{32}$

Equally of interest is the fact that a break point is identified in all four of the data series we assembled. It seems likely that the same factor (or factors) operating to increase homicide rates would also operate to increase fatal shootings or non-fatal shootings. If this assumption is correct, then we would expect to see the same precise breakpoint for all of our data sets. In fact, the breakpoints are very similar, but slightly different, ranging from October 2015 for non-fatal shootings and total shootings to January 2016 for homicides. But perhaps of even more interest is a possible convergence between all four data sets. Looking at the confidence band for the break points in the data sets, all four of the data sets permit the possibility of that break took place in November 2015 .

Finally, the analysis of the data set - both visually and quantitatively through the strucchange program - does not reveal a second break point anywhere in 2016. Whatever changed to cause the spike appears to have remained in place throughout the year.

The critical point, then, is somewhere around November 2015 to January 2016, Chicago homicides and shootings spiked sharply upwards and remained at these higher levels. Why?

\footnotetext{
${ }^{32}$ ChICAGO CRIME LAB, supra note 17, at 8 . The Crime Lab's report is important reading, but ultimately was unable to identify a cause for the spike. See id. at 18 (calling the spike an "unsolved puzzle"). The Crime Lab also called for an "ongoing conversation" about the issue, $i d$. at 26 , and we view our contribution to the conversation as following up to the Crime Lab's call for further research. $I d$. at 26.
} 


\section{Changes In Stop AND FRISK as a CAUSE OF THE Homicide SPIKE}

Having identified a break in the Chicago homicide data and related shooting data in about late 2015, we turn to the question of what caused the break. We begin by trying to identify what the causal factor would probably look like-i.e., what sorts of changes would the causal factor have to explain (and not explain). In light of changes that the causal factor would have to explain, we believe that a reduction in stop and frisks that occurred at approximately the end of 2015 is the single most likely causal factor. Regression equations, which show a statistically significant connection between declining stop and frisks and increasing homicides, support this interpretation.

\section{A. What the Causal Factor Needs to Explain}

\section{The Homicide Spike was Limited to Chicago}

One question that comes immediately to mind about the 2016 spike in Chicago homicides is what was happening during that year in other areas. Was the Chicago surge part of some larger phenomenon outside the city? The quick answer appears to be no.

Let's look first at the national homicide rate trends in 2016. In 2016, the homicide rate around the country increased $8.6 \%$ from 2015.". Of course, that is only a small fraction of the Chicago increase. Indeed, the disparity between Chicago and national trends grows even larger, when we realize that the Chicago spike was so large that it influenced the national homicide rate change. Backing out Chicago homicides (in both 2015 and 2016), the nation's homicide rate increased only $7.0 \%$ from 2015 to $2016 .{ }^{34}$ Chicago's spike cannot be attributed to a broader national pattern.

A similar conclusion emerges if we compare Chicago to other major cities around the country. Not only was the 2016 spike a sharp increase for Chicago, "[n]one of the other five largest cities in the U.S.-Houston, Los Angeles, New York City, and Philadelphia, in addition to Chicago - have witnessed a single-year homicide increase over the past 25 years that rivals Chicago's increase in 2016."35 One way of contextualizing these numbers is that, in August 2016, more people

\footnotetext{
33 See 2016 UCR, supra note 18.

$34(17,250-765) \div(15,883-478)=7.0 \%$ increase. Note: These numbers come from the FBI's Uniform Crime Reports in 2015 and 2016. The number of Chicago homicides listed by the FBI is just slightly different than those listed by the CPD. Because the differences are extremely small, we have not bothered to sort them out.

${ }^{35}$ ChICAGO CRIME LAB, supra note 17.
} 
had been shot in Chicago than in New York and Los Angeles combined, although the population of each of the two cities far exceeds Chicago's. ${ }^{36}$

For direct comparison of Chicago to other large cities, we collected the 2016 change in homicide rates for the nation's twenty largest cities (arranged by population size) in Table 2 below.

Table 2

Rate of 2016 Homicide Increase Nation's Largest 20 Cities 2015 Compared to 2016

\begin{tabular}{|c|c|}
\hline City & Rate of 2016 Homicide Increase \\
\hline New York City & $-4.8 \%$ \\
\hline Los Angeles & $3.9 \%$ \\
\hline Chicago & $58.0 \%$ \\
\hline Houston & $-0.7 \%$ \\
\hline Philadelphia & $-2.5 \%$ \\
\hline Phoenix & $30.4 \%$ \\
\hline San Antonio & $58.5 \%$ \\
\hline San Diego & $35.1 \%$ \\
\hline Dallas & $25.7 \%$ \\
\hline San Jose & $56.7 \%$ \\
\hline Austin & $69.6 \%$ \\
\hline Jacksonville & $9.3 \%$ \\
\hline San Francisco & $7.5 \%$ \\
\hline Indianapolis & $0.0 \%$ \\
\hline Columbus & $18.2 \%$ \\
\hline Fort Worth & $17.9 \%$ \\
\hline Charlotte & $9.8 \%$ \\
\hline Seattle & $-17.4 \%$ \\
\hline Nashville & $12.5 \%$ \\
\hline E1 Paso & $0.0 \%$ \\
\hline
\end{tabular}

Source: FBI Uniform Crimes Reports - 2015 \& 2016

As can be seen, with the exceptions of Austin and San Antonio (which have comparative smaller numbers of annual homicides, making them subject to greater

\footnotetext{
${ }^{36}$ Jerry Gorner, Peter Nickeas, \& Elvia Malagon, City's Deadliest Month Since October 1997, CHI. TRIB., Aug. 30, 2016, at 1, 2016 WLNR 26378967; Gorner, 700 Homicides, supra note 12.

${ }^{37} U C R$ data actually appear to show a slightly larger percentage rate increase- $60.0 \%$. To be more conservative, we use the CPD homicide numbers.
} 
year-to-year percentage fluctuations for idiosyncratic reasons s), Chicago had the highest annual percentage increase in 2016, and the vast majority of other cities had no comparable increase.

Nor can the Chicago figures be explained by something that might have been going on regionally. We compared Chicago to other "Midwestern" cities (loosely defined) in Table 3, below.

Table 3

Rate of 2016 Homicide Increase Midwestern Cities 2015 Compared to 2016

\begin{tabular}{|c|c|}
\hline City & Rate of 2016 Homicide Increase \\
\hline Chicago & $58.0 \%$ \\
\hline St. Louis & $0.0 \%$ \\
\hline Indianapolis & $0.0 \%$ \\
\hline Grand Rapids & $0.0 \%$ \\
\hline Gary (Indiana) & $-0.1 \%$ \\
\hline Detroit & $2.7 \%$ \\
\hline Milwaukee & $-2.8 \%$ \\
\hline Columbus & $18.2 \%$ \\
\hline Cincinnati & $-13.6 \%$ \\
\hline Cleveland & $12.5 \%$ \\
\hline Louisville & $47.4 \%$ \\
\hline
\end{tabular}

Source: FBI Uniform Crimes Reports - 2015 \& 2016

As is immediately apparent, Chicago's annual increase was greater than all the other cities in the region-substantially so in every case with the sole exception of Louisville, where Chicago's increase was still more than ten percentage points higher. ${ }^{.9}$ Also of particular interest is the data from Gary, Indiana, a city that is, in some sense, a Chicago suburb. Gary is just 25 miles from downtown Chicago, and yet it experienced no increase in homicides in 2016.

${ }^{38}$ For example, Austin's year-to-year increase from 2015 to 2016 was 28 to 39 - an increase of less than a dozen homicides. Apparently there were several cases involving multiple deaths that year. See Calily Bien, Austin Sees Increase in Homicides in 2016, Fewer Traffic Deaths, KXAN Investigation, Jan. 3, 2017, http://kxan .com/2017/01/03/austin-sees-increase-in-homicides-in-2016-fewer-trafficdeaths/. In San Antonio, in 2016 there were "a lot of spontaneous murders" and it was "difficult to put a reason" for the increase, according to the San Antonio Chief of Police. Emilie Eaton, Homicides in S.A. Hit a 21-Year High. Why?, MySA.com, Jan. 1, 2017, https://www.mysanantonio.com/news/local/article/Homicides-in-S-A-hit-a-21-year-highWhy-10829542.php.

${ }^{3}$ Louisville appears to have suffered from a spike in local gang-related homicides in 2016. See Mable Cundiff, Louisville Homicides Continue to Increase, WVIH.com (Sept. 3, 2016), http://www.wvih.com/wp1/index.php/2016/09/03/louisville-homicides-continue-toincrease/. 
In a final effort to pinpoint the geographical area where the homicide spike occurred, we looked at data for Illinois. Comparing homicides in Illinois from 2015 to 2016 produces a $20.4 \%$ increase. ${ }^{\circ 0}$ But because Chicago's numbers are such a large part of the Illinois numbers (about two-thirds), we need to back out Chicago's numbers from both years to see what was going on in other parts of Illinois. Doing that reveals that, apart from Chicago, Illinois had only a $4.7 \%$ increase in homicides from 2015 to 2016-far below the increase Chicago experienced and roughly reflective of (and slightly below) the national increase that year of 8.6\%." This strongly suggests that whatever afflicted Chicago in 2016, it was not something that afflicted other parts of the state.

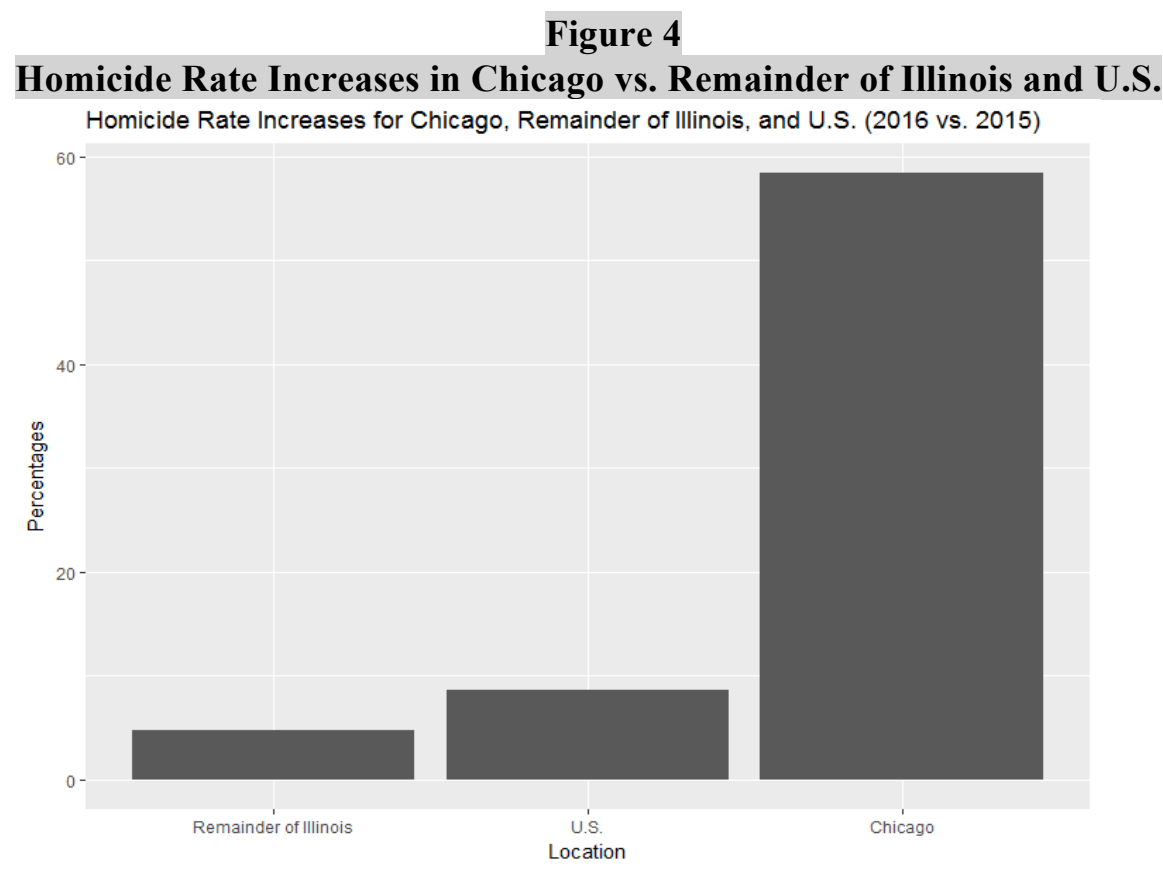

The "takeaway" from these numbers seems obvious: Something happened uniquely to Chicago to cause a homicide spike in 2016.

\section{The Chicago Spike was Largely Limited to Gun-Related Crimes}

\footnotetext{
${ }^{40} 2016$ UCR, supra note 18 (tb.2).

${ }^{41}$ We have left the Chicago data in the national figure, even though this operates to increase size of the national 2016 homicide spike. Also, as discussed below, there was no "break" in the Illinois data set-unlike the sharp Chicago increase. See infra note 332 and accompanying text.
} 
In looking for causes of the homicide spike, another question that arises immediately is whether all forms of crime increased throughout the city in 2016 or just homicides. Here again, it is easy to collect FBI data on the standard crime categories for Chicago, comparing 2015 to 2016. Our results are depicted below, in Table 4.

Table 4

Chicago 2015 to 2016 Year-Over-Year Increase by Crime Category

\begin{tabular}{|c|c|c|c|c|c|c|c|c|}
\hline $\begin{array}{c}\text { Violent } \\
\text { Crimes }\end{array}$ & Murder & Rape & Robbery & $\begin{array}{c}\text { Agg } \\
\text { Assault }\end{array}$ & $\begin{array}{c}\text { Property } \\
\text { Crimes }\end{array}$ & Burglary & Larceny & Vehicle Theft \\
\hline $22.2 \%$ & $58.0 \%{ }^{\circ 2}$ & $11.0 \%$ & $23.9 \%$ & $20.7 \%$ & $8.2 \%$ & $8.4 \%$ & $7.4 \%$ & $12.2 \%$ \\
\hline
\end{tabular}

Source: FBI-Uniform Crime Reports - 2015 \& 2016.

As is readily apparent, whatever caused the homicide spike does not appear to have affected other crime categories nearly as substantially.

It is interesting, however, to move outside the standard FBI crime categories and look at the year-over-year numbers for shootings in Chicago. As shown in Table 5 below, shooting crimes increased substantially in 2016 compared to 2015 .

\section{Table 5 \\ Chicago 2015 to 2016 Year-Over-Year Increase by Shooting Crime Category}

\begin{tabular}{|c|c|}
\hline Crime Category & Rate of 2016 Increase \\
\hline Homicides & $58.0 \%$ \\
\hline Fatal Shootings & $66.4 \%$ \\
\hline Non-Fatal Shootings & $44.2 \%$ \\
\hline Total Shootings & $48.0 \%$ \\
\hline Source: Chicago Police Department Data
\end{tabular}

These numbers suggest that whatever caused the 2016 Chicago homicide spike also caused a spike in shooting (i.e., gun-related) crimes."

${ }^{42} U C R$ data actually appear to show a slightly larger percentage rate increase- $-60.0 \%$. To be more conservative, we use the CPD homicide numbers.

43 A similar conclusion was reached by the University of Chicago Crime Lab, which reviewed detailed CPD records. The Crime Lab compared various categories of crimes to determine a 2015-to-2016 year-to-year increase, finding that gun homicides increased $61 \%$, as compared to $31 \%$ for non-gun homicides; while shootings increased $43 \%$ and gun robberies increased $26 \%$, compared to a $10 \%$ increase in non-gun violent crimes and a $6 \%$ increase in property crimes. CHICAGO CRIME LAB, supra note 17, at 10 (Figure 9). 
Combining what we have learned so far, in searching for the cause of Chicago's homicide spike, we should be looking for something that has four characteristics: (1) it caused an abrupt change that took place near the end of 2015, not predicted by previous trends; (2) it remained in place throughout 2016; (3) it was confined to Chicago and did not affect other major cities in the country, the region, or other parts of Illinois; and (4) it elevated Chicago's gun-related crimes uniquely as compared to other crimes. ${ }^{44}$

\section{B. Changes in Stop and Frisk Policies in 2016}

We are obviously not the first observers to wonder about what caused the 2016 Chicago homicide spike. Others have suggested a variety of different possible causes, including (based on media reports) the following list of possibilities:

fractured gang hierarchies and rivalries; high rates of neighborhood poverty and segregation; an influx of guns from other places; insufficient penalties for illegal gun-carrying; social media disputes; demolition of public housing; a lack of resources devoted to solving serious crimes; police department management and manpower; reduced police activity; changes in city and state funding for social services and other core government functions; the absence of family involvement in the lives of youth; closing of mental health clinics; ... weather, ... the release of video footage showing the shooting by a CPD officer of teenager Laquan McDonald, announcement of a U.S. Department of Justice (DOJ) investigation of CPD, a new state law regarding street stops, and implementation of an agreement between the City and the American Civil Liberties Union (ACLU) concerning street stops."

At first blush, applying to this list of possibilities the four characteristics of a plausible cause, one potential causal factor jumps out: the ACLU agreement concerning street stops. The agreement was an abrupt change at the end of 2015, remained in place throughout 2016, was confined to Chicago, and could uniquely cause gun crimes to increase. Could that agreement be the explanation?

\section{The Decline in Stop and Frisks in 2016}

The ACLU and the Chicago Police Department entered into an agreement on stop and frisks in August 2015, which was implemented towards the end of 2015. In theory, it is possible that that agreement did or did not change the number of

\footnotetext{
${ }^{44} I d$. at 4 (for an explanation to make sense it "would need to involve something that changed abruptly near the end of 2015 and disproportionately affected gun crimes"). ${ }^{45} \mathrm{Id}$. at 8, 24 (order of last two items reversed).
} 
stops and frisks conducted by CPD. We defer discussion of that issue as well as the details of that agreement to a later part of this article." For present purposes, our only interest is trends in the number of stop and frisks around the time of the homicide spike.

On this subject, at least, the data appear to be unequivocal. As shown in Figure 5, reported CPD stops" were running at about 40,000 each month from January 2012 through November 2015. Then, as the settlement agreement phased in, stops declined in December and plummeted sharply in January 2016-plunging to less than one-fourth the previous number (less than 10,000 a month).

Throughout all of 2016, stops remained at this markedly lower level-only 20 to $25 \%$ of what they had been previously.

\section{Figure 5 \\ Chicago Stop and Frisks (2012-16)}

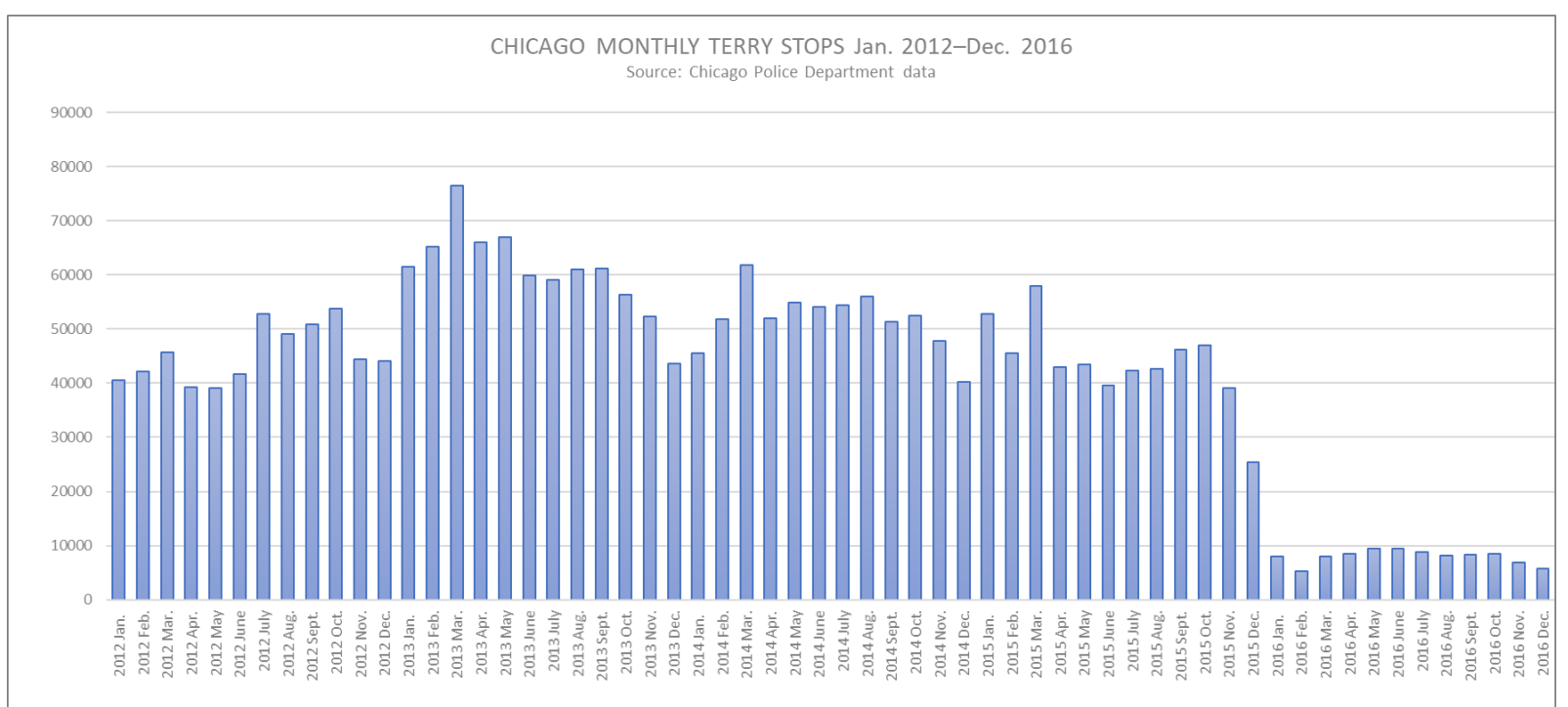

\section{Source: Chicago Police Department Data.}

It is also quite likely that these numbers significantly understate the actual extent of reduction in police stops, because (as was one of the issues addressed in the settlement agreement) CPD documentation of stops before the consent decree had been less than complete. A more accurate figure for the reduction in police stops might show stops declining from a pre-agreement baseline of about 60,000 a

\footnotetext{
${ }^{46}$ See infra notes $266-325$ and accompanying text.

${ }^{47}$ For convenience, we will use the terms "stop and frisks" and "stops" interchangeably, although not every CPD stop led to a frisk.
} 
month to below 10,000 a month in January 2016 - a steep $80 \%$ drop in just two months in stop and frisk activities that was sustained throughout the rest of the year.

\section{The Linkage Between Declines in Stop and Frisks and Gun Crimes}

What would be the expected effect of an abrupt, roughly $75 \%$ to $80 \%$ drop in stop and frisk activities by the CPD? One rather obvious answer is that gun crimes would increase. Stop and frisk is designed to discover and remove illegal firearms from the hands of criminals that police encounter-and thus deter the illegal carrying of firearms in the first place. And it is one of a relatively small number of police practices that has been shown, through suggestive empirical studies, to directly reduce gun crimes."

This cause-and-effect argument between the decline in stop and frisks and the subsequent increase in gun crimes is remarkably easily to articulate. And, importantly, while we make a quantitative connection below, qualitative analysis can also be vital in assessing time series issues." Knowledgeable observers made the linkage in Chicago contemporaneously with the rising gun crimes. For example, as one officer explained during the spike, "Gangbangers now realize that no one will stop them," and "people who wouldn't have carried a gun before are now armed." 51

${ }^{48}$ See CHICAGO CRIME LAB, supra note 17, at 24 (relying on reanalysis of CPD records to show stops falling from right around 60,000 in October 2015 to around 10,000 (or less) throughout 2016. For our purposes, we use the official CPD data, because that provides a "conservative" (i.e., understated) estimate of the effects of changes in stop and frisks.

After our article was circulated for comments, we learned that the stop data we present here may be a more limited data set than all stops - perhaps stops of adults, but not including juveniles. We have compared our data with higher figures from the Crime Lab, finding our series moves in parallel with theirs. Preliminary indications are that swapping in their data series for ours makes no difference in the statistical significance of any our findings, although it might modestly reduce the coefficient of the stop and frisk variables discussed below. We are exploring the differences in the data.

${ }^{49}$ See NAT'l ACAD. OF SCI., Proactive Policing: EFFeCts On CRime ANd COMMUNities 4-22 to 4-24 (David Weisburd \& Malay K. Majmundar eds., 2017); see also Lawrence W. Sherman, Comment on Jacqueline Cohen \& Jens Ludwig, Policing Gun Crimes, in Evaluating Gun Policy: EFFECTS ON CRime AND ViolenCe 217, 240 (2003) (discussing studies showing that intensive police efforts to discourage illegal public gun carrying reduce gun injuries and deaths).

so See generally DAVID A. FreEdman, STATISTICAL Models AND CAUSAl Inference: A DIALOG WITH THE SOCIAL SCIENCES (2010) (discussing the importance of "shoe leather" in interpreting quantitative models).

${ }^{51}$ Heather MacDonald, The "Ferguson Effect" is Destroying Chicago, N.Y. Post, July 9, 2016, https://nypost.com/2016/07/09/how-the-ferguson-effect-is-destroying-chicago/. 
Another example of the recognition of the linkage came from the U.S. Attorney for Northern District of Illinois (i.e., Chicago). U.S. Attorney Zachary Fardon was appointed by President Obama in 2013 and appears have no political axe to grind." In his public letter of resignation in March 2017, he summarized the events surrounding the homicide (and shootings) spike, explaining his conclusion that the decline in stops was a primary cause:

So by January 2016, the city was on fire. . . . Cops had to worry about the ACLU deal. And many of them became scared and demoralized. ... So cops stopped making stops. And kids started shooting more - because they could, and because the rule of law, law enforcement, had been delegitimized. And that created an atmosphere of chaos. ${ }^{53}$

Attributing the rise in shootings and homicides to a decline in stop and frisks has considerable empirical support. Most notably, a November 2017 report from the National Academy of Sciences ("NAS") reviewed the relevant literature on stop and frisk (which they called "stop, question, and frisk" or "SQF").s" The NAS report concluded that "[e]valuations of these focused uses of enforcement tactics that have included pedestrian stops report meaningful and statistically significant crime reductions at targeted locations, though estimated jurisdictional impact (when measured) has been modest."s The report summarizes the results of stop, question, and frisk studies conducted from 2008 to $2016 .^{56}$ The report criticizes early, non-experimental studies as not being useful to make causal inferences. ${ }^{57}$ The NAS then reports on a growing body of experimental research showing that stop, question, and frisk policies reduce crime. ${ }^{58}$ The report concludes that SQF may help reduce crime, while being careful to note that "the[] studies do not specifically isolate the impact of SQF on crime." ${ }^{, 59}$ The report also cautioned that "[n]on-experimental analyses of SQF programs implemented as a general, citywide crime control strategy have found mixed outcomes."

\footnotetext{
${ }^{52}$ Fardon Resignation Letter, supra note 1 ("I am not a political person. I belong to no political party; never have. I am not a Democrat. I am not a Republican. I am not a liberal. I am not a conservative. ... I have no interest in political office.").

${ }^{53} I d$. To be clear, Fardon also referenced the release of the McDonald shooting video, the lack of a police superintendent in January 2016, and the start of the federal investigation as factors are discussed below. See infra notes 129-200 and accompanying text.

${ }^{34}$ NAT'L ACAD. OF SCI., supra note 49, at 4-22 to 4-24.

${ }^{55} I d$. at $4-24$.

${ }^{56} I d$. at $4-22-4-24$.

${ }^{57} I d$. at 4-22-4-23 (critiquing the methodology of the Smith/Purtell and Rosenfeld/Fornango studies).

${ }^{58} I d$. at $4-23-4-24$.

${ }^{59} \mathrm{Id}$. at $4-24$.

${ }^{\infty} I d$.
} possible contributing factors to a lack of police morale. See $i d$. These possible contributing 
Some of the main studies the NAS relied upon are worth a brief review. Christopher S. Koper and Evan Mayo-Wilson analyzed seven experimental studies evaluating police crackdowns on gun carrying in cities in the United States and Colombia. ${ }^{61}$ The police intervention tactics analyzed in the studies included directed or saturation patrols, roadblock checkpoints, enhanced monitoring of probationers and other suspected gun offenders, use of new gun detection technologies, and weapon reporting hotlines. ${ }^{62}$ Six of the seven studies that Koper and Mayo-Wilson analyzed showed that directed police patrols (which includes stop, question and frisks) reduced gun crimes in high-crime places during high-risk times. ${ }^{63}$ With one exception, the American gun crime crackdowns, all of which involved increased use of SQF, found that gun crime declined by $29 \%$ to $71 \%$, depending on the outcomes measured. ${ }^{64}$

Lawrence W. Sherman and his colleagues reviewed data from 1992 to 1993, when the Kansas City Police Department focused extra police patrols on gun crime hot spots. ${ }^{65}$ Stop, question, and frisk accounted for $34 \%$ of the gun seizures during the experiment. ${ }^{66}$ There were 169 gun crimes in the targeted area during the 29 weeks before the hotspot patrols, but only 86 gun crimes during the 29 weeks of the hotspot patrols. ${ }^{67}$ This amounted to a $49 \%$ decrease in gun crimes. ${ }^{68}$

Jerry Ratcliffe and his colleagues reviewed a Philadelphia foot control experiment, in which, in 2009, 60 violent crime hotspots were identified and assigned extra foot patrol officers. ${ }^{69}$ Target areas of the experiment showed violent crime reduction of $23 \%$ compared to control sites. ${ }^{70}$ Though the Ratcliffe study was not designed to specifically address SQF, the researchers made some significant observations. Pedestrian stops (defined in the study as "whenever a police officer conducts a field interview, stop-and-frisk, or search of a suspect in the street" ${ }^{, 71}$ ) increased by $64 \%$ in target areas, compared to less than a $1 \%$ increase

${ }^{61}$ Christopher S. Koper \& Evan Mayo-Wilson, Police Strategies to Reduce Illegal Possession and Carrying of Firearms: Effects of Gun Crime, CAMPBELL SYSTEMATIC REVS., at 14 (Sept. 2012).

${ }^{62} \mathrm{Id}$. at 10 .

${ }^{63} \mathrm{Id}$. at 6.

${ }^{64} I d$.

${ }^{65}$ Lawrence W. Sherman, James W. Shaw, \& Dennis P. Rogan, The Kansas City Gun Experiment, NAT'L InST. OF JUST.: RESEARCH IN BRIEF, at 3-4 (Jan. 1995).

${ }^{66} \mathrm{Id}$. at 5 .

${ }^{67} \mathrm{Id}$. at 6.

${ }^{68} \mathrm{Id}$.

${ }^{69}$ Jerry H. Ratcliffe et al., The Philadelphia Foot Patrol Experiment: A Randomized Controlled Trial of Police Patrol Effectiveness in Violent Crime Hotspots, 49 CRIMINOLOGY 795, 796 (2011).

${ }^{70} \mathrm{Id}$.

${ }^{71}$ Id. at 812 . 
in control areas. ${ }^{72}$ Also, in the target areas that demonstrated the clearest evidence of crime reduction, there was a "substantial jump in proactive activity for foot patrol officers." ${ }^{, 73}$ In short, though the researchers recognized the value of SQF, they were "reluctant to suggest that proactive policing alone resulted in the crime reduction found in th[e] experiment."

David Weisburd, Alese Wooditch, Sarit Weisburd, and Sue-Ming Yang used data on the exact locations of SQF occurrences and non-traffic-related crimes in New York City for the years 2006 to $2011 .^{75}$ They concluded that with a total of $686,000 \mathrm{SQF}$ in a given year (the highest rate of SQFs during the study period), a reduction of 11,771 crimes was expected, or a $2 \%$ decrease. ${ }^{76}$ These crimeprevention benefits were realized primarily within short distances of an SQF occurrence and within a limited time frame (less than five days) after an occurrence. $^{77}$

Wooditch and Weisburd used crime incident data to examine the effect of SQFs conducted by the New York City Police Department in the Bronx, New York over a 150 -day period in $2006 .^{78}$ The findings suggested that SQFs produce a modest reduction in crime, which extends over a three-day period from an occurrence. ${ }^{79}$ SQFs were most beneficial to crime deterrence within 100 feet of a stop location, with benefits decreasing out to 300 feet from an occurrence. ${ }^{80}$ For example, within 100 feet of an SQF event, the likelihood of a crime occurring one day after the SQF was 10\% lower than if the stop had not occurred, with deterrence benefits decreasing with more time and space from the stop. ${ }^{81}$

Interestingly for our purposes - i.e., for trying to explain why Chicago's gun crime rates increased dramatically but not rates for other crimes - one of the conclusions suggested by such studies is that stop and frisk (at least in some forms) will reduce gun crimes, but not other violent crimes. For example, a study in Indianapolis found that targeted offender gun patrols reduced gun-related crimes

\footnotetext{
${ }^{72}$ Id. at $813-14$.

${ }^{73} I d$. at 821.

${ }^{74} \mathrm{Id}$.

${ }^{75}$ David Weisburd et al., Do Stop, Question, and Frisk Practices Deter Crime?, 15 CRiminology \& PUB. POL'Y 31, 34 (2015).

${ }^{76} I d$. at 41 .

${ }^{77} \mathrm{Id}$. at 46 .

${ }^{78}$ Alese Wooditch \& David L. Weisburd, Using Space-Time Analysis to Evaluate Criminal Justice Programs: An Application to Stop-Question-Frisk Practices, 32 J. QuANTITATIVE CRIMINOLOGY 191, 193 (2016).

${ }^{79} I d$. at 208.

${ }^{80} \mathrm{Id}$.

${ }^{81} I d$.
} 
substantially but did not appear to affect violent crimes without firearms." Another study, in New York, found few effects of SQF on robbery and burglary rates.

Based on these studies reviewed - as well as other similar studies reaching similar conclusions - we would expect that the significant and sustained decline in stop and frisks in Chicago at the end of 2015 should have led to an increase in homicides in 2016. And that is exactly what happened, as shown in Figure 6.

${ }^{82}$ E.F. MCGARRELL ET AL., REDUCING GUN VIOLENCE: EVALUATION OF THE INDIANAPOLIS Police DePartment's Direct Patrol Project (NCJ-188740 Nat'l Inst. of Just. 2002).

${ }^{83}$ Richard Rosenfeld \& Robert Fornango, The Impact of Police Stops on Precinct Robbery and Burglary Rates in New York City, 2003-2010, 31 JUST. Q. 96 (2014) (finding no statistically significant correlations between SQF and burglary or robbery using yearly rates of crime and SQF stops across all 75 precincts in the New York City Police Department).

${ }^{84}$ See, e.g., Cohen \& Ludwig, supra note 49, at 230-38 (reporting results of Pittsburg firearm suppression patrols, which "substantially reduce[d] citizen reports of shots fired and gunshot injuries in the target neighborhoods"); ); Jeffrey Bellin, The Inverse Relationship Between the Constitutionality of New York City "Stop and Frisk", 94 B.U. L. REV. 1495, 1514-25 (2014) (collecting evidence on NYPD's stop and frisks policies "have to be considered a plausible explanation for the City's distinctive violent crime decline"). But see, e.g., Tracey L. Meares, The Law and Social Science of Stop and Frisk, 10 ANN. REV. L. SOC. SCI. 335 (2014) (arguing that conflicting research fails to establish a clear connection between stop and frisk and crime reduction). 
Figure 6

Chicago Stop and Frisks vs. Homicides (2012-16)

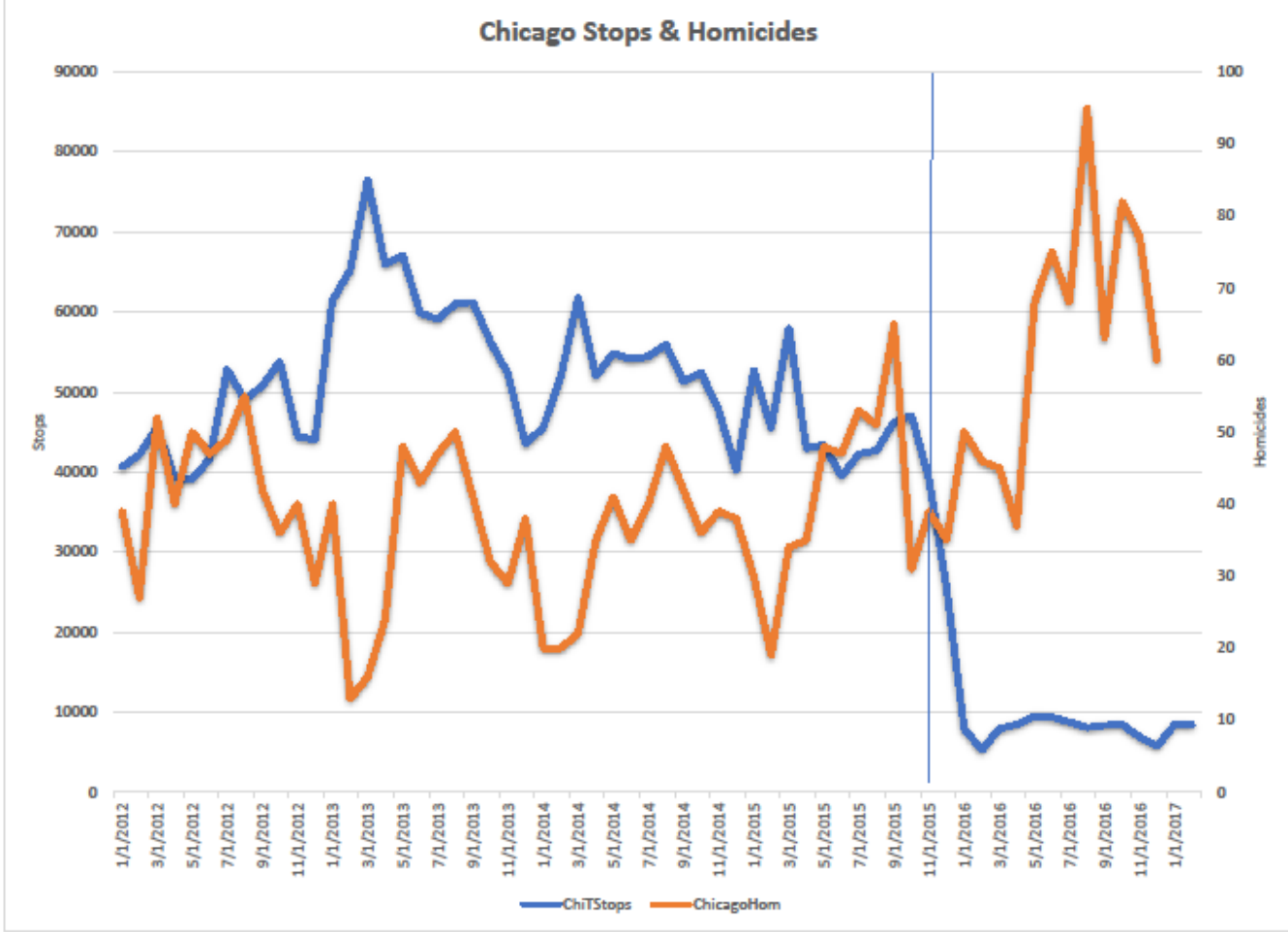

3. The Experience of Other Cities and Declining Stop and Frisks.

The conclusion just reached about a likely connection between simultaneously declining stop and frisks and increasing homicides (and gun crimes) seems fairly straightforward. And yet some observers have been reluctant to reach this conclusion. One example of this reticence comes from an extensive report by the University of Chicago Crime Lab. The informative report, entitled "Gun Violence in Chicago, 2016," was released in January 2017.." It noted the same decline in CPD street stops that we have discussed here, but concluded that it was not "clear what role, if any, the decline in street stops played in contributing to the increase in gun violence in Chicago in $2016 \ldots$. . " The reason given for not

85 CHICAGO CRIME LAB, supra note 17.

86 Id. at 25. 
reaching this conclusion was that "other cities have experienced large declines in street stops without similar increases in gun crime," specifically New York City.

So what about New York City? As the Crime Lab report notes, stop and frisks fell substantially in New York, declining more than 95\% from their highpoint in 2011 to a much lower level in 2015." And while stop and frisks were declining, New York's homicide rates declined or remained roughly stable."

While the results in New York City are interesting, on further examination, their applicability to Chicago seems dubious. The simple point is that New York is different than Chicago - different in its gun crime rate, its police levels, and its population trends. Indeed, with regard to important criminal justice features, New York is clearly idiosyncratic.

Let's first compare New York's homicide rates to Chicago's. In 2016, New York's homicide rate was only 3.9 per 100,000 population, while Chicago's was 27.8 - a rate more than $600 \%$ higher. But the relevant differences between the two cities may be even higher than this already staggering difference suggests.

Looking at homicides committed by firearms, in 2016 New York's rate was 2.3 compared to Chicago's rate of 25.1 - a rate more than $1000 \%$ higher. This is important because, as discussed earlier, gun crimes may be particularly sensitive to stop and frisk policies."

In addition, because New York has such a small number of guns and gun crimes (relative to Chicago and many other cities), it can concentrate resources on preventing gun crimes in a way that other cities cannot. As Professor Franklin Zimring has noted in questioning whether NYPD's success in lower crime rates could be directly transported to other cities, "New York's success may have been assisted by its low rates of civil handgun ownership. Even when there were a substantial number of handguns on New York's streets, the number in homes was much smaller than in other big cities." This means that removing guns from New

${ }^{87} I d$.

${ }^{88}$ Id. at 25, fig. 38. Cf. Al Baker, Street Stops by New York City Police Have Plummeted, N.Y. TimES, May 30, 2017 (noting significant drop in reported stops, but also noting concern that not all of NYPD's stops were being officially recorded). https://www.nytimes.com/2017/05/30/nyregion/nypd-stop-and-frisk.html

${ }^{89}$ ChICAGO CRIME LAB, supra note 17, at 25; see also Michael D. White, Federal Civil Litigation as an Instrument of Police Reform: A Natural Experiment Exploring the Effects of the Floyd Ruling on Stop-and-Frisk Activities in New York City, 14 OHIO ST. J. CRIM. L. 9, 60 (2016) (advancing similar argument).

${ }^{90} \mathrm{Id}$. at 9 , fig. 8.

${ }^{91} \mathrm{Id}$.

${ }^{92}$ See supra notes 81-82 and accompanying text.

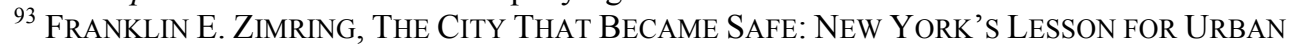
CRIME AND ITS CONTROL 148 (2012). 
York's streets may have been an especially powerful tactic there, because handguns were harder to replace than in other cities."

Another problem in equating New York's circumstances with Chicago's is that the level of police power is different. New York has high levels of law enforcement.s For example, if we look to the FBI's Uniform Crime Reports for 2016, New York had 51,399 police employees compared to 13,135 for Chicago, which even when adjusted for population size, means that New York's overall police force was, on a per capita basis, about 25\% larger than Chicago's." But this comparison fails to capture the true workload differences between the two cities. Using the same crime (homicide) as used by the Crime Lab study, New York had about 153 law enforcement employees for every homicide committed in the city, while Chicago had only about 17 employees for every homicide committed"about a $800 \%$ difference.

The difference is even greater if one combines both the gun homicide and police force numbers. Per gun homicide, New York has roughly 260 employees, while Chicago has only $19 \times$ well over a $1000 \%$ difference. To this point it might be objected that a homicide is a homicide, so it makes no sense to break out gun homicides separately. But homicides are not all alike. To the contrary, in general, homicides committed by firearm are more difficult to solve than other kinds of homicides, only adding to the relative difficulties for the Chicago Police Department. Moreover, in 2016, about 23\% of New York's homicides were gangrelated, ${ }^{1 \infty}$ while roughly $67 \%$ (or more) of Chicago's homicides and shootings

${ }^{94} I d$.

${ }^{95}$ See, e.g., id. at 129, 144.

${ }^{96}$ See Fed. BurEaU OF INVESTIGATION, UNIFORM CRIME REPORTS, CRIME IN THE UNITED STATES 2016, tbl. 26 (full-time law enforcement employees, by state, by city, 2016). The per person law enforcement employees in New York were 0.0060 compared to 0.0048 in Chicago. Id. These figures may understate the differences, because the reported numbers may not include New York's sizeable housing and transit police forces. See ZIMRING, supra note 93, at 116-17 (discussing these police forces).

${ }^{97}$ See id., tbls. 6 \& 26 (51,399 employees $\div 335$ homicides for New York vs. 13,135 employees $\div 765$ homicides for Chicago).

${ }^{98}$ Estimated by using the ratios reported above. See notes 17 \& 96 supra and accompanying text.

${ }^{99}$ See, e.g., Marc Riedel, Homicide Arrest Clearances: A Review of the Literature, 2 SOCIOLOGY COMPASS 1114, 1147 (2008) (reviewing studies and concluding "[t]he reason that [homicides with weapons] other than firearms are cleared more quickly is that forensic evidence is available not available with firearms, especially handguns that kill at a distance").

${ }^{100}$ See Benjamin Mueller \& Al Baker, Drop in Gang Violence Drove New York City Shootings Below 1,000 in 2016, N.Y. TIMES, Jan. 3, 2017 (reporting that NYPD identified only 79 killings in 2016 as "gang related," down from 129 in 2015), https://www.nytimes.com/2017/01/03/nyregion/new-york-city-shootings-gangviolence.html. Dividing 79 by Uniform Crime Report figure of 335 reported homicides in New York in 2016 produces the figure quoted in text. 
appear to have been gang-related. ${ }^{\text {or }}$ Here again, gang-related homicides may be more difficult to solve than are other homicides, ${ }^{\text {(120 }}$ particularly in Chicago.

New York's large police force reserves also permit operational strategies that are not possible in Chicago-including strategies to respond to increasing gun crimes from the absence of stop and frisks. NYPD greatly restricted its use of stop and frisks from 2011 to 2015. Interestingly, at least during some of that time, gun crimes may have increased. For example, in 2013 and 2014, gun crimes in New York City rose for two consecutive two years, the first two-year consecutive increase in nearly two decades. ${ }^{104}$ By June of 2015, murder rates in the city had increased 20 percent and shootings increased nine percent. ${ }^{105}$ The decline in stop and frisks was publicly suspected to be a factor. Thereafter, NYPD Commissioner William Bratton then utilized the large police force uniquely available to the NYPD and instituted a summer program of high-visibility policing

${ }^{101}$ We have been unable to locate precise figure for "gang-related" homicides in Chicago in 2016. The figure quoted above is from the Crime Lab study, based on an analysis of CPD records, of arrests for both homicides and shootings. See ChiCAGo Crime LaB, supra note 17 , at 16 , fig. 3 . This figure probably slightly understates the degree of gang involvement, because gang crimes are probably, on average, more difficult to solve than many other crimes (e.g., simple assaults, domestic disputes) and thus less likely to produce an arrest.

${ }^{102}$ But cf. Kenneth J. Litwin \& Yili Xu, The Dynamic Nature of Homicide Clearances: A Multilevel Model Comparison of Three Time Periods, 11 HomICIDE STUD. 94 (2007) (analyzing Chicago homicides from 1966 to 1995, and finding the gang-related homicides were more likely to be cleared than other homicides, but cautioning that the conclusions may have been affected by the number of cases in which circumstances were unknown may have affected the conclusions); Charles Wellford \& James Cronin, Clearing Up Homicide Clearance Rates, NAT'L INST. OF JUST. J., Apr. 2000, at 4 (reporting that homicides involving a victim as a member of a gang or drug organization was positively associated with clearance of the crime, although this was not a highly correlated factor), https://www.ncjrs.gov/pdffiles1/jr000243b.pdf.

${ }^{103}$ See David Heinzmann, As Chicago Killings Surge, the Unsolved Cases Pile Up, CHI. TRIB., Sept. 9, 2016 (noting that "[m]ost killings in Chicago take place amid a street gang culture that intimidates anyone from coming forward with information"), http://www.chicagotribune.com/news/local/breaking/ct-chicago-homicide-clearance-rate20160909-story.html.

${ }^{104}$ Heather MacDonald, The War on COPS: How the NeW ATtaCK ON LAW AND ORDER MAKES EVERYONE LESS SAFE 108 (2016).

${ }^{105} \mathrm{Id}$. It appears that homicides by guns had increased even more than the overall homicide rate. See Tina Moore et al., Crime Down, But Murders by Gun on the Rise, N.Y. Post, Nov. 2, 2015, https://nypost.com/2015/11/02/crime-down-but-murders-by-gun-onthe-rise/.

${ }^{106}$ See Tina Moore et al., Crime Down, But Murders by Gun on the Rise, N.Y. Post, Nov. 2, 2015 (citing "high-ranking police source" as explaining rise in gun crimes in the first part of 2015), https://nypost.com/2015/11/02/crime-down-but-murders-by-gun-on-the-rise/. 
that "flooded shooting zones with cops." 107 As a result, the shooting surge flattened out and, by the end of 2015 , murders were up by "only" 6 percent. ${ }^{108}$

New York may also be different than Chicago due to long-term population trends. Heather MacDonald has recently argued that New York's "gentrification" is fueling New York's ongoing crime drop." She suggests that population trends are lowering crime rates. ${ }^{.10}$ Her argument is bolstered by criminology research showing that changes in population groups can affect crime rates."' MacDonald contends that high-crime areas in, for example, Chicago have not been gentrified,"12 which could account for the city's continuing struggle with higher crime rates than New York."

The many differences between the cities means that it becomes difficult to draw lessons from New York's experience with its reduction in stop and frisk and apply them directly to Chicago. Professor Zimring expressed this point neatly when he wrote, in 2012, that "[o]ne cannot abstract stop-and-frisk from the complex of information, patrol, and policy in New York City to test it comprehensively in Newark or Miami." "For the reasons explained here, a direct New York to Chicago comparison is probably unhelpful as well.

Instead of looking to a single exceptional city like New York, it may be useful to compare Chicago's experience to a broader set of cities. For such a comparison, it is instructive to look to a recent and important study completed by Professors Stephen Rushin and Griffin Edwards."1s They analyzed the effects of federal consent decrees imposed by the Justice Department on a series of cities across the United States. While they did not focus directly on stop and frisk policies, it is reasonable to assume that the consents decrees may have reduced stop and frisks." Based on collection of seventeen cities (not including either New

${ }^{107}$ MACDONALD, supra note 104, at 109.

${ }^{108} \mathrm{Id}$.

${ }^{109}$ Heather MacDonald, Don't Take the Wrong Lessons from NYC's Murder Drop, NAT'L REV., Dec. 28, 2017, http://www.nationalreview.com/article/454997/new-york-cityhomicide-rate-drop-lessons-proactive-policing.

${ }^{110} \mathrm{Id}$.

${ }^{11}$ See, e.g., ZIMRING, supra note 93, at 132-33 (discussing demographic changes in Manhattan as an explanation for decline crime rates, but noting this is a long-term factor). ${ }^{112}$ By some measures, Chicago remains one of the most segregated cities in the nation, with a higher level of black-white segregation than New York City. See William H. Frey, Census Shows Modest Declines in Black-White Segregation, BRoOKINGS InST., Dec. 8, 2015, https://www .brookings.edu/blog/the-avenue/2015/12/08/census-shows-modestdeclines-in-black-white-segregation/ (in New York metro area, the percent of blacks in the neighborhood of the average black resident was $51 \%$, compared to $64 \%$ in the Chicago metro area).

${ }^{113}$ MacDonald, Don't Take the Wrong Lessons, supra note 109, at 132-33.

114 ZIMRING, supra note 93, at 149.

${ }^{115}$ Stephen Rushin \& Griffin Edwards, De-Policing, 102 CORNELl L. REV. 721 (2017).

${ }^{116}$ See id. at 722-24 (discussing connections between consent decrees and stops and frisks). 
York or Chicago), Rushin and Edwards concluded that, on average, violent crime rates were $2.6 \%$ higher and property crime rates $6.9 \%$ higher in cities subject to consent decrees when compared to the national average." In addition, they found that crime increases were particularly likely to be statistically significant for property crimes and street crimes like homicide, burglary, motor vehicle theft, and robbery- “i.e., criminal activity that is likely sensitive to situational deterrents like aggressive street policing." "The experience in this collection of cities may be more applicable to Chicago than the experience in New York.

\section{Regression Analysis of Chicago's Decline in Stop and Frisks and the Homicide Spike}

Turning back to Chicago, it is possible to quantitatively explore the specific linkage between declining stop and frisks and increases in homicides and shootings. Multiple regression analysis is a commonly-used technique to explore possible causal linkages between variables, particularly in the criminal justice field."19 To explore possible linkages in Chicago, we ran standard ordinary least squares (OLS) regressions on Chicago monthly homicides and the three other shooting crime variables, as explained by a baseline intercept, a time trend, Illinois homicides (minus Chicago), various arrest series, a temperature series, and Chicago stop and frisks.

The reason for including data on temperature has been discussed earlier. ${ }^{\text {ax }}$ The basic idea is that more homicides are committed during warm weather months. Because we included this variable, our dependent variables (homicides and other shooting crimes) were not seasonally adjusted but were simply raw numbers from each month.

The reason for including the Illinois-homicides-apart-from-Chicago is worth brief discussion. We wanted to have some sort of control for broader trend lines that might be causing crime to increase, other than factors unique to Chicago. Using data for homicides in Illinois (apart from Chicago) might be one way of controlling for things happening in Illinois, as homicides in other parts of the state might reflect changes happening there. Moreover, as noted earlier, Illinois trends are not too far off from national trends.

We also included a data set of monthly 9-1-1 calls to the police. These are citizen-initiated calls and thus might be expected to be a measure of police-citizen relations, as discussed at greater length below.

\footnotetext{
${ }^{117} I d$. at 762 , fig. 5,763 , fig. 6.

${ }^{118}$ Id. at $765-66$.

${ }^{119}$ See, e.g., Cassell \& Fowles, Still Handcuffing the Cops?, supra note 30, at 710-14.

${ }^{120}$ See supra notes 25-28 and accompanying text.

${ }^{121}$ See supra note 41 and accompanying text.
} 
One other set of variables is worth brief mention. Other law enforcement efforts might play a role in crime and crime rates. In particular, the ability of CPD to arrest criminals for a variety of crimes might influence subsequent crimes. To control for this possibility, we included in our regression equations several monthly arrest series, specifically property crime arrests, violent crime arrests (excluding homicides and shooting arrests), gun arrests, shooting arrests, and illegal drug arrests. ${ }^{12}$ Because we had several series on arrests, thus having some measure of police success in solving crimes, we did not include any other separate variables for crime clearance rates. ${ }^{12}$

We have tried to put together the simplest model possible for exploring our research question, believing that "simple and transparent analytical strategies" are the best approach. . Our results, obtained in the standard software package $R$, are reported in Table 6 below.

Table 6

Regression Equations of Chicago Crimes Explained by Various Variables (2012 to 2016 Monthly Data)

OLS Regression on Number of Crimes ( $t$ statistics in parenthesis)

\begin{tabular}{|c|c|c|c|c|}
\hline $\begin{array}{c}\text { EXPLANATORY } \\
\text { VARIABLE }\end{array}$ & HOMICIDES & $\begin{array}{c}\text { FATAL } \\
\text { SHOOTINGS }\end{array}$ & $\begin{array}{c}\text { NON-FATAL } \\
\text { SHOOTINGS }\end{array}$ & $\begin{array}{c}\text { TOTAL } \\
\text { SHOOTINGS }\end{array}$ \\
\hline $\begin{array}{c}\text { CHICAGO STOP } \\
\text { AND FRISKS }\end{array}$ & -0.000508 & -0.000594 & -0.00192 & -0.00252 \\
$(-3.833)^{* * *}$ & $(-3.862)^{* * *}$ & $(-4.291)^{* * *}$ & $(-4.863)^{* * *}$ \\
\hline TEMPERATURE & 0.169 & 0.156 & 1.195 & 1.351 \\
& $(1.155)$ & $(0.917)$ & $(2.410)^{*}$ & $(2.360)^{*}$ \\
\hline 911 CALLS & .0000719 & 0.0000740 & 0.000362 & 0.000436 \\
& $(1.366)$ & $(1.210)$ & $(2.024)^{*}$ & $(2.112)^{*}$ \\
\hline ILLINOIS & 0.0358 & 0.0486 & 0.654 & 0.702 \\
HOMICIDES & $(0.171)$ & $(0.200)$ & $(0.921)$ & $(0.857)$ \\
\hline PROPERTY & 0.0206 & 0.0152 & 0.0498 & 0.0650 \\
ARRESTS & $(1.616)$ & $(1.206)$ & $(1.152)$ & $(1.303)$ \\
\hline VIOLENT CRIME & 0.00540 & 0.0215 & 0.0446 & 0.0662 \\
ARRESTS & $(0.193)$ & $(0.66)$ & $(0.470)$ & $(0.603)$ \\
\hline HOMICIDE & 0.392 & 0.320 & 0.756 & 1.0760 \\
ARRESTS & $(2.707)^{* *}$ & $(1.906)^{\dagger}$ & $(1.540)$ & $(1.900)$ \\
\hline$G U N$ ARRESTS & 0.0342 & 0.0366 & 0.252 & 0.288 \\
& $(1.263)$ & $(1.906)$ & $(2.737)^{* *}$ & $(2.716)^{* *}$ \\
\hline
\end{tabular}

${ }^{122}$ The arrest data was graciously provided to us by the University of Chicago Crime Lab.

${ }^{123} \mathrm{We}$ considered constructing separate clearance rate variables by dividing some of crime variables (e.g., the number of homicides) by the sum of the arrest variables (e.g. the number of homicide arrests). But this would have effectively put exactly the same variable on both the left side and right side of the equations, which can be problematic.

12: THAD DUNNING, NATURAL EXPERIMENTS IN SOCIAL SCIENCES: A DESIGNED-BASED APPROACH 313-14 (2012). 


\begin{tabular}{|c|c|c|c|c|}
\hline SHOOTING & -0.243 & -0.137 & -0.0851 & -0.222 \\
ARRESTS & $(-1.233)$ & $(-0.598)$ & $(-0.128)$ & $(-0.288)$ \\
\hline DRUG ARRESTS & -0.00247 & -0.00129 & -0.00472 & -0.00602 \\
& $(-0.437)$ & $(-0.197)$ & $(-0.246)$ & $(-0.271)$ \\
\hline TIME TREND & 0.212 & 0.351 & 1.035 & 1.386 \\
& $(0.886)$ & $(1.262)$ & $(1.274)$ & $(1.478)$ \\
\hline INTERCEPT & -22.910 & -29.720 & -151.9 & -181.6 \\
& $(-0.735)$ & $(-0.820)$ & $(-1.436)$ & $(-1.487)$ \\
\hline ADJUSTED $R^{2}$ & .745 & .743 & .869 & .882 \\
\hline
\end{tabular}
at .10 level

*** significant at .001 level $* *$ significant at .01 level $*$ significant at .05 level $\uparrow$ significant

As can be readily seen, the linkage between stop and frisk and the four shooting crime data series is very strong, statistically significant at the .001 ( $99.9 \%$ confidence) level. ${ }^{15}$ The sign (negative) is as expected-i.e., an increase in stop and frisks decreases each of the four crime variables: homicides, fatal shootings, non-fatal shootings, and total shootings. Interestingly, only two variables show statistical significance across all crime variables: stop and frisk (with a negative sign) and temperature (with a positive sign). As explained above, strong empirical research provides support for both of these particular linkages with those particular signs, ${ }^{\text {,6 }}$ which gives us additional confidence that our equations are tracking real world effects. Our adjusted $\mathrm{R}^{2}$ (a measure of what part of the variance we can explain) is also relatively high, particularly given the limited number of observations that we have over the five year (i.e., sixty month) period.

This may be the appropriate place to say a few words about including arrests as explanatory variables. An argument can be made that they are actually dependent variables, that is, the crime variables explain arrests rather than the other way around. For example, it might plausibly be argued that as homicides increase, homicide arrests will increase, simply by virtue of the fact that more killers are on the loose for police to apprehend.

${ }^{125}$ All statistical significance tests reported in this Article are two-tailed, although an argument could be made for a one-tailed test. We are aware of the controversy surrounding reporting $p$-values and have tried to follow the recommendations of the American Statistical Association in our approach and report of findings. See generally Ronald L. Wasserstein \& Nicole A. Lazar, Editorial, The ASA's Statement on p-Values: Context, Process, and Purpose, 70 AM. STATISTICIAN 129 (2016). All p-values reported in this article should be considered in light of the results from Bayesian Model Averaging reported below at infra notes 260-61 and accompanying text. ${ }^{126}$ See supra notes 53-83 and accompanying text (stop and frisks); supra notes 25-28 and accompanying text (temperature). 
The direction of the causality arrow between crimes and arrests in regression equations remains an interesting point to be considered. But for present purposes, since our focus is on stop and frisk, the key point remains that including arrest variables in our equations does not defeat the statistical significance of the stop and frisk variable. Nor is inclusion of the arrest variables necessary to generate the statistical significance of the stop and frisk variables, as we demonstrate through Bayesian Model Averaging below. ${ }^{\text {.s }}$

Because we were interested in whether trends both inside and outside Chicago could be playing some role in the homicide spike, we also collected data on homicides in cities throughout the "Midwest." Specifically, we collected monthly homicide data from St. Louis, Missouri; Columbus, Ohio; Louisville, Kentucky; Indianapolis, Indiana; Grand Rapids, Michigan; Gary, Indiana; Cincinnati, Ohio; Cleveland, Ohio; and Detroit, Michigan. As with the Illinois homicide data collected above, the theory is not that homicides in, for example, St. Louis, Missouri, somehow cause homicides in Chicago, but rather that there might be some factor influencing both cities at the same time that would be reflected in the data series. ${ }^{n g}$

We are aware that more sophisticated approaches be used in applying such data, such creating a "synthetic control" city to compare to Chicago." Such approaches, however, inevitably require some judgment in constructing the more elaborate models. For purposes of this particular paper, we decided to proceed in the most straightforward manner possible by simply including the other cities' data as explanatory variables. We could understand that some might disagree with this approach, so we simply ran these regression equations separately, so that a reader who believes that inclusion of such variable is inappropriate can simply refer to the table above without such variables. But in any event, adding these cities as possible explanatory variables does not alter our findings. As shown in Table 7,

"2. See Sonja B. Starr, Testing Racial Profiling: Empirical Assessment of Disparate Treatment by Police, UNIV. CHI. L. ForUM, vol. 2016, art. 12, at 485, 512 (discussing "circularity problem" between crimes rates and arrest rates), https://chicagounbound.uchicago.edu/uclf/vol2016/iss1/12.

${ }^{128}$ See infra notes 260-61 and accompanying text.

${ }^{129}$ We preliminarily examined the data from the other cities for "breakpoints" comparable to Chicago's. On quick examination, we found no comparable break points with the exception of St. Louis, which exhibited two possible break points: October 2013 (with an August to November confidence band), and September 2014 (with a confidence interval of August to October). The shooting of Michael Brown, which led to widespread unrest in Ferguson, Missouri (a suburb of St. Louis) occurred in August 2014. Because our focus was on Chicago homicides, we did not follow up this possible explanation for the St. Louis data.

wo $C f$. Rushin \& Griffin, supra note 115, at 762-66 (comparing consent decree cities to nonconsent decree cities). 
the stop and frisk variable remained highly statistically significant with the expected sign — negative — across all four crime variables.

Table 7

Regression Equations of Chicago Crimes Explained by Various Variables Homicides from Regional Cities Also Included

(2012 to 2016 Monthly Data)

OLS Regression on Number of Crimes ( $t$ statistics in parenthesis)

\begin{tabular}{|c|c|c|c|c|}
\hline $\begin{array}{c}\text { EXPLANATORY } \\
\text { VARIABLE } \\
\end{array}$ & HOMICIDES & $\begin{array}{c}\text { FATAL } \\
\text { SHOOTINGS } \\
\end{array}$ & $\begin{array}{l}\text { NON-FATAL } \\
\text { SHOOTINGS } \\
\end{array}$ & $\begin{array}{c}\text { TOTAL } \\
\text { SHOOTINGS } \\
\end{array}$ \\
\hline $\begin{array}{c}\text { CHICAGO STOP } \\
\text { AND FRISKS }\end{array}$ & $\begin{array}{l}-0.000462 \\
(-3.311)^{* *}\end{array}$ & $\begin{array}{l}-0.000525 \\
(-3.403)^{* *}\end{array}$ & $\begin{array}{l}-0.00174 \\
(-4.058)^{* * *}\end{array}$ & $\begin{array}{l}-0.00226 \\
(-4.649)^{* * *}\end{array}$ \\
\hline TEMPERATURE & $\begin{array}{c}0.103 \\
(0.617)\end{array}$ & $\begin{array}{c}0.128 \\
(0.694)\end{array}$ & $\begin{array}{c}1.148 \\
(2.234)^{*}\end{array}$ & $\begin{array}{c}1.277 \\
(2.185)^{*}\end{array}$ \\
\hline 911 CALLS & $\begin{array}{c}0.0000785 \\
(1.183)\end{array}$ & $\begin{array}{c}0.0000702 \\
(0.957)\end{array}$ & $\begin{array}{c}0.000179 \\
(0.878)\end{array}$ & $\begin{array}{c}0.000249 \\
(1.076)\end{array}$ \\
\hline $\begin{array}{c}\text { ILLINOIS } \\
\text { HOMICIDES }\end{array}$ & $\begin{array}{c}0.110 \\
(0.445)\end{array}$ & $\begin{array}{c}0.217 \\
(0.796)\end{array}$ & $\begin{array}{c}0.258 \\
(0.340)\end{array}$ & $\begin{array}{c}0.475 \\
(0.551)\end{array}$ \\
\hline $\begin{array}{c}\text { PROPERTY } \\
\text { ARRESTS }\end{array}$ & $\begin{array}{l}0.0194 \\
(1.328)\end{array}$ & $\begin{array}{l}0.0139 \\
(0.856)\end{array}$ & $\begin{array}{l}-0.00333 \\
(-0.0740)\end{array}$ & $\begin{array}{l}0.0105 \\
(0.206)\end{array}$ \\
\hline $\begin{array}{c}\text { VIOLENT CRIME } \\
\text { ARRESTS }\end{array}$ & $\begin{array}{l}0.00493 \\
(0.149) \\
\end{array}$ & $\begin{array}{l}0.0172 \\
(0.468) \\
\end{array}$ & $\begin{array}{c}0.173 \\
(1.706) \\
\end{array}$ & $\begin{array}{c}0.191 \\
(1.650) \\
\end{array}$ \\
\hline $\begin{array}{c}\text { HOMICIDE } \\
\text { ARRESTS }\end{array}$ & $\begin{array}{c}0.451 \\
(2.825)^{* *}\end{array}$ & $\begin{array}{c}0.389 \\
(2.197)^{*}\end{array}$ & $\begin{array}{c}0.545 \\
(1.109)\end{array}$ & $\begin{array}{c}0.934 \\
(1.673)\end{array}$ \\
\hline GUN ARRESTS & $\begin{array}{l}0.0131 \\
(0.437)\end{array}$ & $\begin{array}{l}0.0124 \\
(0.374)\end{array}$ & $\begin{array}{c}0.190 \\
(0.0462)^{*}\end{array}$ & $\begin{array}{c}0.202 \\
(1.930)^{\dagger}\end{array}$ \\
\hline $\begin{array}{c}\text { SHOOTING } \\
\text { ARRESTS }\end{array}$ & $\begin{array}{c}-0.252 \\
(-1.204)\end{array}$ & $\begin{array}{c}-0.155 \\
(-0.670)\end{array}$ & $\begin{array}{c}-0.113 \\
(-0.177)\end{array}$ & $\begin{array}{c}-0.269 \\
(-0.368)\end{array}$ \\
\hline DRUG ARRESTS & $\begin{array}{c}0.000854 \\
(0.139) \\
\end{array}$ & $\begin{array}{l}0.00273 \\
(0.403) \\
\end{array}$ & $\begin{array}{c}-0.000700 \\
(-0.0370) \\
\end{array}$ & $\begin{array}{l}0.00204 \\
(0.0950) \\
\end{array}$ \\
\hline $\begin{array}{c}\text { ST. LOUIS } \\
\text { HOMICIDES }\end{array}$ & $\begin{array}{l}0.0540 \\
(0.175)\end{array}$ & $\begin{array}{c}0.149 \\
(0.439)\end{array}$ & $\begin{array}{l}1.369 \\
(1.447)\end{array}$ & $\begin{array}{c}1.518 \\
(1.413)\end{array}$ \\
\hline $\begin{array}{l}\text { COLUMBUS } \\
\text { HOMICIDES }\end{array}$ & $\begin{array}{c}-0.128 \\
(-0.329)\end{array}$ & $\begin{array}{c}0.127 \\
(0.294)\end{array}$ & $\begin{array}{c}2.174 \\
(1.814)^{\dagger}\end{array}$ & $\begin{array}{c}2.01 \\
(1.689)^{\dagger}\end{array}$ \\
\hline $\begin{array}{l}\text { LOUISVILLE } \\
\text { HOMICIDES }\end{array}$ & $\begin{array}{c}0.206 \\
(0.474) \\
\end{array}$ & $\begin{array}{l}0.0808 \\
(0.168) \\
\end{array}$ & $\begin{array}{c}-0.576 \\
(-0.433) \\
\end{array}$ & $\begin{array}{c}-0.496 \\
(-0.327) \\
\end{array}$ \\
\hline $\begin{array}{c}\text { INDIANAPOLIS } \\
\text { HOMICIDES }\end{array}$ & $\begin{array}{c}-0.178 \\
(-0.547)\end{array}$ & $\begin{array}{l}-0.00874 \\
(-0.0240)\end{array}$ & $\begin{array}{c}0.183 \\
(0.182)\end{array}$ & $\begin{array}{c}0.174 \\
(0.153)\end{array}$ \\
\hline $\begin{array}{c}\text { GRAND RAPIDS } \\
\text { HOMICIDES }\end{array}$ & $\begin{array}{c}-0.400 \\
(-0.380)\end{array}$ & $\begin{array}{c}-0.948 \\
(-0.815)\end{array}$ & $\begin{array}{c}3.566 \\
(1.104)\end{array}$ & $\begin{array}{c}2.618 \\
(0.713)\end{array}$ \\
\hline $\begin{array}{c}\text { GARY } \\
\text { HOMICIDES }\end{array}$ & $\begin{array}{c}-0.370 \\
(-0.735)\end{array}$ & $\begin{array}{l}-0.931 \\
(-1.673)\end{array}$ & $\begin{array}{l}-2.002 \\
(-1.297)\end{array}$ & $\begin{array}{c}-2.933 \\
(-1.671)\end{array}$ \\
\hline $\begin{array}{l}\text { CINCINATTI } \\
\text { HOMICIDES }\end{array}$ & $\begin{array}{c}-0.360 \\
(-0.667)\end{array}$ & $\begin{array}{l}-0.878 \\
(-1.468)\end{array}$ & $\begin{array}{c}-2.144 \\
(-1.291)\end{array}$ & $\begin{array}{l}-3.022 \\
(-1.601)\end{array}$ \\
\hline $\begin{array}{l}\text { CLEVELAND } \\
\text { HOMICIDES }\end{array}$ & $\begin{array}{c}0.675 \\
(1.721)\end{array}$ & $\begin{array}{c}0.897 \\
(2.066)\end{array}$ & $\begin{array}{l}1.539 \\
(1.277)\end{array}$ & $\begin{array}{c}2.436 \\
(1.779)\end{array}$ \\
\hline DETROIT & 0.217 & 0.218 & 1.726 & 1.944 \\
\hline
\end{tabular}




\begin{tabular}{|c|c|c|c|c|}
\hline HOMICIDES & $(1.018)$ & $(0.925)$ & $(2.637)^{*}$ & $(2.613)^{*}$ \\
\hline TIME TREND & 0.360 & 0.486 & 1.061 & 1.546 \\
& $(1.222)$ & $(1.489)$ & $(1.172)$ & $(1.504)$ \\
\hline INTERCEPT & -37.98 & -44.49 & -135.3 & -179.8 \\
& $(-1.047)$ & $(-1.108)$ & $(-1.214)$ & $(-1.420)$ \\
\hline ADJUSTED $R^{2}$ & .729 & .752 & .885 & .900 \\
& & & & \\
\hline
\end{tabular}
at .10 level

$* * *$ significant at .001 level $* *$ significant at .01 level $*$ significant at .05 level $\dagger$ significant

Inclusion of these additional variables did not significantly improve the explanatory power of the equations, as shown relatively minor increases in the values for the adjusted $R^{2}$. Also, none of the newly included city time series were statistically significant across all four crime categories, reinforcing our earlier conclusion that the Chicago homicide spike was caused by something unique to Chicago.

To be sure, we would like more fulsome regression equations. One difficulty in collecting data is that we wanted to have monthly data, since the changes in stop and frisk practices are best revealed in monthly data sets. There is a great deal of data available about Chicago, surrounding cities, and the entire United States on an annual basis. But finding it on a monthly basis is challenging.

Nonetheless, we think it unlikely that an "omitted" variable problem" exists that is significant enough to defeat the strong statistical significance shown in these equations between shooting crimes and the decline in stop and frisks. We turn to possible omitted variables in the next section.

\section{Other Possible CAUSES OF THE Homicide SPIKE}

So far, we have provided reasons for believing that a steep drop in the number of stop and frisks conducted by the Chicago Police Department triggered the subsequent spike in homicides. In this section, we investigate other possible "alternate causalities" and explain our reasons for believing that they are much weaker candidates for causing the spike than declines in stop and frisks. In section A, we examine several candidates that are plausible, but ultimately inadequate, candidates for triggering the spike. In section B, we examine other candidates that are entirely implausible candidates.

\section{A. Other Plausible, But Ultimately Inadequate, Candidates for the Homicide Spike}

In a previous section, we explained why the triggering mechanism appears to have been something that occurred uniquely within Chicago, not more broadly

${ }^{131}$ See Cassell \& Fowles, Still Handcuffing the Cops?, supra note 30, at 801 (discussing omitted variable problem in regression equations). 
in Illinois, throughout the Midwest, or across the country..12 But within Chicago's boundaries, in late 2015 several changes occurred that could, in theory, have triggered a spike in homicide rates. None of these changes, however, is nearly so strong a candidate as declines in stop and frisk for triggering the homicide spike.

\section{Release of the Laquan McDonald Shooting Video}

Just as stop and frisks were starting to decline in late 2015, another event of possible significance took place. On November 24, 2015, a disturbing video was released showing a CPD officer shooting and killing Laquan McDonald, a young African-American male. Did the release of the video generate the homicide spike?

A time line of the relevant events is fairly easy to construct." On October 20, 2014, Laquan McDonald, a 17-year-old African-American male, was shot and killed by a Chicago police officer, Jason Van Dyke. The initial story was that Van Dyke feared for his life because McDonald was carrying a knife, had a "crazed" look in his eyes, and lunged at Van Dyke. ${ }^{134}$ Multiple officers corroborated this account, and Van Dyke was quickly cleared of any wrongdoing. ${ }^{\text {.s }}$ CPD released a statement explaining that "[o]fficers confronted the armed offender, who refused to comply with orders to drop the knife and continued to approach the officers. As a result of this action, the officer discharged his weapon, striking the offender."136

As the public found out later, this account was untrue and, on April 15, 2015, about six months later, the Chicago City Council recognized that the shooting was improper and voted 47-0 in favor of paying a $\$ 5$ million settlement to McDonald's family. About a month later, a journalist filed a Freedom of Information Act request with CPD, seeking videos from the night Van Dyke shot and killed McDonald. ${ }^{\text {ss }}$ CPD denied the request for production in August, leading to a lawsuit seeking copies of the videos." In early November 2015, a judge ordered CPD to release the videos by November 24.

${ }^{132}$ See supra notes 33-41 and accompanying text.

${ }^{133}$ For a helpful chronology of events, see Nausheen Husain, Laquan McDonald Timeline: The Shooting, the Video and the Fallout, CHI. TRIB., Oct. 20, 2017, http://www.chicagotribune.com/news/laquanmcdonald/ct-graphics-laquan-mcdonaldofficers-fired-timeline-htmlstory.html [hereinafter Chicago Tribune Timeline]. The chronology that follows relies heavily on this timeline, so as to include events that the Tribune thought were significant.

${ }^{134}$ Ben Austen, Chicago After Laquan McDonald, N.Y. Times, Apr. 20, 2016, https://www.nytimes.com/2016/04/24/magazine/chicago-after-laquan-

mcdonald.html?_r=0.

is $I d$.

${ }^{136} \mathrm{Id}$.

${ }^{137}$ Chicago Tribune Timeline, supra note 133.

${ }_{138}^{138} \mathrm{Id}$.

${ }^{139} \mathrm{Id}$.

${ }^{100} I d$. 
On November 24, 2015, mere hours before the release of the videos, Officer Van Dyke was charged with first-degree murder in the shooting of McDonald." This was the first time a Chicago police officer had been charged with first-degree murder for an on-duty fatality in nearly 35 years. ${ }^{142} \mathrm{~A}$ few hours later, the City released a police dashcam video showing Van Dyke shooting McDonald sixteen times, killing him. ${ }^{10}$ The footage appeared to contradict accounts of the shooting given by Van Dyke and other officers. ${ }^{144}$ While officers had initially alleged threatening behavior, the teenager was shown walking (obliquely) away holding a folding knife when Van Dyke unloaded his gun. ${ }^{145}$

Protests swiftly followed the video's release. The night of the release, hundreds of protesters marched through downtown Chicago, ${ }^{, 16}$ chanting "sixteen shots" and calling for the resignation of Mayor Rahm Emanuel and the firing of police Superintendent Garry McCarthy." About a week later, on December 1, 2015, Mayor Emanuel fired McCarthy."* On around the same day, Mayor Emanuel announced the creation of a Task Force on Police Accountability." On December 6, 2015, Attorney General Loretta Lynch announced that the U.S. Justice Department would begin an investigation of CPD's use of force. ${ }^{\text {so }}$ On December 24, 2015, protesters staged a "Black Christmas" march among last-minute

\footnotetext{
"it Id.

${ }^{142}$ Wayne Drash, The Killing of Laquan McDonald: The Dashcam Video vs. Police Accounts, CNN, Dec. 19, 2015, http://www.cnn.com/2015/12/17/us/laquan-mcdonaldvideo-records-comparison/.

${ }^{143}$ Id.

${ }^{144}$ Jeremy Gorner et al., City Homicide Numbers Spike, CHI. TRIB., Mar. 1, 2016, at 1 WLNR 6389204 (noting the video "was starkly at odds with the police account of the shooting). In recent interviews, former Superintendent McCarthy appears to have defended aspects of the shooting, although the validity of that defense has itself been contested. See, e.g., Eric Zorn, McCarthy Talks Like a Cop, Not a Potential Mayor, in Offering Excuses for the Laquan McDonald Shooting, CHI TRIB., Feb. 13, 2018, http://www.chicagotribune.com/news/opinion/zorn/ct-perspec-zorn-mccarthy-laquanexcuses-mayor-0214-20180213-story.html.

${ }^{145}$ See Drash, supra note 142. The video itself can be viewed at http://www.chicagotribune.com/news/85142730-132.html.

${ }_{146}$ Jason Silverstein, Hundreds Protest Laquan McDonald Video in Chicago, N.Y. DAILY News, Nov. 25, 2015, http://www.nydailynews.com/news/national/hundreds-protestlaquan-mcdonald-video-chicago-article-1.2446008.

${ }^{147}$ Chicago Tribune Timeline, supra note 133.

1 s. $I$.

${ }^{n}$ Mayor's Press Office, Mayor Emanuel Announces Task Force on Police Accountability, Dec. 1, 2015, https://www.cityofchicago.org/city/en/depts/mayor/press_room/press_releases/2015/decem ber/Task-Force-Police.html.

${ }_{10}$ Chicago Tribune Timeline, supra note 133.
} 
shoppers in downtown Chicago. sis The number of protesters was "far smaller" than the earlier protests in November and effect on retail sales was minimal.".2.

In 2016, the CPD investigated whether other officers had been involved in covering for Van Dyke. In March 2016, Mayor Emanuel appointed a new police Superintendent, Eddie Johnson, who helped continue the investigation. Ultimately, in August 2016, Johnson recommended that seven officers involved in the shooting's cover-up, many of them patrol officers at the scene of the shooting, be fired.

While the Laquan McDonald video was shocking - and led to significant backlash against the CPD and the mayor -we think it is an unlikely candidate to explain the Chicago homicide spike. To be sure, an argument can be made that the date of the video's release (November 24, 2015) fits the subsequent increase in homicides and shootings that we observed. As noted earlier, there is a breakpoint in our homicide and other series around November 2015. But as the events recounted above make clear, awareness of Officer Van Dyke's actions and rumors of a cover-up was widespread much earlier - such as in April 2015 when a unanimous Chicago City Council voted to pay $\$ 5$ million to McDonald's family.

More important, a causal mechanism through which the video's release triggered the homicide spike is not immediately obvious. ${ }^{\text {ss }}$ The protests that surrounded release of the video concerned alleged racism by the CPD in shooting a young African-American man sixteen times. It is unclear why a result of such events would have been additional shootings of (predominantly"s) young AfricanAmerica men by (predominantly"s) other young African-American men. Nor did the video's release constitute a unique revelation of possible racism by some of Chicago's police officers. Sadly, CPD has a long history of allegations of racism - including widely-publicized allegations preceding the 2016 spike. ${ }^{13}$

${ }^{151}$ Heather Gillers et al., Protesters Stage "Black Christmas" Among Last MinuteShoppers, CHI. TRIB., Dec. 4, 2015, http://www.chicagotribune.com/news/local/breaking/ct-laquan-mcdonald-protest20151224-story.html.

${ }^{152}$ Id.

${ }^{133}$ Chicago Tribune Timeline, supra note 133.

${ }^{1 s 4} C f$. Rosenthal, supra note 16, at 693 (finding little data suggesting that police use of force is connected to community residents' lack of respect for police).

${ }^{155}$ See supra notes 16-17 and accompanying text.

${ }^{156}$ See supra notes 16-17 and accompanying text. Cf. Rosenthal, supra note 16, at 702 (reporting that most crime is intra-racial and that nationally " $93 \%$ of black homicide victims were killed by black people").

${ }^{157}$ See, e.g., Michael E. Miller, Cops Accused of Brutally Torturing Black Suspects Costs Chicago \$5.5 Million, CHI. TRIB., Apr. 15, 2015 (lawsuits settled with plaintiffs alleging torture by CPD), https://www.washingtonpost.com/news/morning$\mathrm{mix} / \mathrm{wp} / 2015 / 04 / 15 /$ closing-the-book-on-jon-burge-chicago-cop-accused-of-brutally- 
One possible mechanism for the video to have interfered with police protections is suggested by a recent study conducted by Professor Matthew Desmond and his colleagues. violence may produce lower crime reporting, leading to an increase in violence. Using an interrupted time series design, Desmond et al. analyzed how one of Milwaukee's most publicized cases of police violence against an unarmed black man - the beating of Frank Jude-reduced police-related 9-1-1 calls in the months immediately following. ${ }^{\text {ss }}$ Controlling for crime, prior call patterns, and several neighborhood characteristics, they concluded that residents of Milwaukee's neighborhoods, especially residents of African-American neighborhoods, were less likely to report crime after Jude's beating was broadcast. ${ }^{10}$ The effect lasted for over a year and resulted in an estimated total net loss of approximately 22,200 calls for service.

Interestingly, Desmond et al. looked at homicides in Milwaukee in the six months following the highly publicized beating. They found a $32 \%$ increase in homicides, which they speculated might be attributable to increased law breaking in the wake of decreased citizen reports to police. ${ }^{12}$ (They did not look at other crime categories.)

Here again, while there is some facial plausibility to reduced police calls as a causal mechanism for the Chicago homicide spike, on closer examination it appears the theory fails to fit all the facts. Desmond et al. found that the publicized police violence produced a reduction in all police-related 9-1-1 calls and also all police-related 9-1-1 calls reporting violence. ${ }^{\text {is }}$ This might suggest an ultimate increase in crime across all crime categories, including in particular violent crime categories. But the Chicago data in 2016 show a unique spike in shooting-related crimes - not all violent crimes. It seems unlikely that reduced police-citizen cooperation would operate exclusively to increase shooting crimes, not other crimes. Thus, while Desmond et al. found an increase in homicides in their study, and it seems likely that had they looked at other crime categories, they would have

torturing-african-american-suspects/?utm term=.800eba5b106d; Carlos Sadovi \& Megan Crepeau, Chicago Cop Disciplined for Playing "Sweet Home Alabama” at Protest, CHI. TRIB., Dec. 11, 2014 (officer disciplined for playing alleged racially offensive song during protest against police violence), http://www.chicagotribune.com/news/local/breaking/chicpd-disciplines-officer-after-sweet-home-alabama-song-played-at-protest-20141211story.html.

158 Matthew Desmond et al., Police Violence and Citizen Crime Reporting in the Black Community, 81 AM. Soc. REV. 857 (2016).

${ }^{159}$ Id. at $859-62$.

${ }^{160} \mathrm{Id}$. at $862-66$.

${ }^{161}$ Id. at $867-68$.

${ }^{162}$ Id.at $870-71$.

${ }^{163}$ Id. at 866 tbl. 2 . 
found similar increases. If so, the pattern we observe in Chicago would not be the same as the pattern in Milwaukee.

In addition, while Desmond et al. found that the publicity surrounding the beating reduced calls to police, the reduction started to dissipate significantly within a year of the publicized event. ${ }^{\text {st }}$ Transporting that finding to Chicago, even if we assume that the "event" of interest was the McDonald video release-rather than earlier publicity surrounding the shooting and a \$5 million settlement with the family - the effects on citizen reports to the police should have declined significantly by the end of 2016. As one indication of this dissipation, as discussed above, the size of the December 24, 2015 protest against McDonald's shooting was "far smaller" than the protest on November 24, 2015 - the day of the video's release."is If the video's release caused a homicide spike shortly after November 2015, Desmond et al.'s study suggests that spike should have dissipated overtime through 2016. And yet we see no evidence of a reduction in the homicide spike towards the end of 2016.

In any event, we have been able to obtain monthly 9-1-1 data from Chicago during the relevant time period. ${ }^{10}$ The data show pronounced seasonality - more calls in the summer months, fewer calls in the winter months. As with the temperature data discussed earlier, we have smoothed the data set by making a standard seasonal adjustment What the data show is generally a long downward trend - no sharp break around the time of the McDonald video release (marked in Figure 7, below, by a vertical line between November and December 2015).

Figure 7

Chicago Monthly 9-1-1 Calls (2012-16)

\footnotetext{
${ }^{164}$ See id. at 867 (figures $2 \& 3$ ).

165 See Gillers et al., Protesters Stage “Black Christmas”, supra note 151 and accompanying text.

${ }^{166}$ Homicides did decline in 2017, compared to 2016, a point we discuss below at infra notes 234-47 and accompanying text.

${ }^{167}$ We appreciate the assistance of Chicago's Office of Emergency Management and Communications (OEMC), who provided the data to us. Interestingly, while there was no sharp decline in 911 calls from 2015 to 2016, there was sharp drop in 2017. See Maya Miller, Call to 911 Drop by Tens of Thousands in First Quarter of 2017, CHICAGO TONIGHT, June 6, 2017, https://chicagotonight.wttw.com/2017/06/06/calls-911-drop-tensthousands-first-quarter-2017.
} 


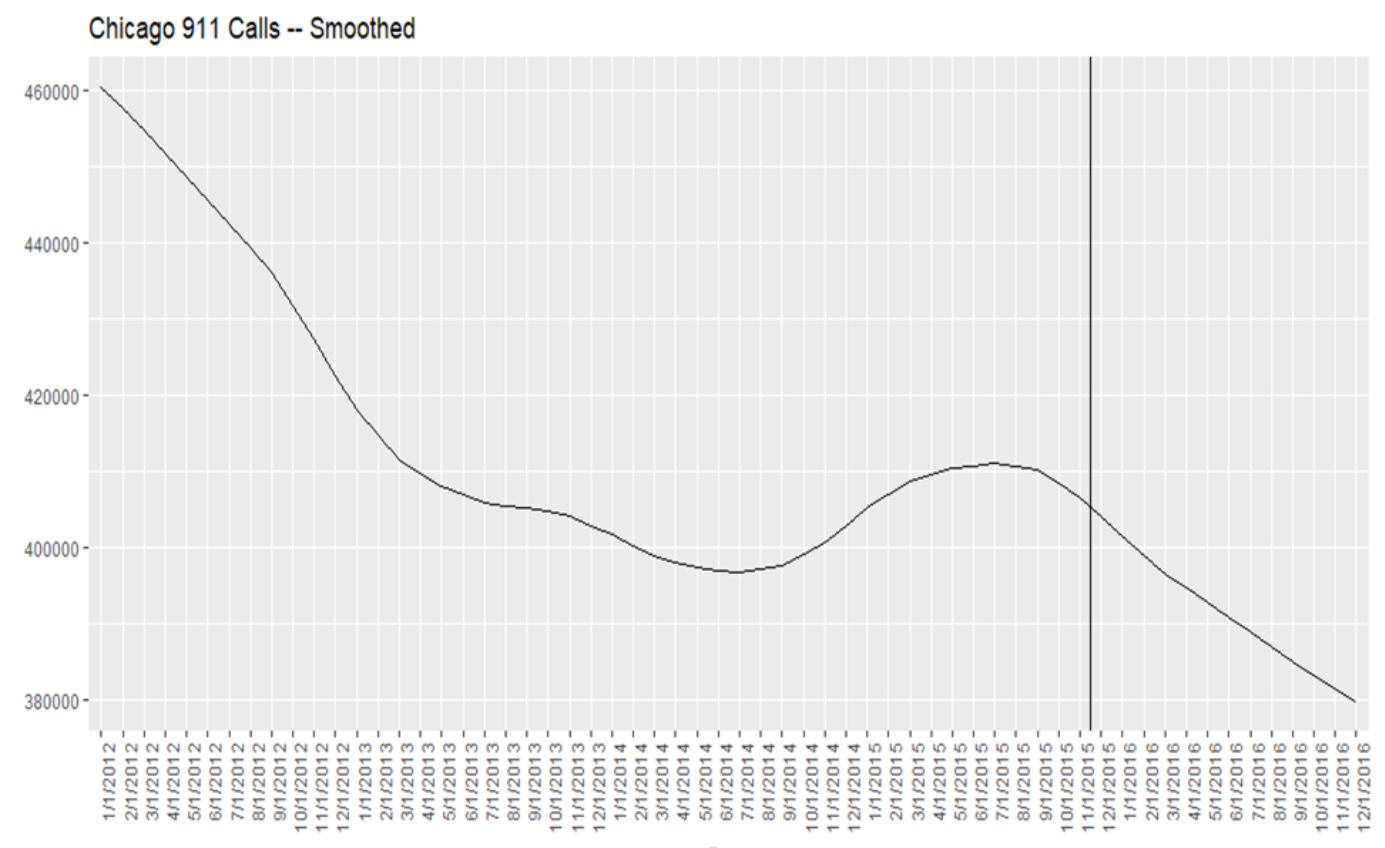

Date

The lack of any unique change trends in 9-1-1 calls at the time of the release of the McDonald video suggest that changes in police-citizen cooperation do not explain the homicide spike. And, in any event, we have included 9-1-1 call volumes in our equations. The inclusion of a 9-1-1 call variable does not alter our conclusions.

A related hypothesis surrounding the McDonald video release is that it might have produced a climate that hampered law enforcement. It is possible that after the video's release, police officers became concerned about increased public scrutiny surrounding stop and frisks and other investigative actions. Former FBI Director James Comey famously suggested that a "chill wind" was blowing through law enforcement, making it harder for law enforcement to do its jobalthough he made this suggestion in a speech in October 2015 explaining events that had taken place throughout the year. ${ }^{\text {se }}$ This timing suggests that unfavorable headwinds were already blowing in Chicago (and elsewhere) well before the homicide spike.

Illustrations of Comey's argument come from a Chicago Tribune story describing an instance where police officers, responding to a report of gunshots, were "taunted and harassed" by bystanders and worried that "the split-second

${ }_{16}$ James B. Comey, Law Enforcement and the Communities We Serve: Bending the Lines Toward Safety and Justice, Remarks at Univ. of Chicago Law School, Oct. 23, 2015, https://www .fbi.gov/news/speeches/law-enforcement-and-the-communities-we-servebending-the-lines-toward-safety-and-justice. 
decisions they make in the normal course of their very dangerous jobs are being second-guessed by people with the power to end their careers." noted that, "[t]he bad element knows that policemen aren't willing to do the job the way they did it [before]." ${ }^{170}$ Superintendent Johnson said, "I've never seen the level of disrespect out there on the streets," and acknowledged officers were more reluctant to conduct street stops for fear of "being the next viral sensation."171 Another officer observed that increased public scrutiny resulted in officers being unable to rely upon their hunches, "[a]n officer's sixth sense is gone," he told the Chicago Tribune. ${ }^{172}$

Perhaps it is true that the McDonald video release contributed to a unique, sharp, and sustained decline in morale. ${ }^{173}$ But even on this theory, our earlier interpretation of our regression results would likely remain valid. We do not see a decline in measures of law enforcement productiveness after the release of the video, such a drop in arrests or firearms seizures. ${ }^{1{ }^{14}}$ So the operative chain of events would still appear to be a decline in morale, leading to a decline in stop and frisks (perhaps for various reasons), ultimately leading to a spike in homicides. If so, the causal mechanism triggering the spike (the decline in stop and frisks) stays the same, and the only debate would be why stop and frisks declined. In a later section in this article, we explore reasons for declining stop and frisks. ${ }^{15}$

\section{The Federal Investigation of the Chicago Police Department}

Another event that was roughly coincident with the homicide spike was a U.S. Justice Department investigation of the Chicago Police Department. In early December 2015, the Justice Department and the U.S. Attorney's Office for the Northern District of Illinois began an investigation to determine whether the Chicago Police Department was "engaging in a pattern of practice of unlawful conduct and, if so, what systemic deficiencies or practices within CPD, IPRA [Independent Police Review Authority], and the City might be facilitating or

\footnotetext{
${ }^{169}$ The Chicago Lessons That Chicago Has To Relearn, supra note 5.

${ }^{170}$ Jeremy Gorner, Morale, Policing Suffering in Hostile Climate, Cops Say "It's Almost Like We're the Bad Guys, " Veteran City Officer Says, CHI. TRIB., Nov. 27, 2016, at 1, 2016 WLNR 36322761.

${ }^{171} \mathrm{Id}$.

${ }^{172} I d$.

${ }^{173} \mathrm{Id}$.

${ }_{174}$ See infra notes 308-12 and accompanying text.

${ }_{175}$ See infra notes 266-325 and accompanying text.
} 
causing this pattern of practice." ${ }^{176}$ A triggering event for the investigation was the release of the McDonald shooting video. ${ }^{177}$

Ultimately, a little more than a year later, on January 13, 2017, the Justice Department released a 161-page report, which concluded that the Chicago Police Department "unconstitutionally engaged in a pattern of excessive force."178 The report also detailed findings such as loss of trust in the police department and feelings of abandonment within the Chicago Police Department, due in part to insufficient training and low morale. ${ }^{179}$ The report described incidents where police shot multiple unarmed victims, claimed the victims were armed, and the Department's Independent Police Review Authority accepted these accounts, despite evidence to the contrary. ${ }^{180}$ The report called on CPD to make a series of changes to its use of force policies.

After a report such as this, one common outcome is the issuance of a "consent decree" between the Justice Department and the investigated police agency." In this case, however, no federal consent decree resulted, perhaps due to the election of President Trump and the appointment of a new Attorney General who was less inclined to impose consent decrees on local law enforcement agencies." In August 2017, the Illinois Attorney General sued to force federal court oversight of the CPD. As of this writing (in April 2018), litigation over the issue continues."14

The reason for tracing out these events in some detail is to show that the federal pattern and practices investigation is a poor candidate as the triggering event for the Chicago homicide spike. While the investigation began in January

\footnotetext{
${ }^{176}$ U.S. DePt. OF Just. CiV. RTS. Division AND U.S. AtTY’s OfF., N.D. Ill., INVESTIGATION OF THE CHICAGO POLICE DEPARTMENT 1 (2017) available at http://chicagoreporter.com/justice-department-report-on-chicago-police-annotated/ [hereinafter CHICAGO DOJ REPORT].

177 Jason Hanna \& Madison Park, Chicago Police Use Excessive Force, DOJ Finds, CNN, Jan. 13, 2017, http://www.cnn.com/2017/01/13/us/chicago-police-federalinvestigation/index.html.

${ }^{178}$ CHICAGO DOJ REPORT, supra note 176.

${ }^{179} I d$. at 4.

${ }^{180} I d$. at $46-84$.

${ }^{181}$ Id. at $150-61$.

${ }_{182}$ See Rushin \& Edwards, supra note 115, at 746-47.

${ }^{183}$ See Matt Zapotosky, Illinois Sues to Force Police Reform in Chicago, Accusing Trump Administration of Dropping the Ball, WASH. Post, Aug. 29, 2017, https:/www.washingtonpost.com/world/national-security/illinois-sues-to-force-policereform-in-chicago-accusing-trump-administration-of-dropping-theball/2017/08/29/1befa686-8cd9-11e7-8df5c2e5cf46c1e2_story.html?utm_term=.afa4d8049690.

${ }^{184}$ Fran Spielman, Another Blow for Police Reform: Deputy IG for Public Safety Resigning, CHI. SUN-TIMES, Jan. 11, 2018, https://chicago.suntimes.com/news/anotherblow-for-police-reform-deputy-ig-for-public-safety-resigning.
} 
2016, no report was issued until January 2017. A mere investigation seems unlikely to have any clear connection to a spike in homicides and shootings.

Moreover, the investigation never actually resulted in a consent decree between the Justice Department and the CPD. Past empirical research has linked federal consent decrees imposed on police departments with increases in crime. In an important empirical study, Stephen Rushin and Griffin Edwards considered the issue of whether legal regulation of police behavior could inadvertently reduce officer aggressiveness, thereby increasing crime. To test this issue, they compared all police departments that have been subject to federally mandated reform under consent decrees with those who have not. They found that the introduction of such external reforms "was associated with a statistically significant uptick in some crime rates, relative to unaffected municipalities." 185 They concluded that this effect was due to "de-policing"-i.e., police becoming less aggressive, and thereby less effective in fighting crime. ${ }^{186}$ Rushin and Edwards thought it was "likely that external regulation of law enforcement comes with growing pains. Frontline officers may find the imposition of external mandates to be procedurally unjust."

Not only did Rushin and Edwards' study track the general conclusions of this study, but it also helps pinpoint the timing of a "de-policing" effect. They identified that point as the imposition of a federal consent decree-not simply the investigation of a police department by the Justice Department. ${ }^{\text {sx }}$ Of course, in Chicago no federal consent decree was ever imposed-although an ACLU "consent decree" was. We believe that a consummated consent decree imposed on a police force is a far more likely cause for change than a mere investigation into police practices. And that is precisely what Rushin and Edwards found through sophisticated analysis - i.e., that a Justice Department investigation (such as the one that took place in Chicago in 2016) did not produce recognizable effects on crime rates. ${ }^{\text {.0 }}$

\footnotetext{
${ }^{185}$ Rushin \& Edwards, supra note 115 , at 759 n.183.

${ }^{186}$ Id. at 736 .

${ }^{187}$ Id. at 773; see also Stephen Rushin \& Allison Garnett, State Labor Law and Federal Police Reform, 51 GA. L. REV. 1209 (2017) (discussing other barriers to police reforms).

${ }^{188}$ See Rushin \& Edwards, supra note 115, at 730 (noting little evidence that DOJ scrutiny contributes to higher crime rates).

${ }^{189}$ Technically the agreement was a "settlement agreement," although it was similar in character to a consent decree, as we discuss in infra note 269.

${ }^{190}$ Rushin \& Edwards, supra note 115 , at 758 (finding, by and large, no statistically significant increase in crime associated with the beginning of a Justice Department investigation, particularly when control variables were introduced into regression equations).
} 
It is also important that the Justice Department's investigation focused on CPD's use of force policies, not its stop and frisk policies." Thus, the investigation would have had, at most, only an indirect connection to stop and frisk practices."12 The federal investigation is a pure candidate for triggering the homicide spike.

\section{Changes in Police Leadership}

One fallout from the release of the Laquan McDonald shooting video was change in the leadership of the Chicago Police Department. On December 1, 2015, just one week after release of the video, Chicago Mayor Rahm Emanuel fired Police Superintendent Garry McCarthy."10 Mayor Emanuel justified the firing by claiming that "the undeniable fact is that the public trust in the leadership of the department has been shaken and eroded."194 The same day he fired Superintendent McCarthy, Mayor Emanuel appointed the second-in-command at CPD, 1st Deputy Superintendent John Escalante, to run the Department while a permanent replacement was sought. ${ }^{\text {ss }}$

${ }^{191}$ See ChICAGO DOJ REPORT, supra note 176 (no substantive discussion of stop and frisk policies and practices).

${ }^{192}$ As a point of reference, the number of police shootings of suspects is a tiny fraction of overall shootings in Chicago. See, e.g., Jennifer Smith Richards et al., 92 Deaths, 2,633 Bullets: Tracking Every Chicago Police Shooting Over 6 Years, CHI. TrIB., Aug. 26, 2016 (noting only 44 police-involved shootings in all of 2015).

To be clear, this article does assess use-of-force policies and does not address the many controversial issues surrounding police use of force. $C f$. INTERNATIONAL Association of Chiefs of Police, National Consensus Policy and Discussion PAPER ON USE OF FORCE (Oct. 2017) (proposing “consensus" standards for use of force), http://www.theiacp.org/Portals/0/documents/pdfs/National_Consensus_Policy_On_Use_Of Force.pdf. We thus do not address CPD's change in its use of force policy designed to de-escalate confrontational situations, a policy change implemented in May 2017-outside the time period for our regression equations. See Tom Jackman, Chicago Police Adopt DeEscalation in Sweeping Change to Use-of-Force Policy, WASH. Post, May 17, 2017, https://www.washingtonpost.com/news/true-crime/wp/2017/05/17/chicago-police-adoptde-escalation-in-sweeping-change-to-use-of-force-policy/?utm_term $=. c 5 \mathrm{ad} 88 \mathrm{~d} 3 \mathrm{af} 2 \mathrm{e}$. See also infra note 385 (noting that we do not propose change in any critical incident reporting requirements).

${ }^{193}$ David A. Graham, The Firing of Chicago Police Chief Garry McCarthy, THE ATLANTIC, Dec. 1, 2015, https://www.theatlantic.com/national/archive/2015/12/garrymecarthy-fired-chicago/418203/.

${ }^{194}$ Mark Berman \& Mark Guarino, Chicago Police Superintendent Fired by Mayor Amid Outcry Over Video of Shooting, WASH. POST, Dec. 1, 2015, https://www.washingtonpost.com/news/post-nation/wp/2015/12/01/chicago-policesuperintendent-fired/?utm_term=.b069807db914.

${ }^{195}$ Interim Chicago Police Superintendent Escalante is a 29-Year Veteran of Force, CHI. TRIB., Dec. 1, 2015, http://www.chicagotribune.com/news/ct-officer-named-interim-policesuperintendent-is-29year-veteran-of-force-20151201-story.html. 
Could this change in police leadership have created instability in the Chicago Police Department, which in turn triggered the Chicago homicide spike? While these changes have been suggested as a possible causal factor, ${ }^{\prime \prime}$ it is an unlikely explanation for several reasons. First, a mere change in police leadership in a large police force like Chicago's would not be expected to have any immediate impact on day-to-day policing. And it is hard to understand how merely replacing the Superintendent with his Deputy would have created immediate and significant changes in Chicago policing or, for that matter, criminal activity.

It is, however, interesting that roughly contemporaneously with replacing the Superintendent, Mayor Emanuel also created a police-accountability task force and announced policy changes intended to reduce incidents of deadly force by Chicago Police. At the end of 2015, the mayor announced measures such as increased training on the use of force and an initiative to provide all officers who respond to police calls with Tasers. ${ }^{197}$ Furthermore, all Chicago police officers were to became equipped with and trained on the use of body cameras and to receive training in de-escalation tactics. ${ }^{198}$ Here again, it is hard to see how such measures (which were only implemented much later) would have had any real impact in triggering a sustained increase in homicides starting in 2016. For example, police officers respond to homicide calls after a death has occurred, not before. Therefore, "de-escalation" training and related use-of-force measures would appear to be largely disconnected from the homicide and the shooting crimes this article investigates.

Moreover, whatever instability might have been created by the firing of Superintendent McCarthy in December 2015 would have largely dissipated a few months later with the hiring of a new, permanent Superintendent. Within three months of McCarthy's firing, in March 2016, Mayor Emanuel hired Eddie Johnson." A Chicago native and 27-year veteran of the CPD, Johnson did not even apply for the job. ${ }^{20}$ However, his many years on the force, combined with his varied experience in different precincts of the CPD, made him the mayor's top

\footnotetext{
${ }^{196}$ U.S. Attorney Fardon briefly referenced lack of a police superintendent in his resignation letter. See Fardon Resignation Letter, supra note 1.

${ }^{197}$ Mitch Smith, Mayor of Chicago Announces Measures to Curb Use of Deadly Force by the Police, N.Y. TIMES, Dec. 30, 2015, https://www.nytimes.com/2015/12/31/us/mayorrahm-emanuel-announces-measures-to-curb-use-of-deadly-force-by-chicago-police.html. ${ }^{198}$ Chicago Police Department 2016 Reforms, CHI. Tonight, 1, 3, http://chicagotonight.wttw.com/sites/default/files/article/fileattachments/Chicago\%20Police\%20Department\%202016\%20Reforms_0.pdf wo How Top Cops Win, or Lose, Chicago, CHI. TRIB., Mar. 29, 2016, at 12, 2016 WLNR 9522570

${ }^{20} \mathrm{Id}$.
} 
choice. ${ }^{201}$ He was quickly and unanimously confirmed by the Chicago City Council. ${ }^{202}$ Moreover, because of Johnson's deep roots in the CPD, he was regarded, as the mayor explained, as "uniquely qualified to rebuild officer morale at the helm of the nation's second largest municipal police force and to tamp down violence while also being a bridge to the community." "Superintendent Johnson has remained in the position since his selection and has drawn generally positive remarks for his leadership. If instability in police leadership caused homicides to spike beginning in December 2015, we would have expected to see a decline after March 2016. And yet no such decline appears.

For all these reasons, changes in police leadership do not appear to explain the homicide spike.

\section{B. Other Highly Implausible Candidates for Explaining the Spike}

We have just explored several causes that have some facial plausibility as significant explanatory factors for the homicide spike but are ultimately implausible. Other theoretically possible candidates also exist, but we find those factors highly implausible.

\section{Fractured Gang Leadership}

One possible factor that has been suggested to have contributed to the homicide spike is "fractured gang hierarchies and rivalries." ${ }_{a s}$ If we understand the theory correctly, the idea would be that gangs splintered in 2016, creating increased gunfire as rival factions battled it out for control of the streets. The theory seems implausible to us.

${ }^{201} I d$. ("His resume runs from violent crimes sergeant supervising homicide cases on the West Side, to commander of a police district on the South Side, to the CPD's citywide chief of patrol").

${ }^{202}$ Mark Berman \& Mark Guarino, After a Blistering Report, What's Next For the Embattled Chicago Police?, WASH. Post, Apr. 16, 2016, https:/www.washingtonpost.com/news/post-nation/wp/2016/04/16/after-a-blisteringreport-whats-next-for-the-embattled-chicago-police/?utm_term $=.565 \mathrm{f} 236 \mathrm{c} 9 \mathrm{eb} 7$ (noting the vote in favor of Johnson was 50-0).

${ }^{203}$ Monica Davey \& Mitch Smith, Eddie Johnson, New Chicago Police Leader, Has Deep Roots in a City Adrift in Turmoil, N.Y. TIMES, Mar. 28, 2016, https://www.nytimes.com/2016/03/29/us/eddie-johnson-new-chicago-police-leader-hasdeep-roots-in-a-city-adrift-in-turmoil.html.

${ }^{204}$ See, e.g., Megan Hickey, CPD Hosts Conference on Smart Policing, Jan. 17, 2018, http://abc7chicago.com/cpd-hosts-conference-on-smart-policing-strategy-/2957217/.

${ }^{205}$ CHICAGO CRIME LAB, supra note 17, at 18; see also MATTHEW FRIEDMAN ET AL., CRIME IN 2016: A PRELIMINARY ANALYSIS 1 (Brennan Center for Justice 2016) (pointing to "increased gang activity" as a possible explanation for the homicide spike). 
For starters, Chicago already had a very high baseline of entrenched gang crimes beginning well before 2016. ${ }^{*}$ Given the existing high level of criminal activity by gangs before 2016, it would be unexpected to find a sudden surge on top of that already high level.

In addition, the fracturing of Chicago's gangs appears to be a longer term phenomenon, starting well before 2016. A CPD audit of Chicago's gangs in 2012 identified 59 active street gangs with 625 factions in Chicago, up from 500 factions and 68 gangs in 2003. And our review of news sources and other contemporaneous accounts of the homicide spike reveals little support for the theory - much less identifying some new and specific gang animosity and consequent violence that suddenly developed in January 2016.

Even more problematic for the theory is the lack of any empirical support. If the fractured-gang-violence theory were true, one would expect to see a significant increase in either gang-related victims or gang-related perpetrators of homicides in 2016 compared to 2015. In fact, no such evidence exists. In 2015, 53\% of Chicago homicide victims showed current or prior gang affiliation, compared to an almost identical 54\% in 2016. . $^{\text {m }}$ A similar lack of connection comes from looking not at victims but at suspects. In 2015, $73 \%$ of Chicago homicide and shooting suspects had current or prior gang affiliation, compared to an even lower $67 \%$ in 2016..$^{210}$

Related to this point is the fact that, although Chicago's homicide rate increased in 2016, "the characteristics of homicide were generally similar in 2016 and 2015," in that "most murders involved guns, occurred in public places, and stemmed from what police believe was some sort of altercation. ... [and] disproportionately affect[ed] the city's most disadvantaged residents." $211 \mathrm{We}$ might expect to see some change in the characteristics of gun violence-i.e., more gang-related crimes if the gang theory were the explanation.

\footnotetext{
${ }^{206}$ See Fardon Resignation Letter, supra note 1, at 2. ${ }^{20}$ Noah Isackson, Garry McCarthy Under the Gun, CHI. MAG., July 5, 2012, http://www.chicagomag.com/Chicago-Magazine/August-2012/Garry-McCarthy-Under-theGun/index .php?cparticle $=1 \&$ siarticle=0\#artanc (noting that fracturing of gangs was being blamed for increasing homicides by CPD in 2012).

${ }^{208}$ This is, of course, not to say that gang fights and rivalries were non-existent in 2016. See, e.g., John Eligon, Bored, Broke and Armed: Clues to Chicago's Gang Violence, N.Y. TIMES, Dec. 22, 2016, https://www.nytimes.com/2016/12/22/us/chicago-gangviolence.html. We simply see nothing in the news reports that would suggest that a unique $50 \%$ increase in year-over-year gang violence suddenly began in Chicago around January 2016.

${ }^{209}$ CHICAGO CRIME LAB, supra note 17, at 14 fig. 17.

${ }_{20}^{21} \mathrm{Id}$. at 16 fig. 23.

${ }^{211} I d$. at 3 .
} 
A final problem with the theory is the lack of any geographical concentration of the homicide spike. Gangs tend form within local geographic boundaries. ${ }^{212}$ If a rivalry developed over a particular gang's leadership, we might expect to see an increase in violence within the gang's boundaries or "turf". But the 2016 homicide spike afflicted many parts of the city. ${ }^{213}$ This suggests that the causal factor was a more widespread phenomenon — such as a city-wide consent decree-rather than something that would cause an increase only within particular neighborhoods.

\section{The Opioid Epidemic}

Another arguable candidate for the Chicago homicide spike would be the opioid epidemic. Sadly, a tidal wave of opioid use and resulting overdose deaths has occurred in recent years. Could that have triggered the spike?

Here again, ample reasons exist for discounting any such theory, which does not appear to have been advanced contemporaneously as an explanation for spike. ." $^{\text {n }}$ Timing is a serious problem. While the use of opioids (as measured by the number of opioid deaths) increased substantially in Chicago in 2016, ${ }^{\text {,s }}$ the starting point for that increase was not January 2016, but several years earlier. In 2017, the Illinois Department of Human Services published a detailed report on "the Opioid Crisis in Illinois." ${ }_{216}$ But the report identified the year in which usage began to increase as 2013 - not 2016. ${ }^{27}$ And the surge continued after 2016 as well. ${ }^{218}$

212 See The Chicago Crime Comm'n, Gang Book: A Detailed Overview of Street GANGS IN THE CHICAGO METROPOLITAN AREA, http://www.chicagocrimecommission.org/. See generally Andrew V. Papachristos \& David M. Hureau, The Corner and the Crew: The Influence of Geography and Social Networks on Gang Violence, 78 AM. Soc. REV. 417 (2013).

${ }^{213}$ See CHICAGO CRIME LAB, supra note 17, at 17 (46 of Chicago's 77 community areas recorded more homicides in 2016 than in 2015).

${ }^{214}$ See, e.g., id. at 18 (listing possible causes of the spike, but not mentioning opioids).

${ }^{215} \mathrm{See}$ CHI. DePT. Pub. HeAlth, EPIDEMIOLOGY REPORT: InCREASE IN OVERDOSE DEATHS INVOLVING OPIOIDS - CHICAGO, 2015-16 (2017) (74\% increase in Chicago opioid deaths from 2015 to 2016), https://www.cityofchicago.org/content/dam/city/depts/cdph/tobacco_alchohol_and_drug_a buse/2016ChicagoOpioidReport.pdf. African-American communities in Chicago were particularly hard hit. See generally Chi. URBAn League, WhitewAShed: The AfricAn AMERICAN OPIOID EPIDEMIC (Nov. 2017), https://www.thechicagourbanleague.org/cms/lib/IL07000264/Centricity/Domain/1/Whitew ashed\%20AA\%20Opioid\%20Crisis\%2011-15-17_EMBARGOED_\%20FINAL.pdf.

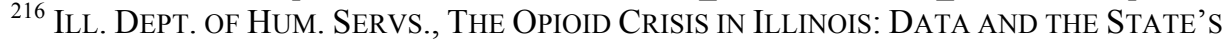
RESPONSE (2017), http://www.dhs.state.il.us/OneNetLibrary/27896/documents/OpioidCrisisInIllinois_051617 .pdf

${ }^{217}$ See id. at $1-2$.

${ }^{218}$ See Chuck Goudie \& Christine Tressel, Deadly Data: 2017 Metro Chicago Drug Overdoses Killed More Than Guns, ABC-7, Jan. 23, 2018, 
Moreover, if opioid usage were the causal factor to the homicide spike, we would expect to see that fact reflected in homicide increases throughout Illinois and, indeed, throughout the country - as the opioid problem is a nationwide tragedy..$^{210}$ Indeed, many rural areas are among the hardest hit. ${ }^{20}$ But as discussed above, Chicago's homicide spike was not generally replicated in other parts of Illinois or other large cities in the Midwest or elsewhere..$^{27}$

Finally, there remains the question of why increasing opioid usage would be reflected uniquely in a spike in homicides and shootings - but not other crime categories. The linkage between opioid use and violent crime continues to be debated. ${ }^{22}$ However that debate is ultimately resolved, we think it unlikely that opioids will be shown to have some special connection to gun violence-and an especially strong connection to Chicago gun violence.

\section{Gun Control Laws}

Another unlikely candidate for the homicide spike is gun control laws. In making this claim, we do not intend to enter the contentious debate about how gun control laws might (or might not) affect crime. ${ }^{23}$ Instead, we make a much more modest claim: That gun control laws applicable to Chicago did not significantly change around January 2016, and therefore Chicago's homicide spike must have been caused by something else.

http://abc7chicago.com/health/deadly-data-2017-metro-chicago-drug-overdoses-killedmore-than-guns-/2981923/.

${ }^{219}$ See, e.g., Nat'l Inst. of Health, Nat'l Institute on Drug Abuse, Opioid Overdose Crisis, https://www.drugabuse.gov/drugs-abuse/opioids/opioid-overdose-crisis.

${ }^{220}$ See Centers for Disease Control and Prevention, CDC Reports Rising Rates of Drug Overdose Deaths in Rural Areas, Oct. 19, 2017, https://www.cdc.gov/media/releases/2017/p1019-rural-overdose-deaths.html.

${ }^{221}$ See supra notes 33-41 and accompanying text.

${ }^{222}$ See Nick Miroff, Trump Sees "Carnage” from America's Drug Boom. But Major Cities Are Getting Safer, WASH. Post, Jan. 28, 2018 (discussing conflicting evidence on connection between illegal narcotics and violent crime), https:/www.washingtonpost.com/world/national-security/trump-sees-carnage-fromamericas-drug-boom-but-major-cities-are-getting-safer/2018/01/28/e5c222a2-f702-11e791af-31ac729add94_story.html?utm_term $=.45496 \mathrm{~d} 234 \mathrm{c} 3 \mathrm{~b}$. The connection between drugs and crime has been $\bar{d}$ ebated in various forms for decades. See, e.g., Cassell \& Fowles, supra note 30, at 812-18 (discussing evidence concerning heroin usage and crime in the 1960s); Rosenthal, supra note 16, at 706-07 (discussing urban crime literature related to competition in the illicit drug market).

${ }^{223}$ Compare, e.g., JOHn R. LOTT, JR., MORE GUNS, LESS CRIME (3d ed. 2010) with, e.g., Abhay Aneja, John J. Donohue III \& Alexandria Zhang, The Impact of Right-to-Carry Laws and the NRC Report: Lessons for the Empirical Evaluation of Law and Policy, 13 AM. L. \& ECON. REV. 565, 566 (2011). 
In advancing this narrow claim, it is initially worth noting that we have not seen any substantial argument developed elsewhere that changes in gun control laws were responsible for Chicago's increase in homicides. Nor did police officers or others "on the ground" contemporaneously identify changing gun control laws as a triggering factor.

Moreover, this idea lacks empirical support. If the idea were correct, it should be reflected in an increase in illegal guns discovered in Chicago in 2016. But, in fact, firearm recoveries by CPD remained essentially unchanged from 2015 to 2016. There were 6,762 firearm recoveries in 2015 and 6,644 in 2016. ${ }^{24}$ Firearm recoveries by CPD from 2013 through 2016 were almost perfectly stable. ${ }^{2 s}$ Nothing in the data suggests that anything changed suddenly around December 2015 to make guns more readily available for illegal activities. ${ }^{26}$

In rejecting this theory, we do not mean to suggest that gun control issues should be absent from a debate about how to prevent gun violence in Chicago. It is true that the guns used illegally in Chicago are often imported from outside the city. A 2017 Chicago Police Department analysis precisely traced most illegal guns seized in Chicago to specific federally-licensed firearms dealers in suburban Cook County and in Illinois" "collar counties," as well as several located in Indiana just across the state border. ${ }^{2}$ But that analysis also suggested that nothing had

${ }^{224}$ CHICAGO CRIME LAB, supra note 17 , at 11 .

${ }^{225}$ Chicago Police Department, Gun Trace RePort: 2017, at 3, https://www.cityofchicago.org/content/dam/city/depts/mayor/Press\%20Room/Press\%20Rel eases/2017/October/GTR2017.pdf.

${ }^{226}$ It might be argued that the fact that gun seizures did not fall along with the decline in stop and frisks shows that stop and frisks were not effective in removing guns from the street. But the typical mechanism by which aggressive policing is expected to prevent gun crimes is not by physically removing guns on the streets but rather through deterring the carrying of guns in the first instance. See Cohen \& Ludwig, supra note 49, at 220 (discussing directed patrol programs focused on illegal gun carrying and explaining that they work via deterrence of illegal behavior more than seizure of firearms); Bellin, supra note 84, at 1529 (reviewing studies on NYPD stop and frisk success and concluding the most likely mechanism is "deterring public gun-carrying"). Moreover, in Chicago in 2016, there were substantially more homicides and shootings than in the previous year. The fact that total gun seizures remained essentially stable would mean that gun seizures per firearm crime declined in that year.

${ }^{227}$ GUN TRACE REPORT: 2017, supra note 225, at 4.

Some firearms used in crimes in Chicago are also apparently stolen from some of the city's railyards. See Michael Tarm, Railroad Thefts and Guns: A Deadly Mix in Chicago, CHI. TRIB., Feb. 15, 2018, http://www.chicagotribune.com/news/ct-chicagorailroad-thefts-20170303-story.html. Here again, we do not see a pattern in gun thefts that would match the homicide spike, as gun thefts from railroads were occurring well before the spike, including 2014. Id. Moreover, given the apparently fairly widespread availability of firearms in Chicago throughout the relevant time, this one source does not seem likely to account for a sudden spike in homicides. 
changed regarding the source of firearms from an earlier analysis conducted in 2014. ${ }^{2 x}$ Whatever problems existed with gun control affecting Chicago before 2016, they appear to have continued into and after 2016.

\section{Educational and Social Spending}

A final issue worth brief discussion is spending on social services, including education in Chicago. During 2016, widely-reported fiscal problems afflicted Illinois in general and Chicago in particular. ${ }^{25}$ But these problems do not appear to be strong candidates for initiating a homicide spike.

For starters, any connection between social spending and crime rates appears to be, at most, a long-term phenomenon that remains poorly understood..$^{2 m}$ We would find it remarkable if changes in social welfare spending had such a strong triggering effect on violence as we see in our data.

Moreover, any theory would have to provide some explanation for why Chicago gun violence increased uniquely. Social welfare spending has been linked to changes in property crime and other broad measures of crime, ${ }^{2 x}$ but we are not aware of empirical research pointing to a distinctive link to gun crimes alone.

In any event, for the reduction-in-social-spending theory to work here, it would be necessary to show some sharp reduction in social service spending centered around January 2016. In fact, so far we can tell, social service spending increased in Chicago during the year. All social service spending in Chicago increased from $\$ 534$ million in 2013, to \$547 million in 2014, to \$561 million in 2015 , to $\$ 581$ million in 2016. . And a subset of social service spendingspending on the Department of Family and Support Services-likewise steadily

${ }^{228} I d$.

${ }^{229}$ Whet Moser, Where Illinois's Fiscal Crisis Came From, CHI. MAG., Aug. 16, 2016, http://www.chicagomag.com/city-life/August-2016/Where-Illinoiss-Fiscal-Crisis-CameFrom/; Liz Farmer, Chicago's Shockingly Bad Finances, GovernING.COM, Mar. 25, 2016, http://www.governing.com/topics/finance/gov-chicago-finances.html.

${ }^{230}$ See generally, Ryan S. Johnson et al., Striking at the Roots of Crime: The Impact of Social Welfare Spending on Crime During the Great Depression, NAT'L BUR. ECON. RES. PAPER, Mar. 2010, (suggesting linkage between rising welfare payments during the Great Depression and reduced property crimes http://www.nber.org/papers/w12825). But cf. John L. Worrall, Reconsidering the Relationship Between Welfare Spending and Serious Crime: A Panel Data Analysis with Implications for Social Support Theory, 22 JUST. Q. 364 (2005) (finding no relationship between several measures of welfare spending and various types of serious crime).

${ }^{231}$ See, e.g., Johnson et al., supra note 230; C. Fritz Foley, Welfare Payments and Crime, Nat'1 Bur. Econ. Res. Paper, June 2008, http://www.nber.org/papers/w14074.

${ }^{232}$ ChicAgo CRIME LAB, supra note 17, at 20 fig. 26. 
increased during the same time period, from $\$ 298$ million in 2013 to $\$ 322$ million in 2014 , to $\$ 333$ million in 2015 , to $\$ 348$ million in 2016 .

It may be worth saying a few words about the role of Chicago's public schools and crime. Famously called the "worst in the nation" in 1987 by then-U.S. Secretary of Education William Bennett, ${ }^{24}$ Chicago's public schools have struggled to provide acceptable education to Chicago's children. As a result, a heroic charter schools movement and other reform efforts have attempted to put pressure on CPS to improve its performance. ${ }^{23}$ It does not seem unreasonable to suggest that Chicago's weak educational system may bear some ultimate responsibility for Chicago's high baseline crime rate. But here again, our focus is not on underlying, long-term crime issues, but the 2016 homicide spike. And as with social spending data, nothing shows a unique change in around January 2016. Indeed, in September 2016, the Chicago Public School system touted its latest graduation rate at $73.5 \%$, marking a steady increase over the last five years..$^{26}$

Finally, just as nothing significant changed with Chicago social service spending in January 2016, nothing significant changed with spending in Illinois generally. Of course, as discussed earlier, we saw no indication of an Illinois-wide phenomenon affecting homicide rates. And all through 2016, Illinois was in the middle of a two-year long budget stand-off that was not resolved until July 2017.27 Changes in Illinois spending do not fit the spike.

To be clear, it is an important debate about whether it would be sound public policy for Chicago - or Illinois - to increase social welfare spending or improve its educational system. We express no views on this subject. Our limited interest is in searching for variables that might have changed significantly around January

${ }^{233} \mathrm{Id}$. at 21 fig. 27.

${ }^{234}$ Casey Benas \& Devonda Byers, Education Chief: City Schools Worst, CHI. TRIB., Nov. 8, 1987, http://articles.chicagotribune.com/1987-11-08/news/8703230953_1_dropout-ratepublic-schools-mayor-harold-washington.

${ }^{235}$ See generally Julia A. Gwynne \& Paul T. Moore, Chicago's Charter High Schools: Organizational Features, Enrollment, School Transfers, and Student Performance, UNIV. OF CHI. CONSORTIUM ON SCH. RES., Nov. 2017, https:/consortium.uchicago.edu/publications/chicago $\%$ E2\%80\%99s-charter-high-schoolsorganizational-features-enrollment-school-transfers-and. Full disclosure: some of Professor Cassell's family members have worked in Chicago's charter schools.

${ }^{236}$ Juan Perez Jr. \& Kyle Bentle, Chicago Public Schools Touts Improved Graduation Rate, CHI. TRIB., Sept. 5, 2016, http://www.chicagotribune.com/news/ct-chicago-schoolsgraduation-rates-20160905-htmlstory.html.

${ }^{237}$ See Monique Garcia et al., Illinois House Overrides Rauner Vetoes of Income Tax Increase, Budget, CHI. TRIB., July 7, 2017, http://www.chicagotribune.com/news/local/politics/ct-madigan-rauner-illinois-house-taxincrease-override-met-0707-20170706-story.html (noting end to 736 days during which Illinois had gone without a budget). 
2016 to trigger a sharp homicide spike. Social service spending does not appear to be a viable candidate.

\section{Socio-Economic Factors.}

We have not included in our regression equations any variables dealing with socio-economic factors, such as race or poverty. While such variables may be important in other contexts, ${ }^{2 . s}$ here we are attempting to explain a phenomenon developing over a relatively short period of time-e.g., a homicide spike that appears in about twelve months of data. Socioeconomic factors would not have changed so rapidly in such a brief time as to explain the spike.

\section{A Preliminary Peek at the 2017 Data}

So far this article has focused exclusively on events occurring before 2017. This is because, when we began our project (in April 2017), we were only able to collect data sets running through the end of 2016. But since then, time has obviously marched on, and as of this writing (in April 2018) additional data has become available. So the reader may wonder, after the homicide spike in 2016, what happened since then?

The quick answer to this question is that Chicago responded to the spike in various ways, but did not attempt to reinvigorate its stop and frisk policies. Notably, on September 22, 2016, Mayor Rahm Emanuel outlined a new "comprehensive" public safety strategy..$^{29}$ He promised to hire 970 new police officers in 2017 and 2018. ${ }^{20}$ He also promised new investments in crime prevention (such as mentoring for at-risk kids), support for longer prison sentences for repeat gun offenders, and expanded economic opportunities for "disconnected youth." ${ }_{21}$ He also promised increased accountability and transparency for the CPD, such as a new policy requiring the release of videos in any officer-involved shootings within 60 days of the event..$^{2 n}$ The mayor did not discuss changes in stop and frisk policy.

Following up on the mayor's promises, CPD took steps to respond more effectively to violence. In an interview at the end of 2016, Superintendent Johnson

\footnotetext{
${ }_{28}$ See, e.g., Rosenthal, supra note 16, at 703 (noting that it is "not race but poverty and a variety of other socioeconomic factors that explain the racial skew in rates of violent crime").

${ }^{239}$ City of Chicago, Mayor's Press Office, Mayor Emanuel Outlines Comprehensive Public Safety Strategy, Sept. 22, 2016, https://www.cityofchicago.org/city/en/depts/mayor/press_room/press_releases/2016/septe $\mathrm{mber} /$ mayor-emanuel-outlines-comprehensive-public-safety-strategy-.html

${ }^{240} \mathrm{Id}$.

${ }^{241} I d$.

${ }^{242} \mathrm{Id}$.
} 
pointed to the anticipated rollout of new data-driven command centers located in two districts with particularly high rates of violence (Englewood and Harrison) ${ }^{2 .}$ He also pointed to the installation of 44 new surveillance cameras in in those districts, along with new gunfire detection technology. ${ }^{24}$

Other responsive measures also took shape in 2017. In June 2017, the Illinois Legislature passed a law (backed by Mayor Emanuel and CPD Superintendent Johnson) increasing sentences for repeat gun offenders. ${ }^{2 s}$ In addition to these state and local efforts, the federal government responded. For example, on January 2, 2017, President Trump tweeted about the alarming number of homicides and shootings in Chicago, and suggested federal law enforcement intervention. ${ }^{2 *}$ As a result, federal firearms prosecutions increased significantly in 2017.". A substantial number of new ATF (Alcohol, Tobacco, and Firearms) agents were also deployed to Chicago during the year, along with additional federal prosecutors focusing on gun crimes. ${ }^{2 s}$

Some of these response seem to have had some success. For example, the data-driven command centers, along with cameras and gunfire detection technology, appear to have reduced crimes in the districts where they were implemented. ${ }^{210}$ And expanding the size of CPD was badly needed, even if the number of new officers added to the force was relatively modest—about a $4 \%$

${ }^{243}$ Katherine Rosenberg-Douglas \& Tony Briscoe, 2016 Ends with 762 Homicides; 2017 Opens with Fatal Uptown Gunfight, CHI. TRIB., Jan. 2, 2017, http://www.chicagotribune.com/news/local/breaking/ct-two-shot-to-death-in-uptownmarks-first-homicide-of-2017-20170101-story.html.

${ }^{244} \mathrm{Id}$.

${ }^{26}$ Monique Garcia \& Kim Geiger, Raumer Signs Gun Crime Bill, Favored by Emanuel, that Cracks Down on Repeat Offenders, CHI. TRIB., June 23, 2017, http://www.chicagotribune.com/news/local/politics/ct-bruce-rauner-gun-bill-met-062420170623-story.html.

${ }^{246}$ Donald J. Trump (@realDonaldTrump), TwitTER, Jan. 2, 2017, https://twitter.com/realdonaldtrump/status/815973752785793024?lang=en ("Chicago murder rate is record setting - 4,331 shooting victims with 762 murders in 2016. If Mayor can't do it he must ask for Federal help!").

${ }^{20}$ Aamer Madhani et al., Chicago to Get More ATF Agents to Fight Gun Violence, USA TODAY, June 30, 2017, https://www.usatoday.com/story/news/2017/06/30/trump-says-hessending-federal-help-stem-chicago-violence/442096001/.

${ }^{2 *} I d$.

${ }^{20}$ Editorial: How to Keep Reducing Chicago Bloodshed in 2018, CHI. TRIB., Dec. 29, 2017, $\mathrm{http}: / / \mathrm{www} . c h i c a g o t r i b u n e . c o m / n e w s / o p i n i o n / e d i t o r i a l s / c t-e d i t-v i o l e n c e-20171228$ -

story.html. For a detailed discussion of the 2017 homicide decline, see the informative talk at the City Club of Chicago by University of Chicago Crime Lab Faculty Director Jens Ludwig on January 29, 2018, available at https://urbanlabs.uchicago.edu/projects/crime-inchicago-beyond-the-headlines. The talk focused on the year-to-year decline from 2016 to 2017 and thus did not offer any further insights into what happened in 2016. That subject was addressed in the Crime Lab's report of a year earlier, which called the issue "unsolved." ChICAGO CRIME LAB, supra note 17, at 18. 
increase occurred in 2017. ${ }^{20}$ During 2017, there were also discussions about whether CPD should enter into a consent decree with the Illinois Attorney General's Office to address problems related to excessive use of force-although discussions dragged on and no agreement was reached.

Our general sense of the 2017 responses is that, while generally useful, they would not have been sufficient to fully restore the baseline level of homicides in Chicago that existed before 2016. And if we look at the data for 2017, we see that while homicides declined modestly in 2017 from the heights they reached in 2016, the number of homicides in 2017 was still substantially above the number in 2015, as show in Figure 8 below.

\section{Figure 8 \\ Annual Chicago Homicides (2012-17)}

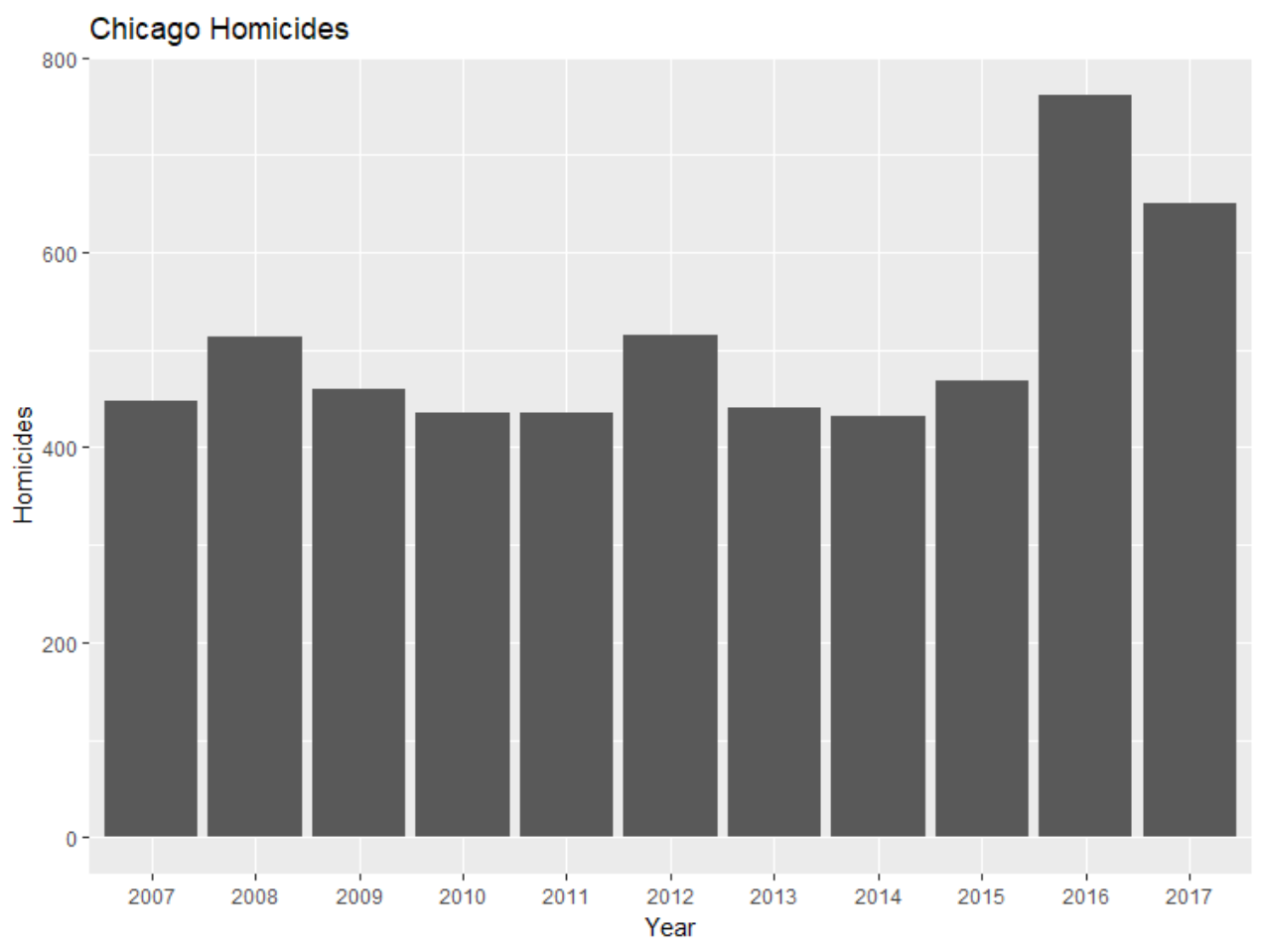

\footnotetext{
${ }^{250}$ At the start of 2017, there were about 12,000 police officers in the CPD, Office of the Inspector General, City of Chicago, http://chicagoinspectorgeneral.org/policeoversight/data-and-analysis/, so adding an addition 500 would be about a $4 \%$ increase. ${ }^{251}$ Editorial: How to Keep Reducing Chicago Bloodshed in 2018, CHI. TRIB., Dec. 29, 2017, http://www.chicagotribune.com/news/opinion/editorials/ct-edit-violence-20171228story.html.
} 
Certainly more research is warranted on what happened with homicides in Chicago in 2017. Interestingly, the pattern of a restriction on policing resulting from the ACLU agreement in 2015, followed by a substantial increase in crime in 2016, and a modest decline in the year following is a consistent with results reported by Rushin and Edwards. In their research on the effect of DOJ consent decrees in various American cities, they found increases in crime immediately after the imposition of the decree, which then faded away into insignificance five to eight years later. ${ }^{22}$ Perhaps we are witnessing some sort of similar reversion to the mean in Chicago, but only time will tell.

While researchers should explore events in Chicago in 2017 and beyond, our plan for this particular article is to remain focused on the 2016 spike. Given the complex and potentially competing array of responses to the homicide spike after 2016 - ranging from expanded police power to the introduction of new technologies to increased investments in crime prevention programs to intensification of federal gun prosecutions - modeling regression equations will be difficult. In contrast, the 2016 spike was a sudden and sustained event, for which it should be possible to determine a cause. After all, the spike occurred well into the twenty-first century, when expanding data sources and increasingly sophisticated research tools are available. And the spike was a highly visible phenomenon-homicides - that took place mostly on the streets of one of our nation's largest cities. Researchers should be able to figure out what happened. We believe our qualitative and quantitative analysis properly identifies declining stops and frisk as the most likely and primary cause.

\section{Model SPECIFICATION OF THE REGRESSION EQUATIONS}

Another question about the robustness of our findings is whether our "model specification"-i.e., the decisions we made about what variables to include in our regression equations - could have affected our results. ${ }^{23}$ A powerful test for analyzing this issue is Bayesian Model Averaging ("BMA"). Historically, uncertainty about which model specification was "correct" was a subject on which classical econometric methods offered little guidance. But recently, interest in Bayesian approaches has grown to address this problem. ${ }^{24}$ In this section, we first discuss the model specification problem. We then report BMA results for our

${ }^{252}$ Rushin \& Edwards, supra note 115 , at 767.

${ }^{253}$ See Cassell \& Fowles, Still Handcuffing the Cops?, supra note 30, at 736-37

(discussing model specification issues with regression equations).

${ }^{254}$ See id. at 743-45. See generally Richard Fowles \& Peter Loeb, Sturdy Inference: A Bayesian Analysis of U.S. Motorcycle Helmet Laws, 55 J. TrANSP. RES. F. 41, 52 (2016). Andrew Gelman et Al., Bayesian Data Analysis (3d ed. 2014); Peter Kennedy, A GUIDE TO ECONOMETRICS 213, 216-31 (6th ed. 2008). For an interesting historical account of early uses of Bayesian methods, see Duo Qin, Bayesian Econometrics: The First Twenty Years, 12 ECONOMETRIC THEORY 500, 503-13 (1996). 
equations, which strongly suggest that our findings are not dependent on model specification.

\section{A. The Problem of Model Specification}

A researcher attempting to quantitatively explore a phenomenon (such as, in this article, homicides) will likely encounter uncertainty about which variables to include in the statistical models. Typically, a researcher must develop a theoretical model that contains some explanatory variables, but the precise set of variables to include is uncertain. ${ }^{2 s}$ More worrisome, a researcher could try a series of alternative specifications until discovering one that "works"-i.e., one that produces a favored statistically significant resultes (or, if trying to debunk a particular theory, one that does not produce a statistically significant result).

Conventionally reported statistical significance measures (such as the $t$ statistics we report above) are of little use in assessing such concerns. These statistics show statistical significance within a particular model, but fail to help answer the question of whether the model itself is correct. Issues of model uncertainty related to the choice of which variables to include in a regression are paramount to problems of simultaneity and multicollinearity. In particular, problems emerge when the associated explanatory variables are correlated within a regression model.

As a consequence of problems such as these, reported econometric results are sometimes fragile to even slight changes in model specification. BMA attempts to address these concerns by helping to assess robustness of regression results with regard to alternative specifications. The interested reader can find more discussion of this issue in other technical literature (including articles previously co-written by Fowles ${ }^{27}$ ) for details about how the procedure works. ${ }^{2 s}$ But, in brief, BMA looks at all conceivable model specifications and then weights them by their

${ }^{255}$ See Jacob M. Montgomery \& Brendan Nyhan, Bayesian Model Averaging: Theoretical Developments and Practical Applications, 18 POL. ANALYsis 245, 246-54 (2010).

${ }^{256}$ See Alan Gerber \& Neil Malhotra, Do Statistical Reporting Standards Affect What Is Published? Publication Bias in Two Leading Political Science Journals, 3 Q.J. POL. SCI. 313, 314 (2008) (" $[R]$ esearchers may engage in data mining to find model specifications and sub-samples that achieve significance thresholds.").

${ }^{257}$ See Gail Blattenberger, Richard Fowles \& Peter D. Loeb, Variable Selection in Bayesian Models: Using Parameter Estimation and Non Parameter Estimation Methods, in 34 ADVANCES IN ECONOMETRICS: BAYESIAN MODEL COMPARISON 249, 261-65 (Ivan Jeliazkov \& Dale J. Poirier eds., 2014); Gail Blattenberger, Richard Fowles \& Peter D. Loeb, Determinants of Motor Vehicle Crash Fatalities Using Bayesian Model Selection Methods, 43 Res. TRANSP. ECON. 112, 119 (2013); Gail Blattenberger, Richard Fowles, Peter D. Loeb \& Wm. A. Clarke, Understanding the Cellphone Effect on Vehicle Fatalities: A Bayesian View, 44 ApPLIED ECON. 1823, 1829 (2012).

${ }^{258}$ See, e.g., Montgomery \& Nyhan, supra note 255 at 247-49 (2010). 
posterior probabilities. ${ }^{2 s}$ For example, if there are $n$ number of variables that might be included in a regression equation, then BMA consider all $2^{n}$ conceivable discrete models and determines whether the variable in question remains significant across those various specifications..$^{20}$ It appears to be generally accepted that "BMA can help applied researchers to ensure that their estimates of the effects of key independent variables are robust to a wide range of possible model specifications." ${ }_{21}$ It is also generally agreed that BMA can be a useful corrective for the (apparently widespread) problem of researchers selectively reporting only models that "work." econometric literature, ${ }^{26 s}$ probably because advances in computing power have promoted made BMA calculations feasible. ${ }^{2 *}$

\section{B. Bayesian Model Averaging of the Regression Equations}

Turning to the specifics of our regressions here and using our basic regression equations (the equations without other regional city homicide series included), the number of explanatory variables is eleven, meaning the theoretically possible number of alternative model specifications is 4,096 ( 2 to the $12^{\text {th }}$ power or $\left.2^{12}\right)$. We used the standard BMA package in $R$, which is readily available and well documented. ${ }^{2 s}$ We used the standard odds ratio of 1:20 for model inclusion. Our BMA results for the regression equations reported in Table 6 above, are reported here in Table 8.

\footnotetext{
${ }^{259}$ See Blattenberger, Fowles \& Loeb, Variable Selection in Bayesian Models, supra note 257 , at 261 .

260 Id.

261 Montgomery \& Nyhan, supra note 255, at 246.

${ }^{262}$ See Leslie K. John, George Loewenstein \& Drazen Prelec, Measuring the Prevalence of Questionable Research Practices with Incentives for Truth Telling, 23 PSYCHOL. SCI. 524, 525 (2012).

${ }^{263}$ Tiago M. Fragoso \& Francisco Louzada Neto, Bayesian Model Averaging: A Systematic Review and Conceptual Classification, 16 tbl.2 (Sept. 29, 2015), https://arxiv.org/pdf/1509.08864v1.pdf [https://perma.cc/J2AZ-GVFG].

${ }^{264}$ KENNEDY, supra note 254, at 217 ("In recent years these practical difficulties have been greatly alleviated by the development of appropriate computer software . ...").

265 Blattenberger, Fowles \& Loeb, Variable Selection in Bayesian Models, supra note 257, at 262, 277 n.14, 278 (citing Adrian Raftery et al., BMA: Bayesian Model Averaging, CRAN.R-PROJECT (Nov. 6, 2015), https://cran.r-

project.org/web/packages/BMA/index.html [https://perma.cc/ECZ3-3T8W]); see also ANDREW GELMAN \& JENNIFER HILL, DATA ANALYSIS USING REGRESSION AND MultileVEL/HiERARCHICAL MODELS 10-11 (2007) (advocating for the use of $R$ software when conducting Bayesian analysis).
} 
Table 8.

Bayesian Model Average of Stop-and-Frisk Variable Inclusion in Various

Model Specifications

(Odds Ratio of 1:20 for Models Inclusion)

\begin{tabular}{|c|c|c|c|c|}
\hline Crime Variable & $\begin{array}{c}\text { Stop-and- } \\
\text { Frisk in } \\
\text { Percent of } \\
\text { Equations }\end{array}$ & $\begin{array}{c}\text { Stop-and- } \\
\text { Frisk in Top } \\
\text { 5 Equations }\end{array}$ & $\begin{array}{c}\text { Bayes } \\
\text { Average } \\
\text { Coefficient }\end{array}$ & $\begin{array}{c}\text { Number of } \\
\text { Models }\end{array}$ \\
\hline Homicides & $100.0 \%$ & $100.0 \%$ & -0.000575 & 35 \\
\hline Fatal Shootings & $100.0 \%$ & $100.0 \%$ & -0.000646 & 33 \\
\hline $\begin{array}{c}\text { Non-Fatal } \\
\text { Shootings }\end{array}$ & $100.0 \%$ & $100.0 \%$ & -0.00201 & 28 \\
\hline \begin{tabular}{c} 
All Shootings \\
\hline
\end{tabular} & $100.0 \%$ & $100.0 \%$ & -0.00259 & 41 \\
\hline
\end{tabular}

Since some readers may be unfamiliar with the standard statistical reporting for BMA results, we will describe the first row of the table in some detail. This row reports BMA results for the earlier regression equations (in Table 6) explaining Chicago homicides. The BMA procedure considered all 4,096 possible specifications of our equations-i.e., all possible combinations of the 11 explanatory variables. The procedure then selected equations that had odds of greater than $5 \%$ of being the correct model. BMA sorts through all conceivable models and retains those that are supported by the evidence and discards models whose support is low. From a Bayesian perspective, it is perfectly sensible to calculate a given model's posterior probability, $P\left(D \mid M_{i}\right)$, where $M_{i}$ represents the $i^{\text {th }}$ model and $D$ represents the observed data. When two models are compared, a selection decision comes down to either dropping one of the models from consideration or keeping both of them. The mechanism to assist in making this decision is the ratio of the posterior probabilities. If the odds ratio is relatively close to 1.0, the two candidate models are kept; otherwise, one model is retained and the other eliminated. With our choice of 1:20, the odds window retains a large number of plausible models, but significantly fewer than all possible ones. As noted above, posterior model probabilities are also used as the weights applied to the estimated coefficients for the retained models when computing Bayesian average.

In this case, the BMA procedure identified 35 out of 4,096 models as being most likely correct. Of these 35 identified models, the stop-and-frisk variable was included in 35 of the 35 identified models (100.0\%). Typically, posterior model probabilities drop quickly, so BMA also identified the top five models and, in these, stop and frisk was included in all five (100.0\%). The average coefficient 
generated from these equations is -0.000575 , meaning that the BMA-selected models had this as the average coefficient associated with stop and frisks. The remaining rows in Table 8 report the same data for each of the other three shooting crime categories this article investigates.

It is also possible to conduct the same analysis with our regression equations that include more variables - i.e., with the equations with regional cities homicide data included as additional explanatory variables reported in Table 7 above. Because this increases the total number of explanatory variables to 21 , the theoretically possible number of different equations is $2,097,152\left(2^{21}\right)$. Table 9 reports the BMA results.

Table 9.

Bayesian Model Average of Stop-and-Frisk Variable Inclusion in Various Model Specifications

Homicides for Regional Cities Included (Odds Ratio of 1:20 for Models Inclusion)

\begin{tabular}{|c|c|c|c|c|}
\hline Crime Variable & $\begin{array}{c}\text { Stop-and- } \\
\text { Frisk in } \\
\text { Percent of } \\
\text { Equations }\end{array}$ & $\begin{array}{c}\text { Stop-and- } \\
\text { Frisk in Top } \\
\text { 5 Equations }\end{array}$ & $\begin{array}{c}\text { Bayes } \\
\text { Average } \\
\text { Coefficient }\end{array}$ & $\begin{array}{c}\text { Number of } \\
\text { Models }\end{array}$ \\
\hline Homicides & $100.0 \%$ & $100.0 \%$ & -0.000520 & 79 \\
\hline Fatal Shootings & $100.0 \%$ & $100.0 \%$ & -0.000559 & 67 \\
\hline $\begin{array}{c}\text { Non-Fatal } \\
\text { Shootings }\end{array}$ & $100.0 \%$ & $100.0 \%$ & -0.00190 & 122 \\
\hline \begin{tabular}{c} 
All Shootings \\
\hline
\end{tabular} & $100.0 \%$ & $100.0 \%$ & -0.00246 & 224 \\
\hline
\end{tabular}

In light of these findings, we think it is fair to say that our stop-and-frisk results are robust - i.e., they are not sensitive to model specification problems, as demonstrated by the BMA procedure which assessed, quite literally, thousands of possible alternative specifications.

\section{QUANTIFICATION OF THE COSTS OF THE DECLINE IN STOP AND FRISKS.}

Our regression equations not only permit us to assess whether the decline in stop and frisks contributed to the homicide spike, but also to roughly quantify the size of that contribution. In this section, we first turn first to the human costs that resulted from the decline in stop and frisks - an approximate number of additional homicides and shootings that resulted. We then attempt to monetize these human 
costs, readily acknowledging that any financial quantification is likely to significantly understate the human consequences involved.

\section{A. Human Costs}

Our regression equations permit us to offer some tentative estimate of the cost - in human lives and additional shooting victims - that resulted from the decline in stop in frisks. As shown in Table 10 below, we quantify approximately how many additional homicides, fatal shootings, non-fatal shootings, and total shootings occurred due to the drop in stop and frisks in 2016. To make this calculation, we simply determined the average monthly number of stop and frisks for the year preceding the structural break in the data-i.e., November 2014 to October 2015. During this period of time, CPD conducted, on average, 45,706 stops each month.

We then determined the average number of stops for calendar year 2016. During that year-i.e., January 2016 through December 2016 - CPD conducted, on average, 7,910 stops each month. The "delta" $(\Delta)$ or change is 37,769 fewer stops each month during 2016.

We then can multiply the coefficient reported in our two BMA tables above to estimate how many fewer homicides, fatal shootings, non-fatal shootings, and total shootings if stop and frisks had simply remained at the same level as they were before November 2015. We report the data for both our smaller or "basic" model and larger model ("Midwestern" cities included) in Table 10 below. ${ }^{2 w}$

Table 10

Additional Crimes in 2016 as a Result of 2016 Reduction in Stop and Frisks

\begin{tabular}{|c|c|c|c|c|}
\hline $\begin{array}{c}\text { REGRESSION } \\
\text { MODEL }\end{array}$ & HOMICIDES & $\begin{array}{c}\text { FATAL } \\
\text { SHOOTINGS }\end{array}$ & $\begin{array}{c}\text { NON-FATAL } \\
\text { SHOOTINGS }\end{array}$ & $\begin{array}{c}\text { ALL } \\
\text { SHOOTINGS }\end{array}$ \\
\hline Basic & 260 & 293 & 911 & 1,174 \\
\hline With Cities & 236 & 253 & 861 & 1,115 \\
\hline
\end{tabular}

As shown, even using our more conservative "with cities" model, the 2016 decline in stop and frisks in Chicago lead to approximately 236 more homicides that same year. Looking at the data for shooting crimes, the 2016 decline in stop

${ }^{266}$ The alert reader may wonder how there can be more "fatal shootings" attributable to the stop and frisk reductions than "homicides," since homicides which include killings committed in ways other than shootings is a broader category in some respects. The answer is that the models we use produce slightly larger number for fatal shootings, due to the varying power of the explanatory variables. 
and frisks produced approximately 253 more fatal shootings, 861 more non-fatal shootings, for about 1,115 more total shootings in 2016 the city.

These numbers also fit with the hypothesis that we set out to explore. As the reader will recall from the opening paragraph of this article, an additional 274 people were killed in Chicago in 2016 above the previous year. Our regression equations suggest that, for example, somewhere around 236 to 260 of those victims were killed due to reductions in stop and frisk. In other words, our regression equations suggest that the answer to the question what caused the 2016 Chicago homicide spike is that declines in stop and frisks explain virtually all of the change. The fact that the additional homicide numbers so closely corresponds to our regression numbers provides additional support for our conclusions, although we offer our numbers of homicides and shootings as suggestive of the magnitude of the effects that we are examining rather than a perfectly precise number.

\section{B. Financial Costs}

We are also able to attach a rough estimate of the financial cost from the increase in homicides and shootings that resulted from the decline in stop and frisks. Both of us have an economics background, so the urge to undertake a financial quantification comes naturally. But others may wonder whether it is appropriate to attach a dollar figure to, for example, the life of a homicide victim.

We are not the first to consider this question. In their informative book Gun Violence: The Real Costs, Professors Philip J. Cook and Jens Ludwig offer a lengthy defense of such monetization. ${ }^{20}$ They explain, persuasively in our view, that "putting a monetary value on gun violence is useful in laying claim to public attention." ${ }_{2 \infty}$ Other social problems of any kind - health care, welfare, education, environmental protection, or highway safety, for examples - all demand attention in the public policy arena due to the financial costs involved. The issues that this article explores can likewise be assessed as a financial burden on society.

Fortunately, in attempting such a quantification, one need not reinvent the wheel. We are able to simply draw upon Professors Cook and Ludwig's previous work, which developed a very substantive framework for quantifying the costs of gun violence. They calculated a cost per crime-related gun injury-either a homicide or other shooting — of about $\$ 1$ million per injury in 2000.

\footnotetext{
${ }^{267}$ Philip J. CoOK \& Jens Ludwig, Gun Violence: The ReAl Costs vii-x (2000).

${ }^{268} I d$. at vii.

${ }^{269}$ Id. at 110; see also Philip J. Cook et al., Gun Control After Heller: Threats and Sideshows from a Social Welfare Perspective, 56 UCLA L. REV. 1041, 1049 (2009) (reiterating \$1 million cost estimate).
} 
Starting with that cost figure and taking our total number of victims (the "all shootings" category) above, and using the more conservative figure of approximately 1,115 additional victims, the total dollar cost of the additional shootings resulting from the decline in stop and frisks in 2016 is an estimated $\$ 1,115,000,000$ in 2000 dollars, or $\$ 1,561,000,000$ in current dollars. ${ }^{2 n}$

High though this estimate may seem, it does not fully reflect the social harms associated with the increase in gun violence we have identified. We know that the vast majority of the victims were African-American and Hispanic, many of them from disadvantaged communities already suffering many other deprivations. In other words, the costs of the increase in violence were not distributed evenly across Chicago (as the average figures recited above assume), but instead constituted a highly regressive "tax" on minority communities already in weaker positions to bear it.

\section{ThE DROP IN STOP AND FRISKS AS AN “ACLU EFFECT”}

In this article's previous sections, we have provided reasons for believing that the decline in stop and frisks was the primary trigger for Chicago's 2016 homicide spike and what the tremendous social costs of that spike were. If our findings are correct, they have tremendous public policy importance, not just for the City of Chicago but for other cities wrestling with stop and frisk issues. The conventional wisdom, at least among some policy makers, has been that reductions in stop and frisk policies are cost free. A good illustration comes from the debate surrounding the Chicago homicide spike itself. On February 1, 2016, the ACLU of Illinois noted that some Chicago police officers were blaming the reductions in stop and frisks for the increasing gun violence. The ACLU emphatically stated that it "reject[ed] any suggestion of a so-called 'ACLU effect' to explain the recent spike in gun violence on Chicago's streets." ${ }_{n \rightarrow}$ The ACLU went on to argue, "[j]ust because a few police officers claim there's a correlation between crime rates and some policy with which they disagree does not make it so. . . There is no discernible link between the rate of invasive street stops and searches by police

${ }^{270}$ This current dollar figure ( $140 \%$ of the earlier figure) is simply an inflation adjustment for the 16 years since Cook and Ludwig made their $\$ 1$ million calculation, using the Bureau of Labor Statistics Consumer Price Index (CPI). This adjustment is likely conservative, as a substantial component of the cost valuations that Cook and Ludwig made were hospitalization costs, which likely increased more rapidly in recent years than other components of the CPI.

${ }^{271}$ A Real "Effect" in Chicago Would be Better Policing, ACLU OF ILL., Feb. 1, 2016, https://www.aclu-il.org/en/news/real-effect-chicago-would-be-better-policing. 
and the level of violence on those streets. . . There simply is not any evidence of this effect." ${ }_{212}$

Whatever may or may not have been the accuracy of that statement on February 1, 2016, our regression equations clearly disprove it now. If nothing else, the regression equations provide strong evidence of a "discernable link" between declining stop and frisks and the tragic spike in homicides in Chicago throughout 2016.

From a public policy perspective, an important remaining question is why stop and frisks declined at the end of 2015. Here, we consider evidence of a socalled "ACLU Effect," that is, evidence that the ACLU's consent decree with the Chicago Police Department caused the decline in stop and frisks. In section A, we

describe the ACLU consent decree with CPD. Section B explores reasons for believing that the consent decree caused the decline in stop in frisks. Section C explains why changes in Illinois legislation regarding stop and frisk do not appear likely to have triggered the reduction.

\section{A. The ACLU Consent Decree}

That stop and frisks declined sharply in Chicago at the end of 2015 is beyond dispute, as we discussed earlier. ${ }^{23}$ But what was the cause of this decline? A settlement agreement or "consent decree" ${ }^{2}$ between the ACLU and the Chicago Police Department - on the very subject of stop and frisks - appears to be the obvious answer.

It is first useful to look at the background surrounding the ACLU consent decree. In March 2015, the American Civil Liberties Union of Illinois (ACLU)

${ }^{272} I d$. (emphasis added). The ACLU also pointed to the reduction in stop and frisks in New York in support of its argument. We discussed the New York's experience at supra notes 84-117 and accompanying text.

${ }^{273}$ See supra notes $46-48$ and accompanying text.

${ }^{274}$ Technically, the document that resulted was a voluntary "settlement agreement" between the ACLU and the Chicago Police Department. See City of ChiCAgo, The CONSULTANT'S FIRST SEMIANNUAL REPORT ON THE INVESTIGATORY STOP AND Protective Pat Down Agreement for the Period January 1, 2016 - June 30, 2016 at $13(2017)$ https://www.cityofchicago.org/content/dam/city/depts/dol/supp_info/TheConsultantsFirstS emiannualReport032317.pdf [hereinafter FIRST CONSULTANT REPORT]. But the term "consent decree" seem reasonably interchangeable in this context, since the agreement called for compliance monitoring by a retired federal court judge. We use both terms interchangeably. 
released a report entitled "Stop and Frisk in Chicago." "2ss The ACLU report reviewed the Chicago Police Department's "stop and frisk" practices-i.e., situations where police officers stopped persons on reasonable suspicion of criminal activity and, if reasonable suspicion of a firearm (or the weapon) existed, frisked the person to discover the weapon. ${ }^{26}$ The report alleged that that the CPD had "failed to train, supervise and monitor law enforcement in minority communities for decades, resulting in a failure to ensure that officers' use of stop and frisk is lawful." ${ }_{m}$ The report contended that "Chicago stops a shocking number of people," more than New York. ${ }^{2 m}$ The report called for the City of Chicago to change stop and frisk practices, by requiring the collection of data on the number of stops, making that data public, increased training for officers, and requiring each officer to issue a receipt at the conclusion of a stop..$^{2 n}$

Several months later, in August 2015, the ACLU of Illinois and the Chicago Police Department entered into a "landmark" settlement agreement in order to avoid a possible lawsuit over the Department's stop and frisk practices. ${ }^{20}$ Under the settlement agreement, officers were required to complete a form after any "investigatory stop and/or protective pat down." ${ }^{281}$ The forms were to be collected and forwarded to the ACLU, entered into a database, and reviewed twice a year by retired U.S. Magistrate Judge Arlander Keys to determine whether the stops were constitutional. ${ }^{282}$ The new forms were significantly longer than the previously required documentation. They required the officer to include much more information, such as "the name and badge number of the officer, the race/ethnicity of the person stopped, the gender of the person stopped, all the reasons for the stop, the location, date and time of the stop, whether or not a pat down resulted from the stop (along with the reason for the pat down), whether contraband was

${ }^{275}$ ACLU OF ILL., STOP AND FRISK IN CHICAGO (2015), https://www.acluil.org/sites/default/files/wp-content/uploads/2015/03/ACLU_StopandFrisk_6.pdf [hereinafter 2015 ACLU STOP AND FRISK REPORT].

${ }^{276}$ See Terry v. Ohio, 392 U.S. 1 (1968) (upholding constitutional of stop and frisk as a constitutional matter if reasonable suspicion exists).

277 See 2015 ACLU STOP AND FRISK REPORT, supra note 275, at 2.

${ }^{278} \mathrm{Id}$. at 3.

${ }^{279}$ Id. at $3-4$.

In April 2015, several plaintiffs filed a lawsuit challenging Chicago's stop and frisk practices, citing the ACLU Report and seeking class action certification. See Darnell Smith et al. v. City of Chicago, No. 1:15-cv-3467 (N.D. Ill. Filed Apr. 20, 2015). The lawsuit remains pending.

${ }^{280}$ The text of the agreement is available on the ACLU's website. See https://www.acluil.org/sites/default/files/exhibits-1-the-agreement.pdf ([hereinafter ACLU Agreement]. See generally Jeremy Groner, ACLU, Chicago Police Agree to Changes on Controversial Street Stops, CHI. TRIB., Aug. 7, 2016, http://www.chicagotribune.com/news/ct-chicagopolice-aclu-street-stops-met-20150807-story.html.

${ }^{281}$ See ACLU Agreement, supra note 280, at 2.

${ }^{282} I d$. at 6-8. 
discovered and what happened as a result of the stop (including an arrest, warning, or no action at all)." 283

The agreement was controversial. Former-Superintendent of the CPD, Garry McCarthy, stated in December 2015 that, "I acquiesced to it because, you know, I'm trying to work with [the ACLU], [and] they're trying to work with us." ${ }_{24}$

The agreement allowed a phase-in period of several months, setting December 31, 2015, as the expected date for CPD to enter new general guidance on stop and frisk practices. ${ }^{2 s}$ Beginning around December 2015, as the implementation of the settlement agreement was put in place, the number of stop and frisks (or, more precisely, stops, since not every stop will lead to a frisk) conducted by CPD fell dramatically.

\section{B. Contemporaneous Reports of an "ACLU Effect"}

The ACLU settlement agreement seems likely to have been the primary cause of Chicago's reduction in stop and frisks. Several reasons support this socalled "ACLU Effect."

To comply with the ALCU settlement agreement, beginning around January 1, 2016, the CPD required officers to complete a two-page "investigatory stop report" (an "ISR") that provided extensive documentation of the stop. ${ }^{20}$ As this new requirement was implemented, stop and frisks in Chicago plummeted. Many contemporaneous reports identified the new paperwork requirement (and related discouragement of stop and frisks) as the cause. ${ }^{20}$

For example, U.S. Attorney Zachary Fardon, in his March 2017 resignation letter looking back on the events of 2016, explained that "[o]n January 1, 2016, a contract began between CPD and the ACLU requiring that officers complete lengthy contact cards for every street encounter. That ACLU deal grew out of a lawsuit about stop and frisk, but the contract that settled the lawsuit swung the

${ }^{283}$ See Landmark Agreement Reached on Investigatory Stops in Chicago, ACLU OF ILL., Aug. 7, 2015, https://www.aclu-il.org/en/press-releases/landmark-agreement-reachedinvestigatory-stops-chicago.

${ }^{284}$ Jeremy Gorner, ACLU, Chicago Police Agree to Changes on Controversial Street Stops, CHI. TRIB., Aug. 7, 2015, http://www.chicagotribune.com/news/ct-chicago-police-aclustreet-stops-met-20150807-story.html.

${ }^{285}$ ACLU Agreement, supra note 280, at 3.

${ }^{286}$ See Jeremy Gorner, After Officers Complain, Chicago Police Simplifying Stop Reports Required by ACLU Deal, CHI. TRIB. Feb. 24, 2016, http://www.chicagotribune.com/news/ct-investigatory-stop-form-replaced-20160223story.html.

287 See, e.g., id. (noting that stops had "plummeted significantly" in early 2016, and stating that it was "[a]s a result" of the new forms officers had to complete). 
pendulum hard in the other direction by telling cops if you (officer) go talk to those kids on the corner, you're going to have to take 40 minutes to fill out a form and you're going to have to give them a receipt with your badge number on it.." ${ }_{2 \mathrm{~s}}$

Interestingly, perhaps in an effort to deflect its responsibility for the decline in stops starting around the beginning of 2016, Karen Sheley, Director of Police Practices for the ACLU of Illinois responded to Fardon's assessment by arguing that "Mr. Fardon is wrong that the agreement took effect on January 1, 2016- the agreement had been in force for four months by that time." ${ }_{20}$ But this argument is disingenuous. ${ }^{20}$ As the ACLU must have known, while the agreement itself was signed on August 6, 2015, it provided a reasonable phase-in period for the new agreed stop-and-frisk procedures to take effect. In particular, the agreement provided that the CPD expected to issue revised general orders relating to stop and frisk "by December 31, 2015." schedule and put in place shortly before January 1, 2016 - precisely when the decline in stop and frisks occurred. . $^{2 n}$

The "ACLU Effect" was something that police officers on the street quickly described as stops were declining. For example, a January 31, 2016, article in the Chicago-Sun Times was entitled "Street Cops Say 'ACLU Effect' Drives Spike in Gun Violence." ${ }^{2}$ The article reported interviews with police officers who generally agreed that "the Chicago Police Department's pact with the American Civil Liberties Union of Illinois to monitor police stops in greater detail is prompting officers to stop policing, leaving the streets to the criminals and leading to the spike in gun violence." ${ }_{2 s}$ Along the same lines, ex-CPD superintendent

\footnotetext{
${ }^{288}$ Fardon Resignation Letter, supra note 1.

${ }^{289}$ Statement of Karen Sheley, Police Practices Project Director, ACLU OF ILL., Mar. 14, 2017, https://www.aclu-il.org/en/press-releases/aclu-statement-open-letter-former-usattorney-zachary-fardon.

${ }^{290}$ The ACLU also apparently took inconsistent positions. In March 2017, when the decline in stop and frisks was being linked to the homicide spike, Ms. Sheley appeared to have disavowed any connection. But in January 2016, before the homicide spike was fully evident, Ms. Sheley said that the decline in stop and frisks was a "good thing" resulting from the ACLU's agreement. See infra note 315 and accompanying text.

${ }^{291}$ See ACLU Agreement, supra note 280 at 3, ๆ II.1..

${ }^{292}$ See Memorandum from Stephen R. Patton and Jane Elinor Notz, City of Chicago Dept. of Law, to Judge Arlander Key, Oct. 6, 2016, at 1 n.1 (referring to new Special Order S0413-09 as having been adopted "prior to January 1, 2016").

${ }^{293}$ See Figure 5, supra (monthly data on stop and frisks, showing sharp decline in December 2015 and new baseline reached in January 2016).

${ }^{294}$ Frank Main, Street Cops Say "ACLU Effect”" Drives Spike in Gun Violence, CHI. SuNTIMES, Jan. 31, 2016, https://chicago.suntimes.com/chicago-politics/street-cops-say-aclueffect-drives-spike-in-gun-violence/.

295 Id.
} 
Garry McCarthy told the Chicago Tribune during 2016 that "the more complicated forms have contributed to the end of proactive policing."

One indication of the contemporaneous concern about the harmful effects of the extensive paperwork was that in late February, 2016 - after the new procedures had only been in effect for a short time - the CPD tried to simplify the Investigative Stop Report form (ISR) because of officer complaints. However, as the ACLU was quick to point out, the modifications to the form were "modest." ${ }_{2 \times}$ Even the purportedly simplified form had more than seventy(!) separate fields that the an officer had to complete, including a lengthy "narrative" section requiring the officer to write down "all factors that support Reasonable Articulable Suspicion to justify the Investigatory Stop, all factors that support Reasonable Articulable Suspicion to justify the Protective Patdown, and the basis and all reasons that led to the search beyond a Protective Patdown. ${ }_{2 m}$

Another indication of contemporaneous concern comes from an account published on the blog "Second City Cop." The blog has a detailed discussion of the simple "Contact Card" that Chicago Police use to complete after stops and the "Investigative Stop Report" that the ACLU agreement required. After running through the byzantine requirements to properly complete the form, the blog concluded: "Little wonder activity has dropped off by extraordinary amounts."

Officers not only had concern about the length of the required forms, but also their recipients. The settlement agreement required that the ISRs be sent to the ACLU for its review on a monthly basis." One officer described the concerns this way: "If tomorrow, we still had to fill out the new forms, but they no longer went to the ACLU, stops would increase." early in 2016 that cops confessed that "they have avoided making many of the

${ }^{296}$ Gorner, Morale, Policing Suffering in Hostile Climate, supra note 170.

${ }^{297}$ Id.

${ }^{298}$ Statement on Changes to Chicago Investigatory Stop Report, ACLU OF ILL., Feb. 24, 2016, https://www.aclu-il.org/en/press-releases/statement-changes-chicago-investigatorystop-report.

${ }^{29}$ See Appendix A, infra, at p. 2. Interestingly, a similar form was ordered as a result of litigation in New York, where a form 250 ("UF-250") was mandated. See Rachel A. Harmon \& Andrew Manns, Proactive Policing and the Legacy of Terry, 15 OHIO ST. J. CRIM. L. 49, 66 (2017) (describing form). While a full exploration of the New York form is beyond the scope of this article, it appears that the form differed significantly from Chicago's in not requiring a full narrative of the circumstances surrounding the stop, but rather just a simple check of a box. See Floyd v. City of New York, 959 F.Supp.2d 540, 561 (S.D.N.Y. 2013) (describing checkoff).

${ }^{300}$ Second City Cop, Contact Card vs. ISR, Jan. 13, 2016, http://secondcitycop.blogspot.com/2016/01/contact-card-vs-isr.html.

301 See ACLU Agreement, supra note 280 , at 5.

${ }^{302}$ MacDonald, The "Ferguson Effect” is Destroying Chicago, supra note 9 
stops they would have routinely done last year. They fear getting in trouble for stops later deemed to be illegal and say the new cards take too much time to complete." ${ }^{303}$

Interestingly, the report of the retired judge monitoring the implementation of the ACLU settlement agreement also noted the decline in stops in the first half of 2016, and further noted that both news media and various law enforcement officials "suggest that the lower stop rates are attributable to the amount of time it takes police officers to document all the information required for each individual stop of a civilian required by the new ISR." ${ }_{{ }_{1}}$ The report noted "time estimates ranging from 10-15 minutes, based on police officer interviews . . to 40-45 minutes, based on news media reports from other CPD officials and outside sources." " After recounting this suggested cause-and-effect relationship, the report did not disagree that the paperwork requirements were the cause but instead argued that the paperwork was important to permit assessment of the legality of CPD's practices. ${ }^{a x}$ This failure to identify any other causal factor for the reduction in stops further supports the conclusion that the form was the main culprit.

The reports from Chicago about concerns with burdensome paperwork dovetail with those from other jurisdictions. Professors Rushin and Edwards collected some of the literature on the subject in their recent article and reported problems with externally-imposed police reforms, which often established "inherently cumbersome" administrative requirements. For example, police in Pittsburgh were worried when "[e]very incident has a paper trail," with the result that "officers were almost afraid to say anything for fear of punishment." ${ }_{s i n}$ In Los Angeles, a stunning $70 \%$ of officers agreed with the statement that "paper work deters officers from making arrests," and even more-79\% — believed that, as a result, external regulation impeded the LAPD's ability to fight crime.

\footnotetext{
${ }^{303}$ Main, supra note 294.

${ }^{304}$ FIRST CONSULTANT REPORT, supra note 274, at 10. The report also suggested that better training could reduce the 45-minute time period that some officers reported it took them to complete the forms. Id. at 206.

${ }^{305} I d$.

${ }^{306} \mathrm{Id}$. at $10-12$

307 Rushin and Edwards, supra note 115, at 768 (citing ROBERT C. DAVIS ET AL., CAN FEDERAL INTERVENTION BRING LASTING IMPROVEMENT IN LOCAL POLICING? THE PITTSBURGH CONSENT DeCREE (2005)), https://www.vera.org/publica tions/can-federal-intervention-bring-lasting-improvement-in-local-policing-thepittsburghconsent-decree).

${ }^{308}$ Rushin and Edwards, supra note 115, at 768 (citing CHRISTOPHER STONE ET AL., Policing los Angeles Under a Consent Decree: The Dynamics of Change AT the LAPD 19 (2009)), http://www.lapdonline.org/ assets/pdf/Harvard-LAPD\%20Study.pdf.

Rushin and Edwards also cite our comprehensive study on Miranda's effects as documenting how external regulations impede police performance and are kind enough to
} 
For these reasons, we think that the paperwork requirement that stemmed from the ACLU consent decree was the primary driver of the reductions in stop and frisk, although it is possible other factors could have played a supporting role. In particular, it appears that following the consent decree, the CPD may have deemphasized its focus on so-called "hot spot" policing. unable to obtain details about this change, one possible explanation is that the ACLU argued in its stop and frisk report that African-Americans were being stopped at a rate that was disproportionate to their percentage of the population.". But, of course, one of the consequences of hot spot policing is to place a disproportionate number of police officers in high crime areas - a fact not discussed in the ACLU report. Perhaps CPD choose to scale back hot spot patrols in an effort to respond to the ACLU's criticisms. If so, then crime rates would

call it "one of the most rigorous studies on the effect of police regulation on officer behavior." Rushin \& Edwards, supra note 115, at 738 (citing Cassell \& Fowles, supra note 4 , at 1118). We appreciate the favorable citation; but for our purposes here, we believe that the stop-and-frisk issues are sufficiently different that we will not press the analogy. ${ }^{3 m}$ While this subject is not the focus of our study, it seems unlikely that concern about actually unconstitutional stops being discovered through the form were a significant cause of the decline, because the forms, completed by the officers, would not a be a good mechanism for discovering questionable stops. It is also interesting to note that detailed analysis of CPD's stops after the consent decree found that 90 to $94 \%$ were, seemingly beyond dispute, "good" stops, see infra note 370 and accompanying text, although this obviously raises the question of what CPD's good stop rate was before the consent decree. Our very limited point is not to suggest that all of CPD's stops were good in 2015, but rather that from an aggregate statistical point of view the number of bad stops would be expected to be relatively small. Cf. Tracey L. Meares, Programming Errors: Understanding the Constitutionality of Stop-and-Frisk as a Program, Not an Incident, 82 U. CHI. L. REV. 159, 165 (2015) ("If a court had analyzed any of the stops carried out as part of the NYPD program, or as part of a similar program in another city, the court likely would have found that police appear to abide by Terry's strictures most of the time"). But cf. Jonathan Mummolo, Modern Police Tactics, Police-Citizen Interactions and the Prospects for Reform, 80 JOURNAL OF POLITICS 1, _- (2018) (finding reduction of stops in NYPD due to recordkeeping requirements led to improved constitutional compliance). See also infra notes 347-52 and accompanying text (discussing "objective reasonableness" of CPD's stop and frisk policies). We also do not see declines in other forms of policing, such as arrests and gun seizures, as discussed in supra notes 220-22 and accompanying text. But cf. Bellin, supra note 84, at 1548 (concluding the NYPD's policies reduced gun crimes only by creating deterrence through fear of unconstitutional stop and frisks). Finally, to the extent that the concern of the ACLU was that a disproportionate number of stops involved African-American and Hispanic residents of Chicago, it does not appear that the agreement reduced the stops for minority residents more than whites. See infra note 377 and accompanying text.

${ }^{310}$ See Reuven Blau, Former Chicago Top Cop Blames City's Spike in Violence on Politicians' Interference with Police Business, N.Y. DAILY News, Dec. 27, 2016, http://www.nydailynews.com/news/crime/ex-chicago-top-blames-city-spike-violencepoliticians-article-1.2925908 (former CPD Superintendent Garry McCarthy says that, after "political pushback against police stops and other proactive measures to curb the ongoing violence," CPD "no longer holds CompStat meetings to focus on crime hot spots").

3112015 ACLU STOP AND FRISK REPORT, supra note 275. 
have been expected to increase due to that change in tactics. According to the National Academy of Science's November 2017 report, hot spot policing is generally effective in reducing crime in the short term, although the long-term impacts remain somewhat unclear. ${ }^{312}$

It is also interesting to consider comments made by Mayor Rahm Emanuel about two months after the ACLU agreement was signed. On October 13, 2015, Mayor Rahm Emanuel asserted that Chicago police officers were becoming "fetal" out of concern that they would get in trouble for actions during arrests." If so, perhaps the ACLU would shoulder some of the blame. But we do not see any real evidence of this in our data. Other than the decline in stop and frisks, we do not see any unique reductions in general measures of law enforcement activity related to violent crime around the time of the homicide spike. For example, as already discussed, firearms seizures by CPD did not exhibit any substantial decline such seizures might reasonably be seen as measure of law enforcement efforts directed towards firearms. ${ }^{3 s}$ Nor were there any unique declines in the number of arrests in 2016," and arrests might also serve as a measure of effort. On these lines, our regression equations, which included multiple arrest measures, did not suggest that declining arrests explained the homicide spike.

The one measure of law enforcement activity that exhibited clear and stark declines at the time of the homicide spike was stop and frisks. ${ }^{3 n}$ Since a preliminary draft of our paper was made publicly available, we have received communications from several CPD police officers, all making clear to us that they were contacting us in their own private capacity, suggesting their general agreement with our conclusions. These communications suggested an answer to one question that puzzled us in researching this subject: If cops were not doing

${ }^{312}$ NAT'L ACAD. OF SCI., supra note49, at S-4.

${ }^{31 \mathrm{~B}}$ John Byrne, Emanuel Blames Chicago Crime Uptick on Officers Second-Guessing Themselves, CHI. TRIB., Oct. 13, 2015,

http://www.chicagotribune.com/news/local/politics/ct-emanuel-fetal-police-met-20151012story.html.

${ }^{34}$ See supra notes $220-22$ and accompanying text.

as To be sure, because gun crimes increased in 2016, a constant level of firearms seizures would mean a lower "success rate" in seizing guns per crime. But our interest here is not in police success, but rather police effort. Given steady seizures, it would appear that effort remained constant.

${ }^{316}$ We ran our arrest series through the strucbreak program and observed no structural breaks.

3 It does appear that Chicago's crime clearance rates declined in 2016, CHICAGO CRIME LAB, supra note 17 , at 23 , but clearance rates would not appear to be a good measure of police effort. Many crimes are cleared for reasons not connected with law enforcement effort. See generally JOHN E. ECK, SOLVING CRIMES: THE INVESTIGATION OF BURGLARY AND ROBBERY (1983); Cassell \& Fowles, supra note 30, at 728 (no statistically significant connection between historical homicide clearance rates and law enforcement variables). Chicago's declining clearance rates in 2016 were mostly likely due to static levels of law enforcement facing increasing levels of crimes. 
stop and frisks, what were they doing instead? The answer appears to be- traffic stops. While we have not obtained exact data, according to one tabulation while stop and frisks declined substantially from 2015 to 2016, the number of CPD traffic stops doubled, from about 86,000 in 2015 to about 190,000 in 2016. ${ }^{.18}$ While traffic stops may be useful for fighting traffic offenses and other types of crimes, their usefulness in suppressing gun violence, and particularly gang-related gun violence, is limited. ${ }^{\text {so }}$ Moreover, in March 2016, the Chicago Police Department instituted what is commonly referred to as a "no chase" policy, prohibiting police chases for traffic offenses ${ }^{30}$ - further reducing the likelihood that such stops would deter possession of firearms. In our view, this redeployment of policing power away from street stops and toward traffic stops produced the expected resultmore gun-related violence.

Finally, and perhaps most important in determining whether the ACLU agreement reduced stops, it should be recalled that one of the main animating factors for the agreement was the concern that too many stops were being conducted. The ACLU Report argued that a "shocking number of people" were being stopped." The ACLU presumably set out to reduce that number in its agreement. And in publicizing its agreement with CPD, the ACLU website announced (in bold typeface for emphasis) that "We are confident that the agreement will result in fewer stops on Chicago streets." ${ }_{32}$

As things unfolded, the ACLU's "confident" prediction was correct. Indeed, at least in February 2016, when it was clear that the number of stops had fallen dramatically - but the consequences had not yet fully materialized-the ACLU appeared to be proud of this particular result. When the Chicago SunTimes pointed out the decline in stops to Karen Sheley, Director of Police Practices for the ACLU of Illinois, she took credit, saying it was actually "a good thing" produced by the agreement.

\section{The ACLU Consent Decree Compared to Illinois Legislation}

One question that could arise in attributing the decline in stops to the ACLU agreement is whether the attribution should instead be made to Illinois legislation dealing with stop and frisks. Just a few months after the ACLU settlement

\footnotetext{
${ }_{318}$ See https://www.aclu-il.org/en/news/piercing-myth-so-called-aclu-effect.

so See Rosenthal, supra note 16, at 710-11.

${ }^{30}$ See CPD Gen. Order G03-0-01, Emergency Vehicle Operations - Pursuits, available at $\mathrm{http}$ ://directives.chicagopolice.org/directives/data/a7a57be2-1291920c-54712-9192aecb02ef $17 \mathrm{e} 0 \mathrm{c} 47 \mathrm{~d}$.pdf?hl=true.

${ }^{321}$ See supra note 273 and accompanying text.

${ }^{322}$ ACLU Statement on Agreement with Chicago Police Department on Stop and Frisk Reform, ACLU OF ILL, Aug. 13, 2015 (emphasis in original), https://www.acluil.org/en/news/aclu-statement-agreement-chicago-police-department-stop-and-frisk-reform. ${ }^{323}$ Main, supra note 294.
} 
agreement was signed, in October 2015, Illinois governor Bruce Rauner signed SB-1304, also called the Police and Community Relations Improvement Act, into law. ${ }^{324}$ The Act became effective January 1, 2016 $6^{\text {ss }}$ and required Illinois police officers to provide citizens with a receipt after a stop and frisk. ${ }^{326}$ The receipt required "the officer's name, badge number and reason for the search or frisk" and what (if any) contraband was found. ${ }^{327}$ The law also required officers to complete a "pedestrian stop card" if a person was detained in public. ${ }^{328}$ The pedestrian stop card required "the race and gender of the person and the reason the person was stopped."329

It is possible that some part of the reduction in stop in frisks in Chicago is attributable to SB-1304 rather than the ACLU settlement agreement. But several reasons suggest that SB-1304 played, at most, a very small role in the process.

First, the receipt requirement is rather modest when compared to the ALCU consent decree requirements. ${ }^{\text {so }}$ The receipt simply echoes information the police already would be recording, requiring far less time to complete than the 70-field ACLU form. ${ }^{331}$ The reader can examine the differences between the two forms by looking at them both-found in Appendices B and C to this article.

Moreover, it is interesting to compare what happened in other parts of Illinois outside of Chicago after SB-1304 went into effect. As noted earlier, ${ }^{3,2}$ we collected monthly homicide data for all of Illinois from 2012 through 2016. We then backed out the Chicago homicides, leaving a data series for the remainder of Illinois. We then ran this data through the strucchange program discussed earlier. Unlike the Chicago homicide series which showed a clear structural break, the series for the remainder of Illinois showed no such break. The fact that, unlike Chicago, homicides outside of Chicago did not sharply increase in 2016 provides indirect support for the proposition that stop and frisks did not decline sharply outside Chicago.

Of course, rather than relying on indirect measures of what happened to stop and frisks in Illinois in 2016, direct data would be preferable. While we have not

\footnotetext{
${ }^{324}$ See New Illinois Law Requires Police to Give a "Stop Receipt" for Pedestrians, WREX (Jan. 5, 2016, 9:37 AM), http://www.wrex.com/story/30888673/2016/01/Tuesday/newillinois-law-requires-police-to-give-a-stop-receipt-for-pedestrians.

${ }^{325}$ See 50 Ill. Comp. Stat. Ann. 727/1-1 through 1-5.

${ }^{326}$ New Illinois Law Requires Police to Give a "Stop Receipt" for Pedestrians, supra note 324

327 Id

328 Id.

329 Id.

${ }^{330}$ See FIRST CONSULTANT RePORT, supra note 274 at 69-71.

${ }^{331}$ MacDonald, The "Ferguson Effect" is Destroying Chicago, supra note 9.

${ }^{332}$ See supra notes 40-41 and accompanying text.
} 
been able to obtain any, we have found a few anecdotal reports from cities outside of Chicago about implementation of SB-1304. The general sense of these reports was that police did not have much concern about issuing the relatively-easy-tocomplete "stop receipts." ${ }_{33}$

For these reasons, we believe that the decline in stops attributable to the Illinois legislation is relatively minor compared to the decline attributable to the ACLU settlement agreement. But regardless of the details of attribution, the larger point remains that a precipitous fall in stop and frisks occurred in 2016-at precisely the same time as homicides spiked. How to respond to that spike is the subject of the article's next section.

\section{POLICY IMPLICATIONS}

In this penultimate section, we turn to policy implications that might be drawn from our findings. Initially, we agree with other researchers that we cannot determine "definitively" what caused the 2016 spike in Chicago gun violence. ${ }^{34}$ Social science research rarely provides conclusive answers. But lack of a definitive answer should not paralyze policy makers seeking to respond to rising gun violence. Public policy decisions must be made on the basis of the available information, and we believe our research shed important light by identifying the most likely cause of the spike.

Our main goal in this article is descriptive - to diagnosis what caused the spike, so that others on the ground in the affected communities in Chicago and other cities facing comparable problems could design appropriate cures. But given the pressing public policy problem described by this article, we would be remiss if we failed to provide at least some tentative recommendations for what could be done to reduce the terrible toll in human lives and suffering in Chicago and other cities facing similar issues. Understanding that our recommendations, like our research, are only part of what will be an on-going discussion, we briefly and tentatively outline several specific steps that our research suggests policymakers should consider in Chicago and elsewhere.

\section{A. Reassessing the Benefits of Stop and Frisk}

\footnotetext{
${ }^{333}$ See, e.g., Jeff Kolkey, Police in Rockford Area, Illinois to Implement New Stop-andFrisk Rules in 2016, ROCKFORD REGISTER STAR, Sept. 19, 2015 (quoting Rockford Assistant Deputy Police Chief as concluding that the new law was unlikely to change how stops were conducted), http://www.rrstar.com/article/20150919/NEWS/.

${ }^{334}$ ChICAGO CRIME LAB, supra note 17, at 26.
} 
In assessing police practices, cost-benefit analysis holds great promise..$^{3 s}$ Perhaps the most obvious conclusion that follows from our research is that Chicago should reassess the benefits of stop and frisks - and other cities should exercise great caution before emulating Chicago's example of steep reductions. Our research is the first study to attempt to quantitatively assess the crime control benefits of CPD's stop and frisk policies. If our findings are correct and if CPD's frequency of stops had simply continued through 2016, they would have prevented the deaths of about 230 victims, the shootings of about 1,100 victims, and the infliction of social harm of about $\$ 1.5$ billion. If our approximate figures are anywhere close to correct, these are very significant benefits (accruing in the course of just a single year) that must be fully and fairly considered in evaluating the desirability of CPD's stop and frisk policies.

It is also important to emphasize that stop and frisk policies can often be implemented within existing police budgets. For example, from a purely fiscal point of view, for CPD to continue its 2015 stop and frisk policies through 2016 would not have required hiring any new officers or otherwise expanding the budget. Given the financial exigencies that Chicago and other cities face, ${ }^{3 s}$ the financial feasibility of using such policies is important.

Our findings also have an important implication for assessing the effectiveness of stop and frisk policies. Some previous studies point to the relative infrequency of actual seizures of firearms to suggest the policies are ineffective. ${ }^{3 n}$ But these challenges assume that the crime-reduction mechanism for stop and frisk policies is incapacitation-i.e., removing guns from the hands of criminals on the streets via the stop and frisk. Our article suggests, consistent with some other research, ${ }^{\text {ss }}$ that the policies operate more through deterrence-i.e., keeping criminals from carrying guns on the street due to fear of being stopped and frisked. ${ }^{\text {so }}$ If this conclusion is correct, then the efficacy of stop and frisk policies should not be assessed solely (or even primarily) through the number of firearms

\footnotetext{
as See generally Policing Project, Achieving Sound Policing: The Promise AND ChALLENGES OF COST-BENEFIT ANALYSIS OF PUBLIC SAFETY (2017), https://static1.squarespace.com/static/58a33e881b631bc60d4f8b31/t/5a81fc3f24a6944a11d 916fe/1518468200792/Policing+Project_Achieving+Sound+Policing+2.9.2018.pdf; Barry Friedman \& Maria Ponomarenko, Democratic Policing, 90 NYU L. Rev. 1827, 1832 (2015) (calling for cost-benefit assessment of policing practices and procedures). ${ }^{336}$ See, e.g., The Civic Federation, Civic Federation Supports Proposed FY2018 Chicago Budget (Nov. 8, 2017), https://www.civicfed.org/ChicagoFY2018Release (noting that Chicago "will face many more tough decisions in the coming years to fully stabilize its financial situation").

${ }^{337}$ See, e.g., 2015 ACLU STOP AND FRISK REPORT, supra note 275, at 15 (citing datum that in New York City fewer than $2 \%$ of frisked persons were carrying weapons).

${ }^{338}$ See supra note 222 and accompanying text.

339 The alternative to deterrence is "incapacitation"-i.e., in this context, direct seizure of a gun.
} 
police seize or the number of arrests they make, ${ }^{30}$ but rather through the policies' contribution to reducing crime rates. Put another way, while removing guns from the streets through stop and frisks is useful, it appears that even more important is preventing guns from being carried on the streets in the first instance.

Our analysis also sheds light on another criticism made of Chicago's stop and frisk policies - that CPD stopped Chicagoans at a far higher rate than other cities. For example, the ACLU collected data showing that in May to August 2014, the Chicago Police Department stopped 93.6 people per 1000, while during May to August 2011 (at the height of NYPD's stop and frisk practices), the New York Police Department stopped 22.9 people per 1000 -making Chicago's stop rate about four times higher. But this difference is easily explained by comparing the size and nature of Chicago's crime rates compared to New York City's. Chicago's homicide rate is about seven times higher than New York's, and its homicide-by-firearm rate is more than ten times higher than New York's. ${ }^{32}$ Since stop and frisk polices aim to respond to crimes - and particularly serious gun crimes - the proper unit of measurement would be stops per serious gun crime rather than stops per person. On this important measure, it appears that Chicago's stop rate before the ACLU agreement was likely lower than New York's. ${ }^{3 s}$

To be clear, we are not reflexively calling for stop and frisk policies as some sort of "cure all" for crime. In Chicago in particular, we are not necessarily calling for a restoration of pre-agreement levels of stop and frisks or the invalidation of the ACLU Settlement Agreement. Stop and frisk policies necessarily entail tradeoffs. For example, stop and frisks involve a restriction of liberty of the person stopped - and an even greater intrusion if the person is frisked. ${ }^{3 *}$ And stop and frisk policies can affect neighborhood perceptions of law enforcement fairness. ${ }^{2.5}$ These are potential costs that have to be evaluated as part of a full cost-benefit analysis. Professors Cook and Ludwig have accurately summarized the relevant tradeoffs in explaining:

${ }^{30}$ For other criticisms of so-called "hit rate" assessments of police efficacy, including an argument that it tends to underestimate burdens placed on racial minorities, see Sonja B. Starr, Explaining Race Gaps in Policing: Normative and Empirical Challenges, U. Mich. Law \& Econ. Paper 15-003 (Jan. 2015), https://papers.ssrn.com/sol3/papers.cfm?abstract_id=2550032.

341 See, e.g., 2015 ACLU STOP AND FRISK REPORT, supra note 275, at 10.

See supra notes 89-91 and accompanying text.

${ }^{34}$ See supra note 89-93 and accompanying text.

${ }^{34}$ See, e.g., JeNNIFER FrATEllo ET AL., COMING OF AgE WITH STOP AND FRISK:

EXPERIENCES, PERCEPTIONS, AND PUBLIC SAFETY IMPLICATIONS 34 (2013).

${ }^{34}$ Henry F. Fradella \& Michael D. White, Stop-and-Frisk, in INST. FOR JUSTICE, REFORMING CRIMINAL JUSTICE 67-68 (2017); Craig B. Futterman et al., Youth/Police Encounters on Chicago's South Side: Acknowledging the Realities, 2016 U. CHI. LEG. F. 1, 62-64 (2016); Renee Hutchins, Stop Terry: Reasonable Suspicion, Race, and a Proposal to Limit Terry Stops, 16 LEGISLATION AND PUBLIC POLICY 883, 899 (2014).

${ }^{346}$ The agreement allows for either party to terminate the agreement "at any time." ACLU Agreement, supra note 280, at 8 \3. 
[T] he best available evidence suggests that police patrols against illegal gun carrying may produce benefits far in excess of measurable costs. The question is whether these substantial net gains are outweighed by the intangible costs of such policies, including the resentment that such programs may engender among those who are stopped and searched. While the imposition is primarily on residents of targeted high-crime neighborhoods, the benefit also accrues primarily to those neighborhoods. The expansion of such efforts deserves serious consideration, with particular attention given to the concerns and preferences of the residents of impacted neighborhoods. ${ }^{3 n}$

Our limited conclusion here generally tracks that of Professors Cook and Ludwig. We do not attempt to reach definitive answer about the desirability of stop and frisk policies in Chicago or elsewhere. ${ }^{\text {ss }}$ Instead, we advance the limited point that, so far as we have seen in public discussion, the benefits of stop and frisk policies appear to have been dramatically undervalued in striking a proper balance between competing concerns. This might suggest that an increase in stop and frisks is appropriate. But our article simply attempts to accurately describe the (literally lifesaving) benefits of stop and frisk so that, with the benefits properly described, policy makers in Chicago and other cities are in a position to make a final determination about how best to proceed.

\section{B. Reassuring Minority Communities about the Value of Stop and Frisk}

We also echo Professors Cook and Ludwig in suggesting that the concerns and preferences of the impacted neighborhoods must be heavily weighted in any calculation of costs and benefits to stop and frisk. All too often, policy makers determining such issues as stop and frisk do not have to bear the burdens of expanded police enforcement - or of increased gun violence. Given that stop and frisk policies may present "deadly dilemmas," ${ }_{30}$ the proper resolution of those dilemmas requires consideration of the weights to be attached to the competing sides of the scales - weights that perhaps can best be attached by those directly affected by the consequences. ${ }^{30}$

${ }^{347}$ CoOK \& LudwiG, supra note 267 , at $132-33$

${ }^{3 *} C f$. Andrew Gelman et al., An Analysis of the New York City Police Department's "Stopand-Frisk" Policy in the Context of Claims of Racial Bias, 102 J. AM. STAT. ASS'N 813, 822 (2007) (calling for quantitative examination "of the issues in dispute" in stop in frisk). ${ }^{349}$ Ronald J. Allen \& Larry Laudan, Deadly Dilemmas, 41 TEXAS TECH. L. REV. 65 (2008). ${ }^{350}$ See Harmon \& Manns, supra note 299, at 66 ("A police chief must integrate all of the competing voices to develop a neighborhood-specific and historically-contextualized understanding of community concerns both about safety and order and about interactions with law enforcement."). 
At the same time, however, our findings may be useful to communities in Chicago and other parts of the country that are considering these issues, particularly minority communities. Our research strongly suggests, contrary to claims made by some observers, that CPD's stop and frisk practices have an important effect in providing increased public safety for minority residents in Chicago. For example, if we simply take our finding that extending the stop and frisk practices through 2016 would have saved approximately 236 lives $^{s-}$ - and if we assume that those saved lives would have been distributed in the same ratios as were found in 2016 for all Chicago homicides ${ }^{32}$ then the lives of about 184 African-American homicide victims and 38 Hispanic victims would have been saved in that one year. Our findings thus suggest that, just as gun violence exacts a disproportionate toll on minority communities, stop and frisk as a response to that violence provides special benefits for those communities - benefits that are often overlooked and may strengthen the arguments of voices within minority communities calling for strong proactive policing. ${ }^{.34}$

In any reassessment of the scope of stop and frisk policies in Chicago (and elsewhere), an overriding consideration will necessarily be constitutional compliance. After all, CPD entered into the settlement agreement with the ACLU only after the ACLU leveled allegations of unconstitutional racially discriminatory application of the stops.

Previous scholars have suggested that "well-designed proactive policing programs that utilize stops and frisks probably could pass constitutional muster." Here, our research on the collective effects of CPD's stop and frisks obviously does not permit us to assess specifically the constitutionality of any particular stop (or even any collection of stops). But at the same time, the general test for the

${ }_{31}^{32}$ See supra note 261 and accompanying text.

${ }^{352}$ See supra note 17 and accompanying text (78\% of the 2016 Chicago homicide victims were African-Americans and $16 \%$ were Hispanics). A listing of the names of all of the 2016 Chicago homicide victims in found in Appendix A.

${ }^{353}$ Cf. Steven L. Carter, When Victims Happen to be Black, 97 YALE L.J. 420, 447 (1988) ("All too often, American legal and political culture seem to suggest ... that there are two varieties of people who are involved in criminal activity, black people and victims").

${ }^{34}$ See, e.g., Ross Sandler, Other Voices on Stop-and-Frisk, 18 CITY L. 74 (2012) (noting African-American mother supporting NYPD's stop-and-frisk policies and observing "an undercurrent of grass-roots support for stop-and frisk"); see also Timothy Mclaughlin, Chicago police push for community assistance after deaths of three children, Reuters (Feb. 17, 2017, 2:20 PM), https://www.reuters.com/article/us-chicago-police/chicago-policepush-for-community-assistance-after-deaths-of-three-children-idUSKBN15W2BP (quoting the mother of Takiya Holmes, an 11-year-old who was killed in Chicago, as saying "[the police] are not our enemy."); Jeremy Gorner, Chicago's homicide total drops by over 100, but violence still 'intolerably high', CHI. TRIB. (Dec. 29, 2017), $\mathrm{http}: / / \mathrm{www}$.chicagotribune.com/news/local/breaking/ct-met-chicago-violence-2017story.html (aunt of a 15-year-old homicide victim, Latasha Green, "I've seen more police officers out here. They do good over here on this side, honestly.").

${ }^{3 s}$ Harmon \& Manns, supra note 299, at 65. 
constitutionality of any stop is whether it is based on "reasonable suspicion," ${ }^{3 s 6}$ a standard that requires only "some minimal level of objective justification" ${ }^{3{ }^{3}}$ that "criminal activity may be afoot." ${ }_{\text {ss }}$ In making a determination of whether to stop a person, officers are allowed to draw on "their own experience and specialized training to make inferences from and deductions about the cumulative information available to them that might well elude an untrained person." ${ }^{3 s}$ The evidence collected here suggests that, at the systemic level, the collective body of CPD's stop and frisks were, in some sense, "objectively justified" because they had such a clear connection to deterring gun violence in Chicago. Put another way, the fact that the 2016 reductions in stop and frisks appear to have caused a sharp increase in homicides (and shootings) suggests that, in general, police practices were properly targeted on reducing crime - rather than on racial harassment. ${ }^{\text {so }}$

Professor Erika George has provided an insightful analysis of these kinds of issues in discussing earlier litigation between the ACLU and the City of Chicagospecifically litigation pertaining to law enforcement operations conducted by the Chicago Housing Authority. ${ }^{36}$ In criticizing a federal court decision restricting (at the ACLU's behest) "sweeps" of public housing, George explained that:

[b]y focusing first and fundamentally on what the residents of public housing have a right to be free from, namely governmental intrusion, the court neglected precisely what public housing residents are entitled to, freedom to flourish. The lack of one of life's most basic necessitiessecurity - prevents residents of public housing from experiencing substantive freedom.

Similar concerns are present in evaluating stop and frisk policies, which require (as George suggests) a more expansive consideration of the competing concerns. ${ }^{3 \mathrm{se}}$

${ }^{356}$ Almeida-Sanchez v. United States, 413 U.S. 266, 268 (1973).

${ }^{357}$ INS v. Delgado, 466 U.S. 210, 217 (1984).

${ }_{3 s 8}$ Navarette v. California, 134 S.Ct. 168, 1690 (2014). Current doctrine does not consider the severity of the offense as a factor in stops, although this failure has been criticized. See Note, An Offense-Severity Model for Stop-and-Frisks, 123 YALE L.J. 1448 (2014).

${ }^{359}$ United States v. Arivizu, 534 U.S. 266, 273 (2002).

${ }^{300}$ Of course, our observation about the general effect of stop and frisks could not be used to authorize any particular stop. To be constitutionally valid, a stop requires "particularized suspicion." See City of Indianapolis v. Edmond, 531 U.S. 32, 36 (2000). But cf. Meares, supra note 309, at 177 ("A programmatic understanding of stop-and-frisk more accurately reflects reality, because stop-and-frisk generally is implemented as a program.”).

${ }^{361}$ See Erika George, Recent Development, The Fourth Amendment's Forcing of Flawed Choices: Giving Content to Freedom for Residents of Public Housing, 30 HARV. CIV. RTSCIV. LIBERTIES L. REV. 577 (1995).

${ }^{362}$ Id. at 593.

${ }^{36}$ Policy evaluations of stop and frisk policies present separate issues from "mass incarceration," in which lengthy sentences have had a racially disparate impact. See, e.g., Michelle AleXANDER, THE New Jim CROW: MASS INCARCERATION IN THE AGE OF 
In connection with this myopic focus exclusively on freedom from governmental intrusion while ignoring "freedom to flourish," it is interesting to observe what appears to be the same problem in an extensive report by Judge Keys, the retired federal magistrate judge appointed as the consultant to supervise the ACLU settlement agreement and to address racial disparity issues. Under the agreement, Judge Keys was to issue semi-annual reports on CPD's compliance with the agreement. On March 23, 2017, Judge Keys issued his first report, but it was limited to the first six months of 2016 (i.e., January 1 through June 30, 2016).

The report noted that "[s]triking the balance between law enforcement interests in preventing crime and civil rights advocates' interest in protecting individual liberties is at the heart of the Agreement." "'ss But thereafter, the 216-page report spent essentially no time discussing the issue of "preventing crime." For example, quite surprisingly, the report does not appear to directly discuss the sharp increase in homicides that occurred in Chicago during the first six months of 2016 (the period of time covered by the report) which was attracting attention all throughout Chicago and, indeed, throughout the country.

Nor did the report look at crime victimization data for the City of Chicago, which would also seem to be relevant to "striking the balance." "For example, a recent analysis of Chicago's National Crime Victimization Survey (NCVS) data showed that the CPD received reports of only about $28 \%$ of all sexual assaults, $56 \%$ of robberies, $55 \%$ of domestic violence offenses, $62 \%$ of aggravated assaults, $40 \%$ of simple assaults, $55 \%$ of burglaries, $79 \%$ of vehicle thefts, and $26 \%$ of thefts. ${ }^{30}$ It would be interesting to see whether consideration of actual victimization rates - rather than reported crime rates - has some explanatory power in the considering differences related to stop and frisk.

Moreover, of particular interest given the focus of this article, the consultant's report thought there was a lack of "any statistical evidence showing a causal connection or statistically significant correlation between the frequency with

COLORBLINDNESS (2010). Issues surrounding how to apprehend potential criminals are different than those surrounding how long to imprison them if convicted. $C f$. Eric Luna \& Paul G. Cassell, Mandatory Minimalism, 32 CARDOZO L. REV. 1 (2010) (criticizing mandatory minimum sentences). Indeed, it may be possible that increases in certainty of punishment could lead to a reduction in sentence severity. See generally WiLliam J. STUNTZ, THE COLLAPSE OF AMERICAN CRIMINAL JUSTICE (2011).

${ }^{364}$ FIRST CONSULTANT REPORT, supra note 274.

365 Id. at 12.

${ }^{366} C f$. Douglas E. Beloof, Paul G. Cassell \& Steven J. Twist, Victims in Criminal PROCEDURE (3d ed. 2010) (discussing how crime victims are generally overlooked in criminal justice decisions).

${ }^{367}$ Victimization, CRIME \& PUNISHMENT, http://crimepunishment.smartchicagoapps.org/victimization.html 
which police officers stop and frisk criminal suspects and any decrease in crime rates." ${ }^{\prime s}$ Of course, this article now provides such statistical evidence specifically for Chicago, which we believe should form part of future discussions about stop and frisk policies in America's "Second City" and other cities as well. Moreover, the consultant's report (released in March 2017) may have overlooked other studies on stop and frisk policies, as summarized by the National Academy of Science review of the literature (released in November 2017). A number of those studies did suggest a causal connection between stop and frisks and crimes, as discussed earlier. ${ }^{3 \infty}$

The consultant's report also addressed at length the issue of the extent to which CPD's stops were, in the consultant's view, "good" or "bad"-i.e., the extent to which CPD paperwork documented that the stop complied with constitutional requirements or not. The report found a "good" stop rate between 90 and 94 percent, depending on how certain events were coded..$^{s 0}$ The consultant concluded that this was an "excellent start" to implementing the agreement, although a 4 to $10 \%$ bad stop rate would involve a large number of stops. One difficulty in interpreting the data is that, it turns out, most of the "bad" stops, rested simply on a determination that there were "not enough facts" recorded in the report to justify a stop-which could simply be a failure to record in the report all the information justifying the stop. ${ }^{32}$ Because the report offered no details about how the bad stop determinations were made (other than the judgment of the consultant), it is impossible to reach further conclusions about the nature of the determinations. ${ }^{3 s}$ But, concerningly, the report found that the chance of being subjected to a "bad stop" was higher for African-American and Hispanic civilians, although it was not possible to say whether these differences were caused by race or unobserved variables not tested in the statistical model. ${ }^{s / 4}$ Our equations suggest that one of the interactions between variables that should be carefully considered in assessing such stop and frisk issues is the likely linkage to rising crime rates as stop and frisks decline.

Since the release of the consultant's first six-month report in March 2017, the process of semi-annual reports appears to have slowed down even further. It took another year-until March 2018 - to release the second six-month report, this

368 FIRST CONSULTANT REPORT, supra note 274, at 8.

${ }^{369}$ See supra notes 53-80 and accompanying text.

${ }^{370}$ FIRST CONSULTANT REPORT, supra note 274, at 29.

${ }^{371}$ Id. at 117.

${ }^{32}$ REVISED FinAl TECHNICAL REPORT TO First CONSUltant REPORT, Mar. 17, 2017, at 18-19, https://www .aclu-il.org/sites/default/files/appendix-a-analysis-of-coded-isrnarratives.pdf.

See also infra notes 371-72 and accompanying text (noting lack of transparency inherent in these determinations).

${ }^{374}$ Id. 
one discussing the second half of 2016..$^{35}$ As with the first report, this report also did consider whether declining stop and frisks placed minority communities at special risk of increased victimization in 2016 and beyond - one relevant factor in the balance between the need for preventing crime and the need for protecting individual liberties. The report did, however, conclude that CPD had "come long way in its attempts to alleviate the concerns raised by the ACLU in March of 2015 ...." ${ }_{m}$ Interestingly, to the extent that the ACLU was concerned that police were stopping a disproportionate number of African-American and Hispanics, the agreement did not appear to have had any significant effect in changing the proportions. Comparing the last six months of the 2015 to the last six months of the 2016, stop rates for all racial groups declined by about the same rate-stops rates for Black non-Hispanics declined 81\%, for Hispanics 79\%, and for White non-Hispanics $82 \%{ }^{m}$

Finally, on the subject of balancing individual liberties with effective crime control, it is important to note that remedies exist for unconstitutional stops and frisk by law enforcement agencies. Not only can illegally-obtained evidence be suppressed under the exclusionary rule, but for innocent persons unlawfully stopped, a civil rights action under $\S 42$ U.S.C. 1983 is available. On the other hand, for victims of ineffective crime control—such as someone shot or killed because the government failed to make a stop - the possibility of a remedy is remote. ${ }^{3 s}$

\section{Removing or at Least Simplifying the Investigative Stop Report}

\footnotetext{
${ }^{375}$ See City of ChicAgo, The Consultant’s SECOND SEMiAnNuAl RePORT ON THE InVEStigatory Stop AND Protective PAT Down AgreEMENT (2018), https:/www.cityofchicago.org/content/dam/city/depts/dol/supp_info/InvestigatorStops2nd Report7116_123116/TheConsultantsReportJuly12016December312016.pdf [hereinafter SECOND CONSULTANT REPORT].

${ }_{376} I d$. at 220. The second report noted that while for the first six months of 2016, the best estimate was that between $91.99 \%$ and $93.75 \%$ were good stops, for the second six months of 2016 the best estimate was $93.2 \%$ to $95.2 \%$. Id . at 168. As with the first report, the determination of what was a "good stop" and a "bad step" was based on the documentation provided, see id. at 166, not any actual determination that the stop was, in fact, unconstitutional.

in $I d$. at 145 .

${ }^{38}$ The ability of crime victims to challenge government's failure to effectively enforce the law is severely restricted. See BELOOF ET AL., supra note 366, at 177-205. Under current doctrine, recourse is likely only available in circumstances where government (in)action is based on the race of the criminal or the perpetrator. See Elliot-Park v. Manglona, 592 F.3d 1003 (9th Cir. 2010). It is in interesting question whether, in light of the racially disparate impact of the resulting homicides from reductions in stop in frisk, a viable constitutional challenge could be made to those reductions. Title 42 U.S.C. $\$ 2000$ d covers unjustified discriminatory effects of actions by recipients of federal funds, although any such actions must be brought by the federal government rather than individual plaintiffs. Alexander $v$. Sandoval, 532 U.S. 275 (2001). This complicated legal issue is beyond the scope of this article.
} 
Related to the previous policy recommendations, we believe that policy makers need to be extremely concerned about placing unnecessary impediments to police stop and frisks. In Chicago, for example, policymakers should give serious consideration to removing or at least simplifying the cumbersome stop and frisk form (the Investigative Stop Report or "ISR"). As discussed earlier, it appears that completing the report in connection with each stop takes at least ten to fifteen minutes, maybe even as long as 45 minutes for some officers. ${ }^{3 m}$ Presumably this is largely due to the "narrative" section of the form, which could take an extended time to fill out. We see little evidence in our data that the length of time is simply due to lack of training or familiarity with the form. After the form was first introduced at the end of 2015, it appears that, roughly speaking, the number of stop and frisks did not increase through 2016, but rather simply fell to a new, much lower, level. ${ }^{\text {so }}$ If the length of time were simply a training problem, we would have expected to see the number of stop and frisks rise throughout 2016 as officers gained greater familiarity with completing the form.

It is important to understand that nothing in the Constitution requires that the CPD keep such complicated records that involve so much time for its officers to complete, as least based on the current state of litigation. ${ }^{\text {sin }}$ Instead, the requirement to complete the form stems solely from the ACLU agreement - an agreement from which CPD is free to withdraw at any time. Moreover, pursuant to the terms of the agreement, this information is kept confidential by the CPD and is only made available to the ACLU and the consultant monitoring the agreement. ${ }^{32}$ Accordingly, it does not appear to be available to independent academic researchers, not to mention the general public. While the reports are reviewed by Judge Keys, any conclusions he reaches will essentially rest on a black box of data that cannot be examined. It is thus hard to understand how the information called for in the ISRs could play a significant role in transparent oversight of the CPD, in contrast to other cities where publicly-available stop and frisk data has helped improve public knowledge.

In any event, whatever may be the merits or demerits of initially collecting such information, the only relevant issue now is whether it is desirable to continue collecting such information. As of this writing (April 2018), CPD has collected

\footnotetext{
${ }^{379}$ See supra note 300 and accompanying text.

${ }^{380}$ See Figure 5, supra (monthly stop and frisks). We have requested 2017 stop and frisk data from the CPD and are awaiting its receipt. This may shed further light on the subject. ${ }^{31}$ Of course, later in litigation, if a district court were to find a systemic constitutional violation, it could consider possibly issuing an injunction with supra-constitutional requirements, if those requirements were designed to cure pre-existing constitutional violations. See, e.g., Milliken v. Bradley (II), 433 U.S. 267 (1996).

${ }^{382}$ See ACLU Agreement, supra note 280, at 93.1

as $C$. Harmon \& Manns, supra note 299, at 66 (noting that in New York, public availability of NYPD stop and frisk forms "allowed a much richer public debate about stops and frisks and their value").
} 
about 27 months of data, and only 12 months have even been analyzed (so far as can be determined in public reports). Thus, plenty of data now exists for the ACLU and the monitoring consultant to evaluate CPD's stop and frisk practices. Given the heavy price that collecting the data may exact in human lives and shooting injuries, further cumbersome collection of data may not pay its own way in terms of lessons learned. Specifically, our research suggests that abolishing the general requirement for CPD officers to complete the ISR - as part of an effort to restore stop and frisk to pre-agreement levels ${ }^{\mathrm{s}}$ - might potentially save more than 200 lives each year, the vast majority of them crime victims who are racial minorities. If even a fraction our regression calculation of the tradeoff is accurate, the reports would have to contain extraordinarily valuable new information to justify that cost in human suffering, something that seems unlikely.

In recommending that the ISR be abolished, we hasten to add that we are not recommending changes to the stop "receipt" that officers in Chicago (and elsewhere) deliver to persons who have been stopped. ${ }_{. . s}$ The reader can compare the two forms in Appendices B and C. The receipt form is much shorter and much simpler to complete. More important, the receipt form serves a valuable public purpose beyond simply recording data about stops. The receipt is designed to reassure persons who have been stopped that there was a valid basis for the stop. This reassurance is an important public policy goal, designed to not only reduce anxiety among those who have been stopped but also help to maintain public

${ }^{3 s 4}$ If additional, highly-detailed data is needed about stop and frisks, a point we explore below at infra notes 385-91 and accompanying text, it could presumably be accomplished by collecting such data from a small sample of police officers, rather than the entirety of the force.

${ }^{3 s s}$ From what we can tell, CPD had required record-keeping requirements on stops throughout 2015, as pursuant to Special Order S04-13-09 (issued January 7, 2015), officers were required to complete a "Contact Information Card" for any stop that did not result in an arrest. Contact Information System, Special Order S04-13-09,

http://directives.chicagopolice.org/directives/data/a7a57be2-12a864e6-91c12-a864e985efd125ff521f.pdf. This policy also contained guidance on the circumstances in which stop and frisks were appropriate. From what we can tell, the substantive guidance on circumstances in which officers could make stop and frisks did not change during the relevant period of time, although CPD did provide additional training on stop and frisk policies. See Declaration of Anne Kirkpatrick, DE 113-2, Smith v. City of Chicago, No. 1:15-cv-03467 (N.D. Ill., Aug. 30, 2016). Our article, of course, does not recommend eliminating policy guidance to officers on the circumstances in which stop and frisks are appropriate (not to mention other law enforcement tactics), such as the guidance contained in Special Order S04-13-09.

Nor are we recommending any changes in other record-keeping requirements, as our article focuses on stop-and-frisk. In particular, to avoid any confusion, we are not addressing the recently-enhanced CPD requirements for reports in connection with police department use of force, which stemmed from recommendations from the U.S. Justice Department. See CPD, General Order G0-02-02, Incidents Requiring the Completion of a Tactical Response Report (Oct. 16, 2017), http://directives .chicagopolice.org/directives/data/a7a57be2-1291da66-88512-91e2cdd76fd8ae76d83d.html?ownapi=1. 
confidence in the police. ${ }^{\text {so }}$ And with regard to this particular form, it appears that the law enforcement effectiveness is not diminished. As discussed earlier, police agencies in other parts of Illinois outside of Chicago appear to have been able to implement this requirement without the increase in crime rates that Chicago experienced. ${ }^{*}$ Based on the analysis presented in this article, Chicago (and other cities) should keep the receipts - and discontinue burdensome additional recordkeeping requirements, such as the ISRs.

\section{Relying on Body Cameras}

One reason that we feel comfortable in recommending that the Chicago Police Department (and other law enforcement agencies) should consider abolishing impediments to stop and frisk such as the cumbersome ISR form is that recording data via such electronic "paperwork" now seems terribly outdated. Indeed, if we look specifically at Chicago, as of December 2017, CPD became the largest police force in the nation fully equipped with body cameras. Following a two-year rollout, in December 2017 Mayor Rahm Emanuel and CPD Superintendent Eddie Johnson touted the fact that all 7,000 CPD patrol officers had been equipped with cameras, calling it "the largest deployment of the technology in the United States."

There is a considerable empirical debate about whether body cameras reduce excessive force by law enforcement officers. While one early study found significant reductions in complaints against officers, ${ }^{30}$ more recent studies have been somewhat mixed. For example, in November 2017, the Metropolitan Police Department of the District of Columbia (MPD) reported the results of a randomized controlled trial to examine the effects of MPD's body camera program." The study found that body cameras had "no effect on police use of force, citizen complaints, policing activity, or judicial outcomes." "' And, of course, body cameras are not a panacea for police misconduct. A clear illustration of this sad fact comes from the McDonald video (made by a dashboard camera rather than

${ }^{3 * 6}$ See PRESIDENT's TASK ForCE ON $21^{\text {st }}$ CENTURY POLICING, FinAl REPORT 24 (2015) (calling for collection of demographic data on, among other things, stop and frisks); Craig B. Futterman et al., Youth/Police Encounters on Chicago's South Side: Acknowledging the Realities, 2016 U. CHI. LEG. F. 1, 36 (calling for sharing of information about police stops). ${ }^{387}$ See supra notes 316-25 and accompanying text.

${ }^{388}$ Mayor: All Chicago Patrol Officers Now Have Body Cameras, CHI. TRIB., Dec. 12 , 2017, http://www.chicagotribune.com/news/sns-bc-il--chicago-police-cameras-20171211story.html. ${ }^{3 s 9}$ See Rosenthal, supra note 154, at 699 \& n.117 (collecting conflicting research).

390 TONY FARRAR, THE INESCAPABLE PANOPTICONIC GAZE: THE EFFECT OF BODY-WORN CAMERAS ON POLICE USE-OF-FORCE (2013).

${ }^{391}$ David Yokum et al., Evaluating the Effects of Police Body-Worn Cameras: A Randomized Controlled Trial, Oct. 10, 2017, https://osf.io/rk2pa/. ${ }^{392} I d$. at 22. 
a body camera) which did not deter the officer involved from repeatedly shooting McDonald. ${ }^{3 s}$

For our purposes, however, we need not enter into the broader debate about whether body cameras change police behavior. Our limited point is that, at a minimum, body cameras objectively record actions taken by a police officer far more effectively than subsequent paperwork. ${ }^{3 m}$ Indeed, a 2015 national ACLU "White Paper" on police body-mounted cameras took the position that body cameras could be an important check

against the abuse of power by police officers. Historically there was no documentary evidence of most encounters between police officers and the public, and due to the volatile nature of these encounters, this often resulted in radically divergent accounts of incidents. Cameras have the potential to be a win-win, helping protect the public against police misconduct, and at the same time helping protect police against false accusations of abuse. ${ }^{3.5}$

It seems redundant to have CPD officers make a video recording of any stop and frisk that they conduct and then subsequently take an additional fifteen minutes to complete the ISR. One electronic record should be enough to provide whatever information needs to be reviewed about the stop-as well as to create whatever deterrence effect to inappropriate police behavior might be possible. And given the fact that law enforcement agencies all over the country appear to be rapidly expanding their use of body cameras, ${ }^{3 *}$ other agencies may be able to take similar simplifying steps.

One note of caution needs to be sounded about body cameras. One early controlled study comparing officers with cameras to those without found that officers with cameras "conducted significantly fewer stop-and-frisks and arrests than officers who were not wearing the technology." "While more recent research

\footnotetext{
${ }^{33}$ See supra notes $130-50$ and accompanying text.

se See Michael D. White, Police OfFicer Body-Worn CAMERAS: AsSESSING THE EVIDENCE (2014).

${ }^{395}$ Jay Stanley, ACLU Senior Policy Analyst, Police Body-Mounted Cameras: With Right

Policies in Place, a Win for All (March 2015),

https://www.aclu.org/sites/default/files/assets/police_body-mounted_cameras-v2.pdf. ${ }_{30}$ Police Body Worn Cameras: A Policy Scorecard, Leadership Conf. (Aug. 2016), https://www.bwcscorecard.org/ [https://perma.cc/L89W-JHMV].

${ }^{397}$ See, e.g., Justin T. Ready \& Jacob T.N. Young, The Impact of On-Officer Video Cameras on Police-Citizen Contacts: Findings from a Controlled Experiment in Mesa, Arizona, J. EXP. CRIMINOLOGY (June 14, 2015), http://centerformediajustice.org/wpcontent/uploads/2015/06/The-Impact-of-On-officer-Video-Cameras-on-Police-CitzenContacts-JEC.pdf.
} 
does not appear to replicate this finding, frisks should be monitored carefully in Chicago and other cities.

\section{E. Researching Stop and Frisk Questions}

A final recommendation we make is for further research on the important topic of stop and frisk. In particular, it would be desirable for controlled randomized field studies in various neighborhoods of Chicago and other cities to examine whether expanded stop and frisk programs have the kind of crime reduction effects that we find in our regression equations. If this article's conclusions are correct, field studies would replicate such effects and demonstrate important crime control benefits to this tactic, but conducting such empirical research is the only way to find out.

This article relied on time series regression analysis to identify the cause of the homicide spike out of necessity. Because the entire City of Chicago appeared to experience the homicide spike at the same time (although to different degrees in different parts of the city), it appears that something city-wide triggered the spike. Our time series analysis suggests that the decline in stop and frisk was the likely cause. But a preferred methodology for making causal assessments is experimental design, in which two areas (at a minimum) are compared, one that is subject to the new policy with another "control" jurisdiction that is not. ${ }^{399}$

It would be possible to conduct such experiments with stop and frisk in Chicago and other large cities. As is generally recognized, the strongest form of evidence on social policies comes from randomized controlled trials (RCTs) or similar quasi-experimental designs, ${ }^{\text {to }}$ the so-called "gold standard" for measuring outcomes in policing practices." Along these lines, it should be possible to employ enhanced stop and frisk patrols (subject, of course, to appropriate training and safeguards) in certain neighborhoods in a city, but not others. ${ }^{* 20}$ It would then be possible to compare results and determine whether stop and frisks helped to reduce gun-related crimes.

This experimental approach was recently used to determine possible ways to respond to gun crimes in St. Louis and Philadelphia. Different areas within the

${ }^{398}$ See Yokum, supra note 391, at 14 (using measures of discretionary police activity, not including stop and frisk, that showed no reduction with introduction of bodycams). 399

Rushin \& Edwards, supra note 115, at 740; see also; Daniel E. Ho \& Donald B. Rubin, Credible Causal Inference for Empirical Legal Studies, 7 ANN. REV. L. \& Soc. SCI. 17, 20 (2011) (collecting illustrations of this approach).

${ }^{\star 0}$ NAT'L ACAD. OF SCI., supra note 49, at 1-16.

${ }^{* 0}$ POLICING PROJECT, supra note 335 , at 8.

"an The selection process for such "test" neighborhoods should be based solely on scientific needs and sensitive to avoiding racially-disparate impacts. The St. Louis and Philadelphia studies discussed in the next paragraphs illustrate ways this might be done. 
cities were exposed to different policing strategies, with an unaffected area left as a "control." In St. Louis, significant reductions in firearms violence resulted from patrols directed at crime hotspots that involved enhanced enforcement activity, although whether reductions were attributable to stop and frisks was disputed. ${ }^{a n s}$ In Philadelphia, it appeared in one study that pedestrian stops conducted by foot patrol officers lead to crime reductions, although a follow-up study was unable to replicate the gains. ${ }^{\text {an }}$ These studies were not specifically designed to test the efficacy of stop and frisk as a crime-fighting measure, and our findings of significant changes in crime rates associated with changes in stop and frisk practices suggest that further studies focusing specifically on this law enforcement tactic are warranted. And because the success of stop and frisk may vary from city to city, ${ }^{\text {as }}$ it would be particularly useful to conduct such research in various cities, including Chicago, to try to best understand the effects of stop and frisk policies.

\section{CONCLUSION}

This article set out to explain what caused the 2016 Chicago homicide spike. Based on the analysis presented here, the sharp reduction in the number of stop and frisks conducted by the Chicago Police Department, coinciding precisely with the spike, was most likely the cause. Using multiple regression analysis, we tentatively calculate that, in 2016, reductions in stop and frisks by CPD were responsible for approximately 236 additional homicides and 1115 additional shootings - thus explaining essentially the entire homicide spike. These findings are highly statistically significant; they are also robust, as they survive rigorous scrutiny under Bayesian Model Averaging. And they do not appear to be due to any "omitted variable" excluded from our equations.

This article also explores what caused the clear decline in stop and frisk in Chicago in 2016. It appears quite likely that a consent decree between CPD and the ACLU addressing stop and frisks, implemented in late 2015, triggered CPD's decline in stop and frisks. In short, we conclude that the so-called "ACLU Effect" was real and that, in 2016, gun violence in Chicago apparently increased dramatically - and tragically - as a result.

While our findings are obviously important to residents of Chicagoparticularly African-Americans and Hispanics who disproportionately were the victims of the increased gun violence-our findings have far broader import. Based on recent experience in New York City (where stop and frisks may have declined without an apparent increase in violence), a conventional wisdom has begun to develop that stop and frisks are unnecessary for effective law enforcement. This article explains why any lessons to be drawn from New York

${ }^{*}$ R. Rosenfeld, M. Deckard \& E. Blackburn, The Effects of Directed Patrol and SelfInitiated Enforcement on Firearm Violence: A Randomized Controlled Study of Hot Spot Policing, 52 CRIMINOLOGY 429 (2014).

${ }^{\star 4}$ E. Groff et al., Does What Police Do at Hot Spots Matter? The Philadelphia Policing Tactics Experiment, 53 CRIMINOLOGY 23 (2015); Ratcliffe et al., The Philadelphia Foot Patrol Experiment, supra note 69.

as NAT'L ACAD. OF SCI., supra note 49, at 1-16. 
City's experience may represent something exceptional and do not translate to the nation's "Second City." And for many of America's other cities that have gun violence problems comparable to Chicago's, a sharp reduction in stop and frisks might be expected to have similar lethal consequences.

Throughout our article, we have tried to emphasize the tentative nature of our findings - as well as our plea for further research into this important subject. And we have also emphasized that stop and frisk policies in Chicago (and presumably elsewhere) have social costs of their own. The costs include intrusions on the privacy interests of those persons who are stopped, and in some cases, frisked, as well as the potential for harming community trust in law enforcement agencies. We have called for all these subjects to be explored at length, so that policymakers have the best available information on which to proceed. But along with these costs to stop and frisks, it is important to consider the benefits. At least in the City of Chicago, these benefits appear to have been generally overlooked.

In closing, we would be remiss if we failed to mention what appears to be a reluctance by some observers even to consider the possibility that stop and frisks reduce crime. As we researched the Chicago homicide spike, we were repeatedly struck by the fact that this obvious possible explanation was so often quickly swept under the rug. But the costs of crime - and particularly gun crimes - are too significant to avoid considering every possible measure for reducing the toll. The evidence gathered here suggests that stop and frisk policies may be truly lifesaving measures that have to be considered as part of any effective law enforcement response to gun violence. 


\section{APPENDIX A: THE 2016 CHICAGO HOMICIDE VICTIMS}

The following is list of the 2016 Chicago homicide victims, as tabulated on the Chicago Sun-Times website "Homicide Watch Chicago: Mark Every Death/Remember Every Victim/Follow Every Case." http://chicago.homicidewatch.org/photo-gallery/2016/index.html.

If the conclusions drawn in this article are correct, approximately 230 of these persons would not have been killed if stop and frisks had been maintained in Chicago in 2016 at the same levels of 2015:

Sylvia Brice, Kenneth Weaver, Gregory Livingston III, Andre Lacaze, Carlos James, Louis Pena, Yuri Hardy, Matthew Herring, Christopher Brown, Jamil Shuaibi, Steven Freeman, James Gill, Roy Gill III, Jamil Farley, Jerry Thomas, David McClure, Fabian Ortega, Niko Walker, Nathaniel Edwards, Demetrius Newell, Juan Gonzalez, Derrick Jones, Stephen Tucker, Richard Chambers, Manual Guzman, Rolando Gamino, Quesola Mimms Anthony Durham, Joel Planas, Scott Thompson, Shacora Jackson, Nateyah Hines, Elijah Jackson, Shakeyah Jackson, Crispin Coliz Jr., Michael Newell, Daniel Torres, Arturo Zizumbo, Corey Martin, Lavaris Johnson, Antonin Mixon, Quenten Wright, Lawrence Matchem, Anthony Shorter, Anthony Barr, Otis Hatchett, Derrick Swanigan, Shaqwon Stidhun, Nathaniel Lewis-Edwards, Timothy Harmon, Sylvester Rainge, Elijah Jones, Lafayette Montgomery, Darren Smith, Ed Brown, Antron Young, Deangelo Martin, Bartiomiej Barczyk, Christopher Luckett, Carl Jones, Curtis Lowells, Ronald Allen, Reginald Smith, Marqual Bailey, Trayvon Dickerson, Mandell Lee Johnson III, Addonis Johnson, Gregorio Aguilar, Charles Johnson, Leny Cervantes, Jamie Cervantes, Delvon Watson, Rickey King, Erik Peoples, Gregory Thomas-Bell, Dequan Barnett, Diego Alvarado, Thomas Smith, Jeffrey Banks, Moises Gonzalez, Deshawn Adams, Zenan Hernandez, Ketrell Hill, Paul Cruz, Abimbola Sheleru, Michael Gipson, Matthew Rodgers, Odell Jones Jr., Carlos Williams, Kevin Shorter, Simion Jackson, Guadalupe Saucedo-Garcia, Javon Wilson, Joseph Anderson, Jarod Morris, Eddie King, Elijah Murphy, Roy Love, David Martinez, Michael Anderson, Aaron Perez, Renee Davis, Harry Cannon Jr., Joe Lacasto, Taurus Williams, Victor Fernando, Garcia Darian, Tyler Grayson, Langdon Tridell, Parker Annette, Harris Louis, Torres Lorenzo, Dixon Javoun Burnes, Giovanni Garcia, Raiylana Vasquez, Manuel Vega, Jeremiah Parker, Orephus Washington, Clarence Coakley, Kevin Faulkner, Keith Hayes Jr., Travis Harris, Luis Villa, Adam Moye, Elijah Terry, Rushun Gaddis, Cynthia Richardson, Deon Virges, Seneka Harrison, Steven Hicks, Soloman Walker, Francisco Guzman, Aliser Maldonado, Emoni House, Elijah House, Richard Porter, Terrell Griffin, Gregory Wong, Arthur Malone, Larry Matthews, Douglas Bowman, Raymond Griffin, Tidarrius Smith, Donald Dockery, Gerald Gordon, Jacolby Cannon, Tayveon Thomas, Kevin Wilson, Mark Higgins Jr., Walter McCurry, Edwin Bryant, Edward Bryant, RaeQuonn Ricks-Williams, Clara Gonzalez, Lindsey Anderson, Gilbert Leroy Wainwright III, Luis Corona, Robert McClinton, Aaron Bennett, Deandre Banks, Robert Bishop, Demarco Webster Jr., Martell Turner, Tyrice Anderson, Brian Fields, Chiquita Ford, Hernando Lamont Caster, Steven Cowan, DeAndre Walton, Lawrence Washington, Phillip Lewis, Loretta Purcell, Tramell Williams, Lamar Watson, Unknown Female, Jaylen Howard, Samuel Williams, Taiwan Fox, Kahn Butler, Jason Balboa, Lucius Delaney, Rashad Xavier Collins-Baker, Jonathan Sanchez, Issiah Hurley, Giovanni 
Galvan, Sentwali Adissa Davis, James Gerage, Alejandro Morales, Christopher Walters, Marilyn Duffie, Luis Romero, Jamar Robinson, Ronald McBee, Timothy Agnew, Demetrius Griffin Jr., Gregory Tucker Jr., Latwon Rogers, Gene Williams, Vincent Zarco, Davon Smith, Trasean Stokes, Jeffrey Brinson, Jamel Thomas, Jermale Richardson Jr., Faizon Smith, Aaron Jackson, Devante Norwood, Tony Hussaini, Aaron Smith, Carlos Ocampo, Lyndell Hodges, Maurice Hilliard, Javier Martinez, Raheem Dismukes, Kewon Vilella, Victor Sanjuanero, Martell Rhodes, Tommie Darling, Dorise Anderson, Danny Darling, Julia Martin, Jacory Jones, Miguel Adan Ramirez, Antonio Lee, Tyrone White, Said Hayik, Adrianna Mayes, Samuel Rockett Jr., Lazerrick Ratliff, Corvus Humphries, Jean Vital, Naome Zuber Anthony Banks, Byron Walker, Devon Almon, Jonathan Ortiz, Treamel Gray, Alvonta Pinex, Arian Smith, Jevon O'Brien, Reginald Fleming Jr., Jose Ernesto Martinez, Peter Fabbri, Antonio Porterfield, Nathan Watson, Jewneus Wilson, Jose Vizcarra, Izael McKenzie, Joaquin Gonzalez, Carlos Jackson, Jeremiah Curtis, Marvin Keyes, Lee Stemley, Anthony Thorpe, Eric Banks, Manuel Aguilar, Donald Brunson, Miguel Williams, Bruce Smith, Evette West, Ural Durant, Eddie Huff, Maurice McKnight, Parasha Beard, Marquese Fleming, Kiev Dobbins, Stanley Easley, Tontrice Weathersby Jr.,, Deamar Bingham, Venancia Veracruz Benitez, Ahmad Morgan, Shaquille Alexander, Alexander Townsend, Michael Buckner, Tony Saffore, KeeKee Fleming, Sergio Zaragoza, Salvador Muniz, John McKinley, Nahmar Holmes, Dominic Hallom, Louis Rodriguez, Jerry Lee Cummings, Israel Aragon Jr., Marqui Williams, Gregory Sims Jr., Dequan Trimble, Charles Smith, Devon Reavley, Paul Hamilton, LeShawn Carr, Kenneth Whitney, David Baldwin Enrique Morales, Allen Smith, Jamel Rollins, Korry Rogers, Robert Porter Jr., Alberto Medrano Juan Pita-Rosas, Stephen Toplin, Malik Philpot, Hani Youset, DeLon Sims, Brian Winters, Armani Fiero, Kristopher Weiss, Elijah Sims, Jamarh Carter, Raheem Gray, Roberto Rodriguez Jr., Othijah Mooney, Terrence Murphy, William Smith, Omar Kent, Demarco Richards, Mahdi Herring, Dylan Dent, Corey Strothers Jr., Robert Kraft, Ramon Tolbert, Nykea Aldridge, Travis Allen, Rashon Nichols, Johnell Johnson, Victor Mata, Tykina Ali, Christopher Hibbler, Shaniya Staples, Kirk Johnson, Madison Watson, Melanie Watson, Mario Cousins, Booker Parrow, Kendrick Thornton, Daniel Delgado, Malik Causey, Darius Brownlee, Jesus Santiago Valois, John Alexander, Mario Mojica-Rios, Miles Kent, Martell McCary, Tyshun Jones, Chavrone Finley, Kenneth Carrington, Mikel Maragh, Baby Boy Welch, Kirino Fabian, Aaron Brown, Chavaris Guider, Vincent Winkfield, Anthony Nelson, Ladrell Brown, Alfronso Kyles, Antoine Johnson, Derrick Canady, Arshell Dennis III, Yanong Woods, Abner Garcia, Louis Carrasquillo, Jonathan Stewart, Johnny Butler, David McCray, Winstone DeLaney, Stephen Triplett, Jaime Williams, Dontae Roberts, Cortez Tate, Demarco Kennedy, Julius Coleman, Andre Jackson, Anthony Hatchett, Erik Williams, John Hosey Jr., Cory Hughes, Denzell Mickiel, Ireal Mitchell, Michael Lucas, William Villa, Lee Martin, Corey Buckner, Luis Marin, Everick Coleman, Victor Alvarado, Mario Venegas Jr., Maurice Selvy, Miguel Bahena, Delance Price, Toryius Keefer, Penny Gearhart, David Plank Sr., Michael Montgomery, Ronnie Hutchen, Donta Lee, Miguel Diaz, Jeffrey Arnold Jr., Trinyce Sanders-Wilson, Latrell Gipson, Roy Bergman, Marteace Rhone, Denear Scott, Jonathan Lane, Paul Farlinger, Mbiganyi Lashani, Demarius Roseman, Demetrius Paskel, Jessica Williams, Kayana Ormond, Denzell Childs, Keith Jackson, Africa Bass, Keyon Boyd, Vincent Davis Sr., Jonathan Mills, Taylon Hughes, Gregory Chacon, Katana Greenlee, Jesus Martinez Jr., Deandre Gray, Roberto Ortiz, Tabari Freeman, Ernest Hudson, Andre Wells, 
Kyara Newell, Jamie Varvaris, Anthony Nicholas, Kashawan Johnson, Darrell Peden, Artivis Gladney, Carlos Harding, Raygene Jackson, Chureno Gatewood, Lloyd Daniel, Trevon Smith, Rachee Williams, Clarence King, Sydni Murray, Bryan Cooley, Clarence Jones, Christopher Roberson, Marwan Sedeq, Anthony Thomas, Kenshon Ward, Rodney Phillips Orr, Daniel Watkins, James Moore, Silvestre Mejia Jr., Shemeki Heard, Demetrius Warren Glennell Fairley, Leander Winford II, Kendall Smith, Maurice Ross, Kewan Gillespie, Carlos DeLourdes, JQuinn McCune, Derion Smith, Laron McCoy, Mecahel Holder, Michael Griffin, Travon Clemmons, Willlie Pittman, Hector Badilo Jr., Kenneth Whitaker, Robert Vaughn, Chanda Foreman, Larry Lawrence, Marshawn Hilson, Darrell Guy Jr., Matusalem Dominguez-Gutierrez, Alfondia Kelly, Kentrail McCray, Dujuan Williams, Lonnie King, Frederick Johnson, Selton Ellis, Wondale Collier, Trayvon Wilson, Reginald Turner, Brandon Nolls, Jeremy Clark, Trevell Parker, Eric Burgin, Jessica Hampton, Stanley Boston, Amari Catchings, Ramal Hicks, Eugene Singleton, George Morgan Jr., Otis Richmond, Salvador Suarez, Carlton Hallom, Michael Brown, Alejandro Fuentes, Margaret Shanahan, Eric Smith, Eric Knox, Latrell McMahon, Charles Wiley, Melvin Cook, Renee Showers, Victor Robinson, Demetrius Archer, Angelo Davis, Denzel Thornton, Jeremy Rogers, Antonio Perkins, Steven Edwards, Darryl Ferguson, Antoine Randle, Davion Barron, Adrian Watson, Jordan Liggins, Angelique McClellan, Dwayne Triplett, Antwon Brooks, Javil Nunn, Christopher Fields, Travell Montgomery, Terry Bates Jr., Jeremy Ray, Paul Webster, Lewis Johnson, Lanorris Webster, Anreco Nichols, Anthony Williams, Sami Salaymeh, Carmen Venegas, Dontay Murray Jr., Kori Sellers, Bryson Holman, William Palmer, Darnell Hardeman, Anthony Howard, Daniel Alcantana, Henry McCann Jr., Christian Bandemer, Jamaal Bellamy, Kaysar Chako, Marshawn Clinkscale, Victor Felix, Kevin Atkins, Fabian Lavinder, Johan Jean, James Taylor, Dora Corbin, James Harris, Pamela Johnson, Garvin Whitmore, Damien Cionzynski, Veronica Lopez, Mark Lindsey, Shawn Ewing, Kevin Larry, Marshawn Cooper, Gerald Sias, Trevonne Austin, Gregory Carr, David Easley, Michael Wickliffe, Semial Sigle, Yvonne Nelson, Prince Wilson, Damarcus Williams, Marcus Patrick, Romaine May, James Hooks, Eric Nieves, Ashraf Sennouni, Maurice Johnston, Eric O'Reilly, Stacey Flukes, Willie Jones, Frank Hill Jr., Marco Mendez, Camille Cooley, Dekayla Dansberry, Albert Hurd, Kevin Milton, Mark Vargas, Michael Harmon, Lee McCollum III, Kiara Kinard, Jerome Wright, Makeesha Starks, Ira Cotton, Deangelo Diggines, Marquel Sharp, Jeremy Hosey, Michael Cunningham, Ladarrius Jackson, Kimble Knox, Deshawn Thompson, Nathan Hicks, Kourtney Young, Keon Lewis, Najee Williams, Andres Rivera, Michael Montgomery, Carl Handley, Terrell Burkhart, Eddy Brooks, D'Andre Johnson, Devon Watson, Timothy Hill, Jesus Juarez, Jeremy Parker, Antonio White, Robert Rosenau, Randle Young, Leonardo Betancourt, Willie Pratt, Karina Soria-Bautista, Guadalupe Dean, Deitrick Stogner, Lamar Watson, Glenn Wheeler, Pierre Johnson, Davharea Wilson, Davon Barrett, Devin Hamb, Justin Bowman, Darrell Wilson, Tiara Parks, Gino Carrasco, Kenneth Allen, Kimberly Schnackenberg, Jason Napoles, Michael Williams Jr., Damond Dawson, Frederick Blount, Andrew Haynes, Pierre Payne, Raymond Prior IV, Davon Spivey, Arturo Pina, Rhonda Stevenson, Dennis Bradford III, Lauren Membreno, Ramon Ramirez, Johnathan Sanchez, Diangelo, Black, Deandre Trotter, Marcus Smith, Marvin Lee, Gerwancey Rambus, Aurelio Guzman, Babette Miller, Anthony Heatherly, Angel Ortiz Jr., Petro Rymar, William George, Demetrius Tolliver, Dejenaba Altman, Mario Guzman, Luis Gonzalez, Alejandro Velazguez-Perez, Brion Barlow, Cashes McCree, Cordero 
Mosley, Andrew Love, Antonio Johnson, Mario Ramirez Jr., Armani Dickinson, Jarvis Coleman, Alcarez Reyes, Marcus Smith, Christian Ortiz, Marteace Tiffith, Jeanette Laureano, Lorenzo Lancaster, Tyree Grant, Lucas Spicer, Kenneth Brown, Victor Navarrette, Antoine Crowder, Charis Eaton Jr., Taylor Flowers, Marvelle Arnold, Andre Taylor, Ricardo Montes, William Smith, Terall Adams, Orlando Porter, Paul Woods, Askie Wajd, Ronald Thomas, Cesar Perez, Daysha Wright, Gerardo Rodriguez, Maurice Cavin, Wavey Brown, Courtney Copeland, Darrin Joss, Tommie Pledge, Natyia Bowen, William Bustos, Frederick Brown, Eric Henry Jr., Shari Graham, Djuan Williams, , Shawndale Neal Diamond Garner, Jesus Reyes-Ortiz, Nicholas Robinson, Kamil Shamji, Carlos Hemphill Jr., Raheem Robinson, Maricela Villegas, Brian Johnson, Terrell Sykes, Richard Thrasher, Tiana Brown, Jonathan Luna, Iaron Brooks, Rashawn Gooden Jr., Steven Tate, Jeremy Hunter, Lawrence Campbell III, Terrell Peters, Vincent Avila, Latania Anderson, Lorenzo Garcia, Reginald Bonner, Lazane Clark, Hassan Childs, James Lewis, Aaren O'Connor, Marques Gaines, Dwight Hughes Jr., Matthew Williams, Tony Jones, John Mackey, Rosaura Martinez, Leonardo Cruz, Noe Martinez Jr., Alexis Cruz, Noe Martinez Sr., Maria Martinez, Maria Ramos, Martel Anderson, Hector Del Rio, Metabias Biles, Paul Sappington, Edward Flowers, Roberto Sanchez, Alan Garcia, Charles Smith, Reginald Brown, Floyd Hodges, DeMarrow Stephens, Damon Allen Jr., Martice White, Algie Ferguson, Jermiron Morris, Allen Levin, Lester Weatherspoon, Robert Howard Jr., Cory Brown, Ricardo Villanueva, Claude Cannon, Senclair Hill, Torrance Dortch, David Martinez ,Trevon Stiger, Davon Horace, Orlando McArther, Alphonzo Guinyard, Derrius Larres, Courtney Taylor, Juan Gonzalez, Deante Dale, Martell Howard, Lionel Williams, Giovani Salgado, Rene Ramirez, Henry Cruz, Quintae Little, Corey Ferguson, George Anderson, Michael Fernandez, Phillip Dupree, Elliott Brown, Antonio Pollards, Ronell Andrews, William Larson, Keshawn Marzette, Erick Lacey, Matthew Ehrenberg, Darius Brown, Raymon Blount, Pablo Ulloa, David Gonzalez, Erskin Palm, Franklin Aguilar, Ronald Clarke, Jonathan Jimenez, Sakinah Reed, Donta Porter, Georgio Byrd Jr., Jose Rodriguez, Jeffrey Mattix Jr., Antwan McBee, Roderick Snowden, Donzell Davis, Deandre Holiday. 


\section{APPENDIX B: THE CHICAGO INVESTIGATIVE STOP REPORT}

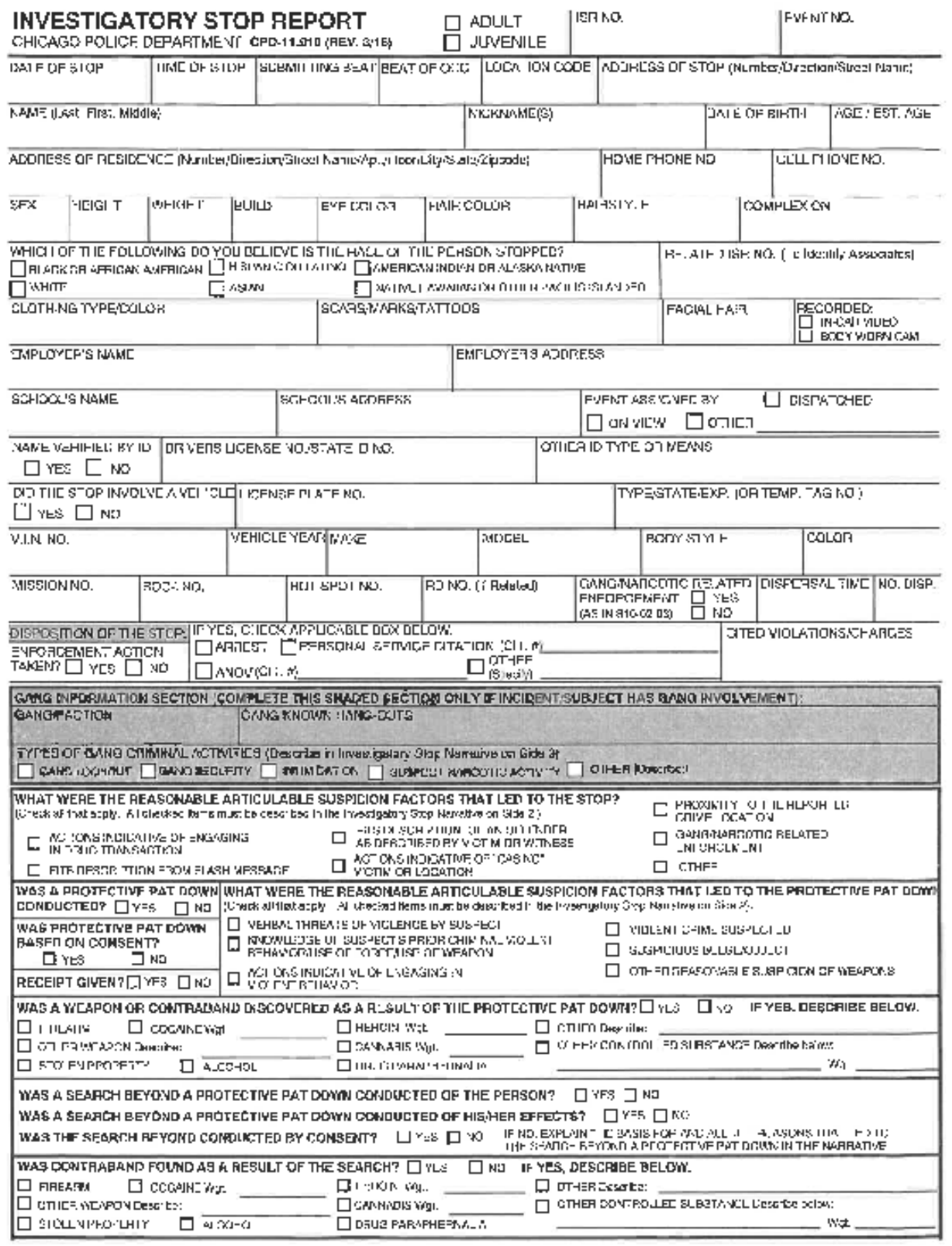




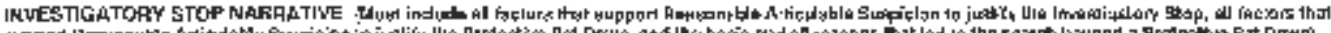

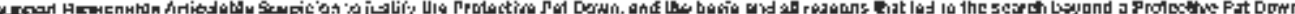

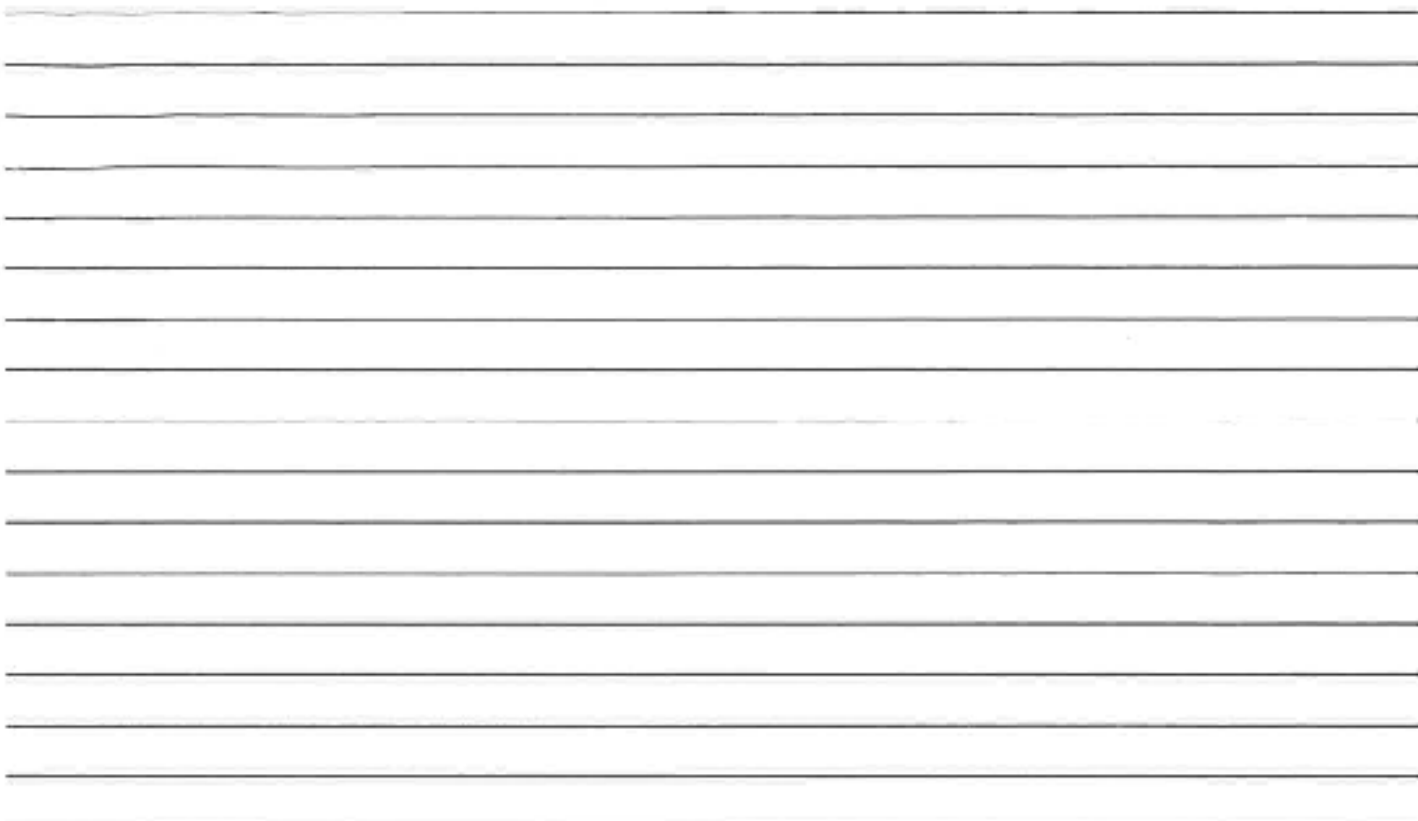

DIETRIBLTION: Forward ariginel resort to the Plecords Dh slen

\begin{tabular}{|c|c|c|}
\hline "ᄀRST DFFGE & CLOOND OCTICEA'S KAAL N.JD G'AF WO. & [ั้. \\
\hline
\end{tabular}


APPENDIX C: THE CHICAGo INVESTIGATIVE STOP RECEIPT

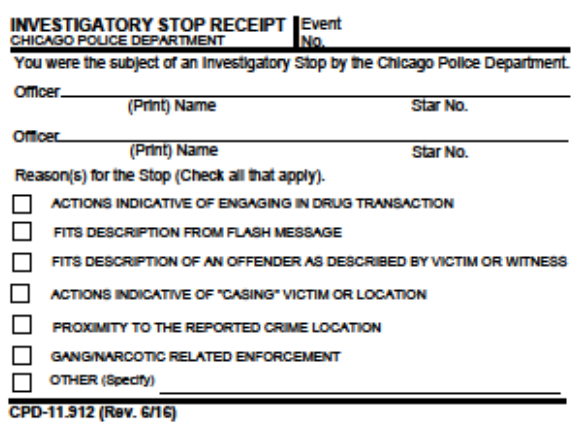

CHICAGO ALTERNATIVE POUCING STRATEGY (CAPS)

SAFE NEIGHBORHOODS ARE EVERYBODY'S BUSINESS

active and informed community working with the polce and other city agencles

to really make a dimerence. Join your neighoors and your neighborthood pollce

our caty Become part of the CAPS team in your community. To find out how.

call 311 or vist online at: hittp: $/ / w w w$. chicagopolice. org. 